Propositions:

1. The asymmetry in power relationships between social actors in banana production is inversely proportional to prospects for effective disease control.

(this thesis)

2. Harmonisation in international governance platforms does not translate to legitimacy in domestic legislation.

(this thesis)

3. Critical legal analysis only reveals how power relations shape legal norms when it recognizes that what is not said is just as important as what is said.

4. The biggest constraint to a rights-based approach to food and land security is the ideology that free, unregulated food and land markets lead to a just distribution of food and land.

5. Blaming the poor for ecological destruction creates more poverty and more ecological destruction.

6. State intervention is necessary to bridge inequality in access to agricultural research and plant disease strategies.

Propositions belonging to the thesis, entitled

Panama Disease in banana and neoliberal governance: towards a political ecology of risk

Jaye de la Cruz

Wageningen, 23 October 2017 


\section{Panama Disease in Banana and Neoliberal Governance:}

Towards a Political Ecology of Risk

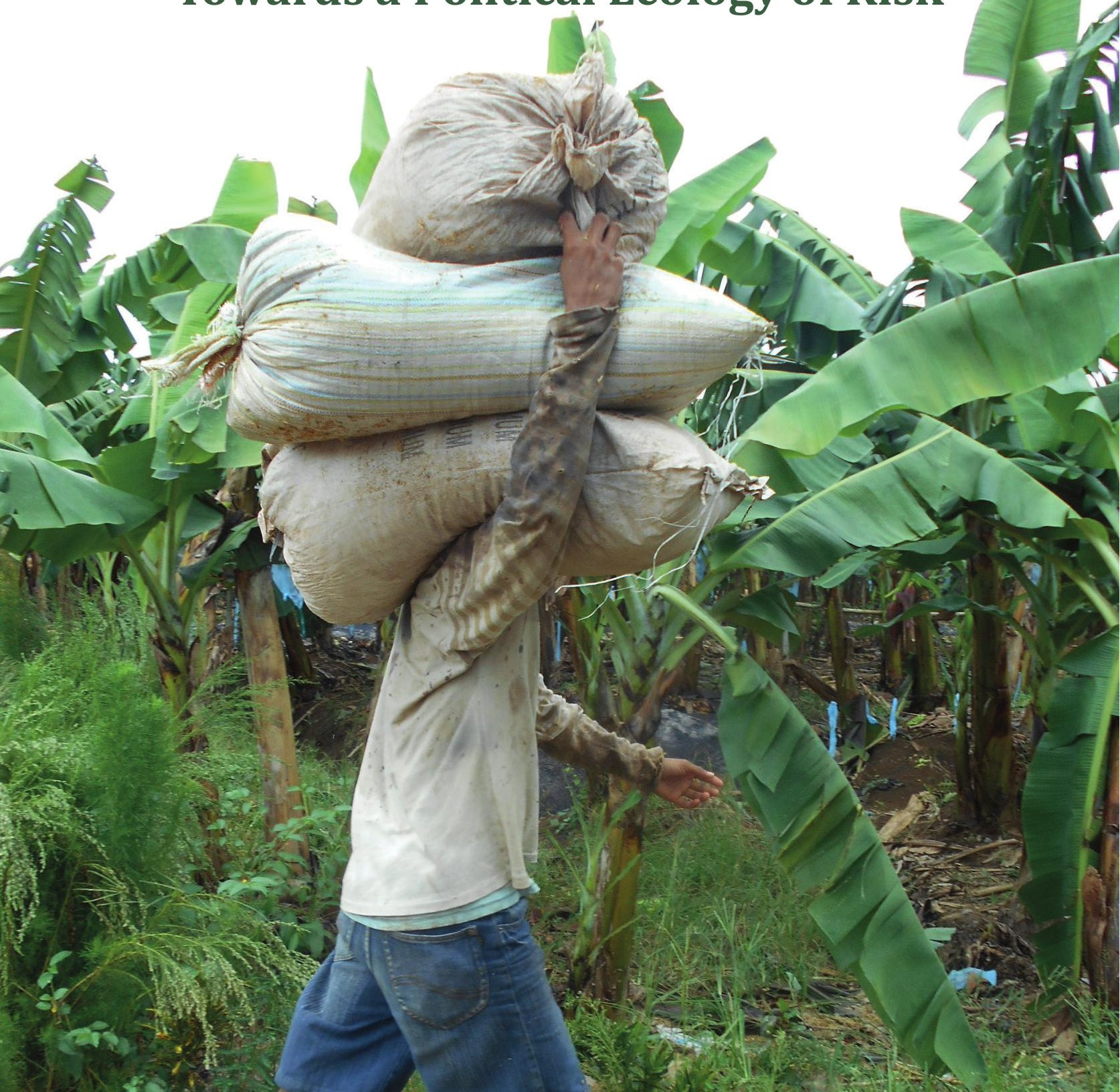


Panama Disease in Banana and Neoliberal Governance:

Towards a Political Ecology of Risk

Jaye de la Cruz 


\section{Thesis committee}

\section{Promotor}

Prof. Dr Philip Macnaghten

Personal Chair at the Knowledge, Technology and Innovation Group

Wageningen University \& Research

\section{Co-promotor}

Dr Kees Jansen,

Associate professor, Knowledge, Technology and Innovation Group

Wageningen University \& Research

\section{Other members}

Dr A. Gupta, Wageningen University \& Research

Prof. Dr P-B Joly, INRA \& Laboratoire Interdisciplinaire Sciences Innovations Sociétés, France

Prof. Dr G.H.J. Kema, Wageningen University \& Research

Prof. Dr E. Turnhout, Wageningen University \& Research

This research was conducted under the auspices of the Wageningen School of Social Sciences 


\title{
Panama Disease in Banana and Neoliberal Governance: Towards a Political Ecology of Risk
}

\author{
Jaye de la Cruz
}

\section{Thesis}

submitted in fulfilment of the requirements for the degree of doctor, at Wageningen University

by the authority of the Rector Magnificus,

Prof. Dr A.P.J. Mol,

in the presence of the

Thesis Committee appointed by the Academic Board

to be defended in public

on Monday 23 October 2017

at 4 p.m. in the Aula. 
Jaye de la Cruz

Panama Disease in Banana and Neoliberal Governance: Towards a Political Ecology of Risk

110 pages.

PhD thesis, Wageningen University, Wageningen, the Netherlands (2017)

ISBN: 978-94-6343-796-7

DOI: $10.18174 / 423693$

Cover photo: Marilou Montiflor 


\section{SUMMARY}

The emergence of Panama disease Tropical Race 4 (Fusarium oxysporum f.sp. cubense) or TR4 - a fungal disease in banana that is considered by horticulture experts as not only one of the most destructive diseases in the world (Ploetz 1994) but one with no on-hand socio-cultural or chemical method to control it satisfactorily (Ploetz 2015) - has generated conversations, dialogue, inquiry and at times controversy at various scales on how this risk is to be managed.

The onslaught of Tropical Race 1 (TR1) in the 1900s, destroying many banana plantations in Latin America and the Carribbean, provided a lens by which the political economy of Latin America can be examined. Much, however, has changed in global political economy configurations between the onslaught of TR1 and TR4. Confronted once more with the disease in contemporary settings, we are provided with an opportunity, and a context within which, to evaluate the ways by which societies, governments and peoples work to address the disease and mitigate its threats in a new time-space constellation. The rise of globalisation and the neoliberal model have ushered in profound changes within the last three decades - changes that have driven social and political processes on multiple scales of governance, and that have influenced relationships, behaviours, ways of life and perceptions. Proceeding from this, this research asks the central question: Do features of neoliberal governance influence risk perceptions and decision-making on Panama disease, and if so, in what ways?

This research draws from political ecology as a framework to analyse how political and economic relationships impact on people's understandings of risk in the context of a phenomenon that has ecological or bio-physical roots. At the heart of the thesis lies the central matter of risk politics: that risk decisions - focusing in particular on what risks matter, who decides, who should be exposed to what, and to what degree - are both an effect of power and an exercise of power.

The thesis is based on a multi-site and multi-scale study consisting of two in-depth case studies - one conducted in the Philippines, the other in Australia - alongside expert interviews conducted in Kampala (Uganda), Rome (Italy), Wageningen (the Netherlands) and Florida (USA). The research is multi-scale in that three different scales of interaction are examined: at the global scale, as situated in the discourse and practice of international governing bodies; at the national scale, by studying the rules and laws in countries which have had experience of Panama disease, and by examining how biosecurity responses have been shaped in the context of a national policy of privatised agriculture; and at the local scale, where agrarian dynamics between small-holder farmers and large corporations are studied. The research is designed not to compare contexts with each other, but to provide illustrative snapshots of the many ways that risk can be shaped by its social milieu.

The first Chapter of this dissertation looks at how the risk of Panama disease is evaluated by international regulatory bodies and actors in global governance networks such as the 
International Plant Protection Convention (IPPC) within the Food and Agriculture Organisation, and examines the contestations that underlie the question of whether or not Panama disease control and management constitute a Global Public Good. It has been found with clarity that adherence to free trade principles influence and constrain the ways by which international organizations perceive the risk of, and how they address, this transnational plant disease.

The second Chapter, based on field work in the southern part of the Philippines where a Panama disease infestation has been confirmed and where social relations in rural livelihoods are characterized by a contentious agrarian history, investigates how asymmetric binary relationships between the social actors in a contract growership arrangement -- specifically large banana corporations and smallholder farmers -influence the possibilities and limitations of disease control.

The third Chapter demonstrates, using the example of Australia, important limitations in the neoliberal 'user-pays' model in its ability to address emergency plant disease outbreaks, particularly when swift rule-making and rule-enforcing powers of the state are necessary. While the shared responsibility approach can keep the wheels grinding in a business-as-usual context, within a rapidly-evolving epidemiological emergency, the terms of engagement between government and industry need to be recast.

The fourth Chapter examines the issue of genetic modification - bannered by some scientists as the only or at least the most plausible solution to the urgent problem of Panama disease - and the current state of the global regulatory framework on bio-safety. Developing countries with confirmed Panama disease infestations (Philippines, Indonesia, Jordan, Mozambique and Pakistan) were used as units of analysis. Using tools of legal text analysis, a comparison is made between the National Reports of the countries to the Bio-Safety Clearing House of the Cartagena Protocol on Bio-Safety and international commitments to the IPPC, World Trade Organisation (WTO) and the Cartagena Protocol. This chapter challenges the notion of a 'uniform science' and finds that while individual countries ostensibly accept that science, or scientific knowledge, can be used as a unifying framework to consolidate multiple appreciations of risk and divergent approaches in addressing and confronting it, a perusal of their domestic legislation shows contradictions between what was committed in international platforms, and what is implemented domestically. Contrary to the purely scientific standards upheld by the IPPC and the WTO, socio-economic risks and cultural considerations have been found within domestic legislation.

Drawing from these chapters, this research proposes that neoliberalism influences Panama disease strategies in at least three ways: one, through the organisation and harmonisation of systems of behaviour, practices and legislation; two, through the promotion of its narratives and the marginalisation of counter-narratives; and three, through the endorsement of tools that support its agenda. 
Firstly, neoliberalism organises and harmonises systems of behaviour, practices and legislation so that it conforms with its own logic and processes. An intuitive abhorrence of protectionism results in the perception that plant health measures that may result in trade barriers inherently suspect, and thus should be avoided, except in the most exigent of circumstances. The international regulatory system has been substantially re-written so that even collective action becomes increasingly hard to be mobilized, and that international support cannot be activated without the imprimatur of the International Plant Protection Convention, given fears that such action might constitute the basis for future trade restriction. Through adherence to neoliberal principles, the global system has been in effect re-engineered in such a way as to limit the latitude and capacity of countries to identify and designate what they believe to be a risk, as a pluralistic interpretation of risk can be defined as constituting protectionism. Science and scientific knowledge are deployed not in furtherance of the wider considerations of plant health, but to ensure that considerations of plant health keep 'within limits' and do not cross over to impinge on borderless international trade.

Secondly, neoliberalism influences plant disease strategies through the propagation of a dominant narrative that protects its interests and the marginalization of counternarratives that challenge its own dominant narrative. A narrative that blames smallholder farmers for Panama disease reinforces the trope on the unsustainability of smallholder agriculture and the lack of capacity of smallholder farmers. In contrast, a narrative that blames large companies or corporations for the spread of the disease is one that challenges the wisdom of corporate agriculture, and one that may have the consequence of state regulation of corporations, which contradicts the ideological core of neoliberalism which is that the market must remain unhampered and unencumbered by strong state intervention.

Thirdly, neoliberalism influences Panama disease measures through the endorsement of tools against Panama disease that are consistent with its agenda. The research surfaces the aggressive promotion of biotechnology as the only solution - or the 'silver bullet' to the possible extermination of Cavendish bananas because of Panama disease, and the endorsement of a biotechnology-permissive global regulatory regime. Neoliberalism did not create Panama disease, nor are proponents of genetic modification always driven by market compulsions, but neoliberal globalism has been shown, for instance through predatory patenting schemes, to reinforce and exacerbate the tendencies of the 'biotechnology revolution' to cause social polarisation.

In sum, neoliberalism influences Panama disease strategies by framing risk - by managing and controlling how the risk of Panama disease is perceived, measured and decided upon by social actors. Its framing of risk is negotiable, malleable and contingent on what the system needs at a given time. This research concludes that neoliberalism has the effect of instrumentalising risk by deploying it as a tool that is used to protect the dominance of its ideology. The framing of risk - the answers to the fundamental questions of what risks matter, who decides, who should be exposed to what, and to what degree - is, indeed, an 
exercise of power. But at the same time, it is done to protect accumulated power, and in the course of this research, it strove to demonstrate, using the example of Panama disease, the precise ways by which neoliberalism has exercised its power in multiple levels of governance and within social relations of production to frame plant disease risk to its strategic advantage. 
This thesis is dedicated to Ka Eric Cabanit, a farmer-leader who was at the forefront of the struggle for land rights in one of the largest banana plantations in the Philippines before he was gunned down in Panabo City, Davao del Norte in 2006.

You will not be deleted. 


\section{Table of Contents}

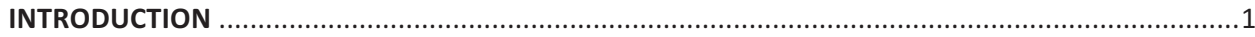

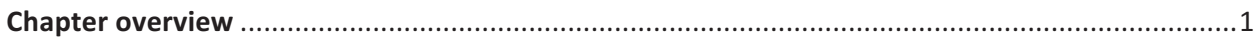

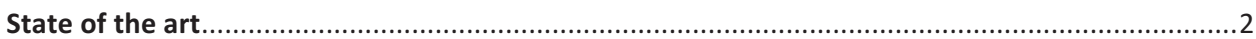

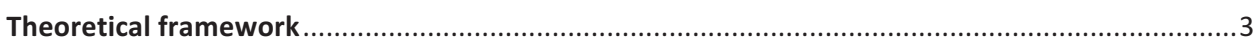

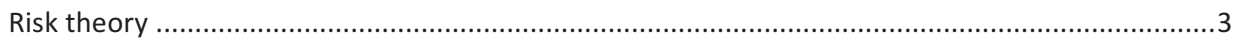

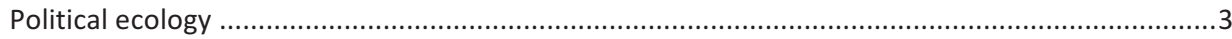

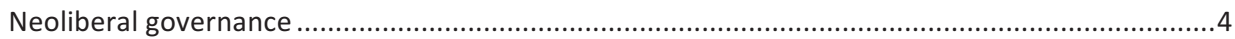

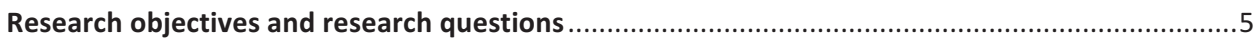

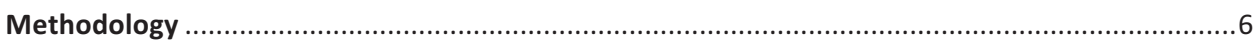

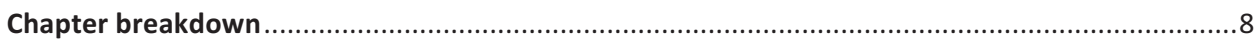

NEOLIBERAL GOVERNANCE AND GLOBAL PUBLIC GOODS: CAN MARKET-BASED SOLUTIONS

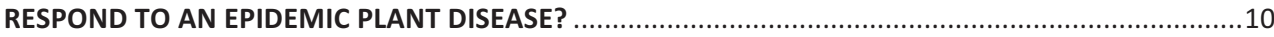

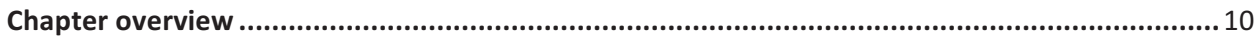

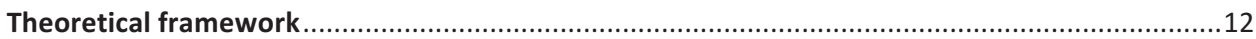

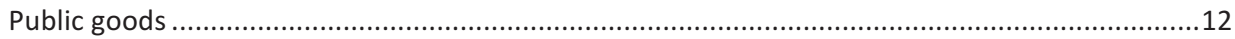

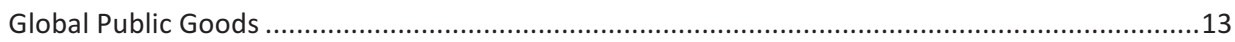

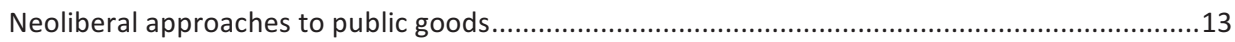

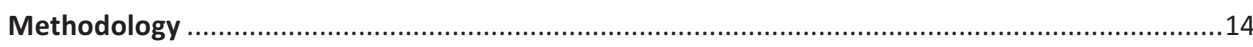

Evolution of plant disease control and Panama disease regulation: How neoliberalism shifted the

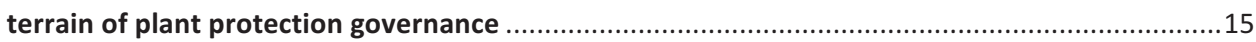

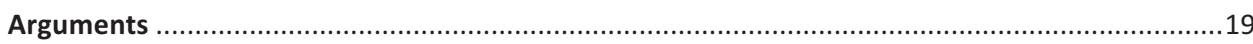

Who bears the burden for plant disease?..................................................................................19

Protection or protectionism? The balancing act between plant protection and free trade..........21

Market-based solutions and the neoliberal toolbox: The road to GMOs ...................................24

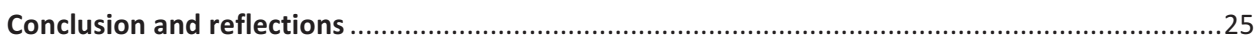

PANAMA DISEASE AND CONTRACT FARMING IN THE PHILIPPINES: TOWARDS A POLITICAL

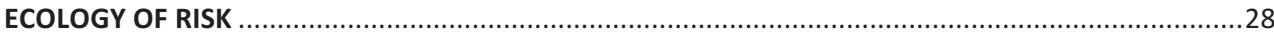

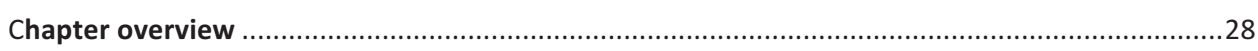

Theoretical framework: Using Cultural Theory to build a political ecology of risk .......................31

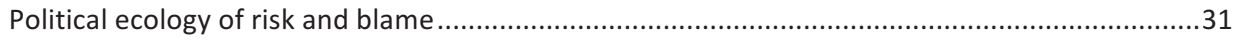

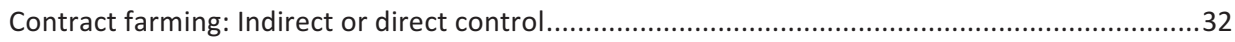

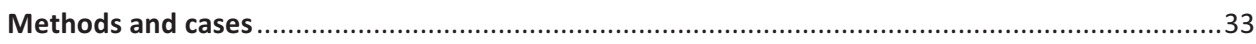

The importance of the political economic history for current perceptions of Panama disease .....36

Post-land reform and current-day iterations of political economic history ................................39

Who bears the burden for plant disease control? .................................................................. 41

The terms of the contract and farmers' assumption of risk ..............................................4 41

Blaming is used to reinterpret Panama disease risks in terms of oppositions in agrarian

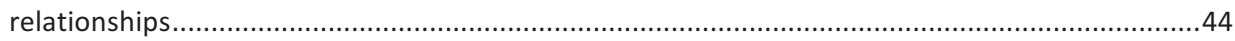

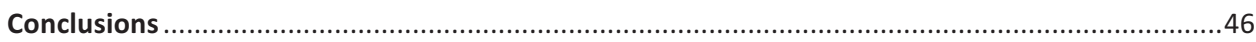

PUBLIC-PRIVATE COLLABORATIONS AMIDST AN EMERGENCY PLANT DISEASE OUTBREAK: THE AUSTRALIAN EXPERIENCE WITH PANAMA DISEASE ...........................................................

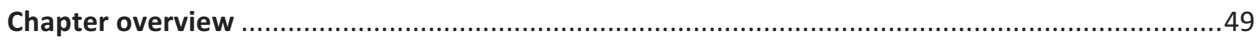

Theoretical framework: Problematising agricultural privatisation......................................51 
Overview of Australia's agriculture policy and plant disease protection framework: The march to

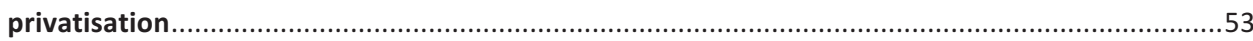

Australian agriculture policy: A brief historical overview .......................................................53

The R\&D framework: Rural Development Corporations and the levy system .............................53

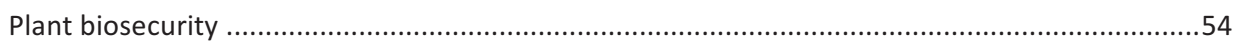

The Australian banana sector: When government and industry collaborate ..........................55

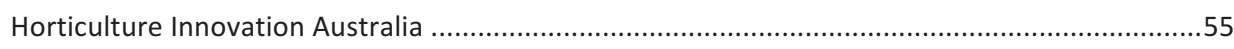

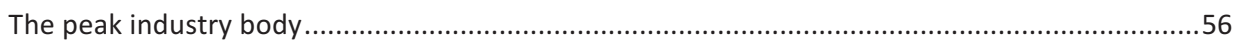

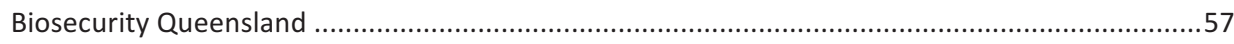

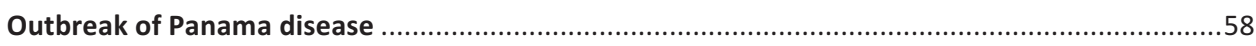

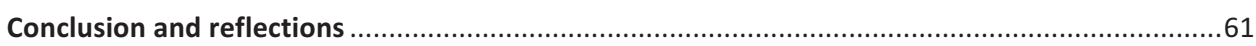

GENETICALLY MODIFIED BANANAS AGAINST PANAMA DISEASE: A SILVER BULLET IN A

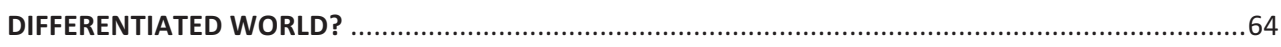

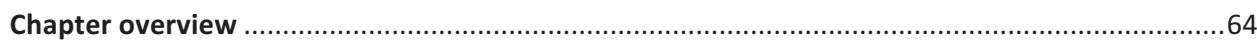

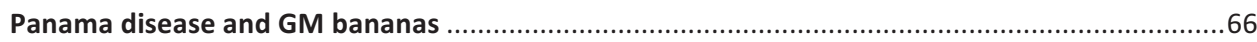

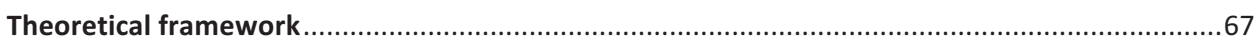

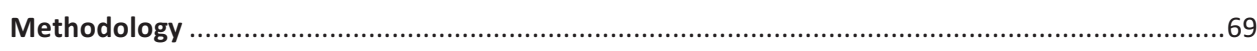

The bio-safety global governance regime: A case of harmonisation at the top? .......................69

Harmonised international commitments ............................................................................ 73

Iterations of the precautionary principle and science-based risk assessment ............................74

Identical approach in risk and risk trade-off: "Human health" and the "environment" as risk, and

"food security" as risk trade-off.................................................................................. 76

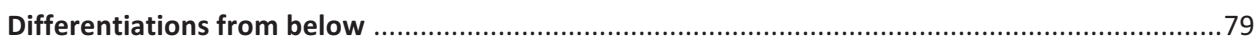

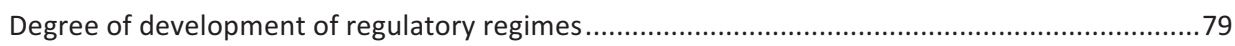

What do we value? Socio-economic considerations in GMO decision-making ............................83

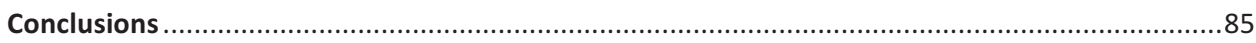

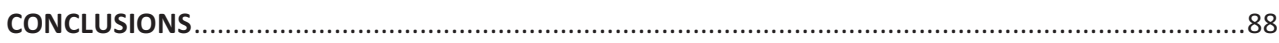

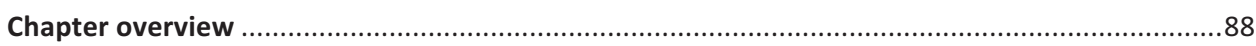

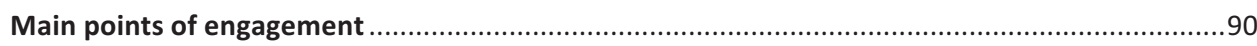

Free trade and global public goods: Can international organisations founded on free trade ideals address transnational plant disease? .............................................................................90

Contract farming in agrarian settings: Can relationships of asymmetry produce optimal outcomes

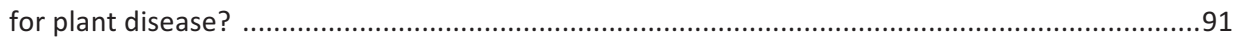

Privatised agriculture and a plant disease outbreak: How does a market-led approach respond to

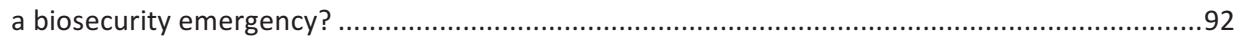

Genetically-modified bananas and the global regulatory framework on biosafety: When regulatory harmonisation at the top does not meet local legitimacy below ...............................93

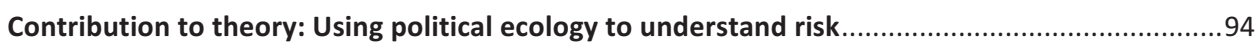

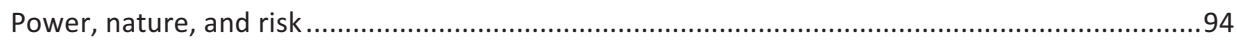

Neoliberalism as driver of risk perceptions and risk decisions on Panama disease......................95

References ....................................................................................................................... 98 
Table 1. Cavendish production in the Philippines (2002-2013) 34

Table 2. Areas covered with Panama disease (Philippines) 2015

$\begin{array}{ll}\text { Table 3. Summary of agreements } & \mathbf{7 2}\end{array}$

$\begin{array}{ll}\text { Table 4. Fusarium wilt TR4 countries and the agreements } & \mathbf{7 3}\end{array}$

Table 5. Legislative interpretations of the precautionary principle and $\quad \mathbf{7 5}$ science-based risk assessment

Table 6. Legislative basis for GMO regulation at every stage $\quad \mathbf{8 0}$

Table 7. Robustness of regulatory regimes based on self-assessment $\quad \mathbf{8 1}$

Table 8. Socio-economic considerations

83 


\section{INTRODUCTION}

\section{Chapter overview}

"Yes! We Have No Bananas" is the title of a Broadway novelty song in 1922, owing to a banana shortage in the early part of the century. The emergence of Panama disease Tropical Race 4 (Fusarium oxysporum f.sp. cubense)or TR4 - a disease considered by horticulture experts as one of the most destructive diseases in the world (Ploetz 1994) with no cultural or chemical method to control it satisfactorily (Ploetz 2015) - has resuscitated the jocular phrase for contemporary use. With banana being one of the most important agricultural products in the world, critical to rural livelihoods of smallholder farmers and an important part of daily nutrition in many cultures, the rapid spread of Panama disease TR4 across banana plantations and countries has generated conversations, dialogue, inquiry, and at times controversy at various scales on how this risk is to be managed.

This has not been the first experience with Panama disease. In the 1900s, Tropical Race 1 (TR1) of the soil-borne fungus destroyed Gros Michel crops in Latin America, bringing banana corporations to their knees. It was not long, however, before the discovery of the Cavendish cultivar resuscitated the industry. Resistant to TR1 and delectable to the Western palate, this new cultivar enjoyed wide commercial success. But the disease proved to be a sleeping giant. Re-emerging under a new strain, TR4, the disease re-established decimating Cavendish plantations. To date, Panama disease TR4 has been detected in eleven countries: Australia, Mainland China, Jordan, Indonesia, Malaysia, Philippines, Mozambique, Oman, Taiwan (FAO 2014), and the two newest countries, Pakistan and Lebanon (Ordoñez and Garcia 2015). Many experts argue that long-term chemical and physical measures against the disease are not (yet) available (Pérez-Vicente et al. 2004, 2014, Ploetz 2006, Pocasangre et al. 2011). Hence, pesticide spraying against the disease is not practised. Researchers are just starting to understand the genetic diversity of the pathogen itself, in order to develop methods and tools to diagnose the disease in the field before it can destroy a plantation (Ordoñez et al. 2015).

The onslaught of TR1 in the 1900s provided a lens by which the political economy of Latin America can be examined, and an opportunity to reflect on the power grids that cross and connect transnational corporations, social movements and activist networks, national and local governments. Much, however, has changed in global configurations between Tropical Race 1 and Race 4. Confronted once more with the disease in contemporary settings, we are provided with an opportunity and a context within which to evaluate not simply the dramatic impacts of the disease, but the ways by which societies, governments, and peoples scramble to address it and mitigate its threats in a new time-space constellation. The advent of globalisation and the neoliberal model have ushered in profound changes within the last three decades that include: the retreat of government spending in agriculture services, the rise of the corporate food regime, and the emphasis on market-based approaches as solutions to food security and resource 
scarcity. These changes are all key elements of this new paradigm that has driven social and political processes on multiple scales of governance, and that has influenced relationships, behaviours, ways of life, and perceptions. Proceeding from this, this research asks the central question: Do features of neoliberal governance influence risk perceptions and decision-making on Panama disease and, if so, in what ways?

Predicating our research on the assumption that risk perceptions and risk decisions are outcomes of various systems of knowledge and understanding, as well as economic structures (see for example, Arnoldi 2009), we are interested in investigating how actors in differentiated positions within the banana economy construct risk, and how risk decisions are influenced by factors beyond the sterile petri-dish of the natural sciences; factors that have been varied, divergent, and in many cases contradictory. At the heart of it is the central thesis of risk politics: that risk decisions - the answers to the fundamental questions of what risks matter, who decides, who should be exposed to what, and to what degree - are both an effect of power and an exercise of power.

We draw from political ecology to analyse how political and economic relationships impact on people's views on risk in the context of a phenomenon with ecological or bio-physical roots. We seek to join the premise of political ecology, which views environmental change as a product of a political process (Robbins 2011), with risk theory, and find in that intersection a viable tool to ask the questions: (1) how social and political factors frame environmental risk and consequently influence risk decisions, (2) how power arrangements determine who are exposed to, and bear the burden of risk, and to what degree, and (3) how one environmental risk is considered more important than another, and who gets to decide, and ultimately unpack the neoliberal agenda that directs how these questions are answered.

\section{State of the art}

There is no dearth of literature from the natural sciences on Panama disease TR4, called "the most important lethal disease of banana" (Ploetz 2005). Not only has the disease been determined to be infeasible to eradicate at the current state of science (ibid.), continuing studies being developed on Panama disease demonstrate its transnational spread (see for example, García-Bastidas et al. 2015, Ordoñez et al. 2015)as well as the inability of conventional breeding technologies to develop resistance in export-quality Cavendish cultivar (Aguilar Moran 2013).

Most of the social science literature on Panama disease has looked at it as a tableau through which the inter-linkages and relationships amongst the social actors - and the shifting paradigms and communities of meaning - can be viewed and analysed. By using the illustrative example of United Fruit Co., Marquardt (2001) depicted the disease as having "humbled a multinational corporate giant whose economic, social and political powers remain legendary in the Western Hemisphere", and he invited us to "view the fungus as an unlikely environmental locus of resistance to corporate agriculture's will to power". Soluri (2002) also contributed to the social science debate by showing the 
converse perspective: how social relationships, political and economic arrangements, and the like impact on the disease. He argued that:

Panama disease then, cannot be explained entirely in terms of local agroecological processes. The complex relationship between pathogen, plant host, and environment shaped the epidemic, but so too did the cultural, economic, and social processes that gave rise to mass markets for bananas.

While there has been a rich resource written on the disease and its manifold social causes and effects, there has been no analysis conducted as yet on the risk perceptions and risk decisions of social actors on the disease, and on the structural arrangements that influence them. Moreover, no analysis has as yet been conducted on the disease that focuses explicitly and systematically on the current time-space constellation of neoliberalism. This is the gap in literature that this research project seeks to address and from which it draws it societal significance.

\section{Theoretical framework}

\section{Risk theory}

Risk - its social construction as well as its distribution - is inherently a political and cultural matter (Arnoldi 2009). Risk theory is composed of several different approaches. Ulrich Beck (1992) developed one such approach where he suggests that society as a whole increasingly orders itself in accordance with the ways that subjects within it perceive, mobilise against, and mitigate risk (what he terms the 'risk society'). Earlier than Beck, however, the Cultural Theory of Risk as proposed by Mary Douglas (1992) adopts an anthropological approach that seeks to explain competing interpretations of environmental and technological risks by looking at "cultural ways of life". Douglas proposes a grid to explain how risk choices are determined by the cultural groups that people fall into. A third approach, pioneered by Michel Foucault (1991), looks at how risk is being used a strategy to govern, and analyses the ways by which risk is instrumentalised as a tool to wield power, to control subjectivities, and to protect institutions.

Our approach draws substantially from Douglas's (1992) Cultural Theory of Risk, which holds that risk perceptions and choices - what risks are most important, who is to be blamed, who should address what - are influenced by systems of thought and practice within a particular culture. We expand this notion by looking also at the economic and political compulsions that bear upon these perceptions and choices. We address not only how various groups make risk decisions themselves, but also the interests and pressures that lead people to these groups and their associated ways of thinking (Barraza et al. 2011, Boudia and Jas 2011). Our approach supports the idea that these social, economic, and political pressures, in addition to cultural factors, shape how individuals are grouped and subsequently, how they make decisions on risk.

\section{Political ecology}


To explicitly identify power as a variable, this project uses political ecology as a tool of analysis. Political ecology analyses how power asymmetries in relationships between and among various social actors can produce different ecological outcomes that compound, reinforce, or mitigate existing inequalities (Bryant and Bailey 1997, Jansen 1998), and on how societal forces bear upon ecosystems (Zimmerer and Bassett 2003). Like political economy, political ecology analyses how historical changes result from specific patterns of wealth distribution (Jansen 2006), but it adds a concern about the reordering of nature and technology. Scholars of political ecology have typically looked at how state actors, social movements, and transnational corporations impact on resource management (Sheridan 2001, Mackenzie 2003, Paulson et al. 2004, Whitehead et al. 2007); how environmental narratives are being constructed and their effects on environmental change (Escobar 1999, Castellanos-Navarrete 2015); and how historical processes of capital accumulation and consumption impact on agriculture and rural livelihoods (Bury 2008).

The distinct facet of political ecology that makes it particularly useful to our study is that it analyses not only how realities are constructed, but also its material base critical, in light of the undeniable material base of the disease and its empiricallyobservable features and outcomes. It is useful as a lens of analysis to look at the broad range of pressures and forces that are implicated in how Panama disease is perceived as a risk, and consequently, the decisions arising from these perceptions. Further, we aim not only to look at how scientific knowledge is embedded within society, but also the ways by which it is deployed, understood, and perceived by social actors across power grids. We use political ecology as a framework to examine why actors in differentiated circumstances make the decisions that they do and why similar risks (similar at least in technical terms) are perceived in different ways in different geographical and sociopolitical contexts.

\section{Neoliberal governance}

Neoliberal governance plays an integral role in this study, and we look at the concept both at the global scale and as a set of policies within nation states. By neoliberal global governance, we look at the framework that emerged following the Washington Consensus, described by Gill (2002) as "the spatial expansion and social deepening of economic liberal definitions of social purpose and possessively individualist patterns of action and politics".

The political and ideological project of neoliberalism - characterised by a tenacious faith in the power of markets to provide efficient outcomes even in social and political decisions, and, corollary, a growing mistrust of state interventions in delivering what people need (see for example, George 1999, Birch 2006, Busch 2010, Hall et al. 2013) - signalled a break from the Keynesian economics in the post-war setting towards the notion of a 'self-regulating market' that Karl Polanyi (1944) describes. A key feature of neoliberalism is the abandonment of an inclusive social welfare system as a state 
mandate, in favour of increasing competitiveness and economic efficiency in the belief that the latter would better provide public goods (Larner and Laurie 2010). It gained firm foothold in the 1980s, owing to policies set in motion under the Reagan and Thatcher regimes. Lawrence et al. (2013) distinguished between the 'rollback' and 'roll-out' features of neoliberalism: the former having to do with the retreat of the state and the accompanying dismantling of state-sponsored welfare systems, and the latter involving the creation of policies and regulations that enable and support market-based decision making.

However, neoliberalism should not be conflated with laissez-faire economics, although laissez-faire economics lies at its heart. The belief in the near-infallibility of the wisdom of free trade and free movement of goods over protectionist policies, and the emphasis on market-based approaches as solutions to resource scarcity, are features of laissez-faire economics, but neoliberalism takes it one step further and says that these elements should be central in social and political relations and as the main driver of global processes. Neoliberalism, therefore, can be seen as a political philosophy that aims to redefine the boundaries between the state and the economy (Córdoba and Jansen 2014), making the market the organising and regulatory principle underlying virtually all domains of decision-making, including those of the state.

In environmental governance and agriculture, processes of neoliberalism have led to the creation of 'neoliberal enclosure regimes' which use market-based tools to deepen capitalist asymmetrical social property relations, aided by direct action of the State (Akram-Lodhi 2007). Akram-Lodhi further expounds that the process of neoliberal enclosure is characterised by the creation of "bifurcated structures" (ibid.) - two different productive sub-sectors existing side by side, with the former driven by the need to maximise competitive profitability "within an increased globalised circuit of capital", producing for markets "primarily but not exclusively located in the North, and the latter subsector whose terms of incorporation are dependent on labour-power provided, and whose linkage into the logic of the market is heavily regulated by the dominant class".

\section{Research objectives and research questions}

This research seeks to understand the cultural, economic, and political dynamics that underpin risk perceptions of and risk decisions on Panama disease, and the extent to which these dynamics are influenced by elements of neoliberal thought. We examine the myriad and disparate ways that groups in differentiated positions perceive, frame, and make decisions on how to address Panama disease, and the various forces and pressures that impact on these processes at various scales and levels of governance.

Our main research question is: In what ways do features of neoliberal governance influence risk perceptions and decision-making on Panama disease. We further ask the following sub-questions: 
1. To what extent can market-based solutions provide global public goods, and what are the elements of the current neoliberal global governance regime that constrain and enable the delivery of Panama management strategies as a global public good?

2. To what extent does the nature of relationships between the social actors in a contract growership arrangement influence the possibilities and limitations of disease control?

a. How is the risk of Panama disease distributed under a contract growership arrangement?

b. What is the role of blaming in the uneven distribution of risk in a contract growership arrangement?

c. How does this impact on how Panama disease is viewed, and its elimination and mitigation strategies are crafted?

3. In what ways do the features of a market-led, privatised agriculture model influence how risk decisions are made in the context of a Panama disease outbreak?

a. How is the notion of a 'shared responsibility' biosecurity model operationalised during an agricultural biosecurity emergency and what, if any, are the tensions and contradictions that arise between industrygovernment collaborations?

b. Did the outbreak of Panama disease trigger a shift in the roles of the public and the private sector with respect to risk decision-making?

c. What conditions enable the successful management of the disease within a privatised framework?

4. What efforts have been undertaken within the global governance regime on biosafety in harmonising domestic legislation, and to what end? How do countries with Panama disease construe bio-safety risk, and how are these constructions articulated and reproduced within their bio-safety legislation?

The research questions are designed to provide insight into how social structures and economic arrangements impact risk assessment of and solutions to Panama disease, in various contexts. It is the hypothesis of this research that central features of neoliberal governance underlie these structures and arrangements, and in turn influence Panama disease regulation.

\section{Methodology}

This is a multi-site and multi-scale study consisting of two in-depth case studies one conducted in the Philippines, the other in Australia - alongside expert interviews conducted in Kampala (Uganda), Rome (Italy), Wageningen (the Netherlands), and Florida (USA). These locations were either areas of study, hubs of regional banana 
research, bases of international organisations, or venues of conferences during which interviews were scheduled. The research is multi-scale in that we examine three different scales of interaction: at the global, as situated in the discourse and practice of international governing bodies; at the national, by studying rules and laws in countries which experience Panama disease, and by examining biosecurity response in the context of a national policy of privatised agriculture; and at the local, where we look at agrarian dynamics between smallholder farmers and large corporations. The research is designed not to compare contexts with each other, but to provide illustrative snapshots of the many ways that risk can be shaped by its social milieu.

Multiple qualitative methods were also employed throughout this research, but the main methods are the extended case study and legal text analysis.

Firstly, we used the extended case study approach, which aims to provide insights into the experiences of particular social groups to explain why they perceive the world in the way that they do and that seek to locate everyday life experience in a historical context (Burawoy 1998). This method is particularly useful in that we aspire to draw linkages between everyday risk decision-making and the social, political, and economic structures surrounding the decision-maker. We use this approach in our case studies in the Philippines and Australia, two specific and different banana-growing contexts that are coping with the regulatory issues of Panama disease.

In the Philippines, data collection was primarily done in 2013. We conducted focus group discussions with two banana farmers' cooperatives that have contract growership agreements with two major multinational banana companies. The focus group discussions were conducted to understand perceptions, behaviour, and attitudes of the banana farmers working within these cooperatives. Semi-structured interviews were conducted with key informants including local government officials, non-government organisation workers, representatives of multinational corporations, and members of the academe. Content analysis was also done on the growership contracts between the farmers' cooperatives and the multinational corporations.

In Australia, our data was the result of field work carried out primarily in Brisbane in July 2015, as well as a review and analysis of documents obtained from government instrumentalities and research organisations. Interviews were conducted with key representatives of the government (Biosecurity Australia, Department of Agriculture), university researchers (University of Queensland and Queensland University of Technology), representatives of the Australia Banana Growers Council, an independent contractor and consultant on plant protection, and two farmers in Northern Queensland. Interviewees were selected for their expertise, and appointments were made with them primarily through the assistance of the head of the Banana Plant Protection Program. Transcripts from the interviews were analysed and triangulated with documents procured in the course of the field work. 
The other primary method is the socio-legal analysis. A socio-legal approach is employed in that the primary methodology is an analysis of legal text, but it is an analysis of law not confined to the text but proceeds from the assumption that legal rules cannot be disembedded from the social order to which they belong. Taking this approach, policy prescriptions are rarely simply outcomes of sterile scientific experimentation but are imbued with and mediated by the values, biases, and strategic considerations of policy actors.

We obtained the National Biosafety Frameworks and/or copies of national legislation of the Philippines, Indonesia, Pakistan, Mozambique, and Jordan; all are countries with Panama disease selected as the unit of analysis, and chosen based on criteria of geographic spread, availability of legal texts in English, and a decision to focus on the developing world. We analysed the texts with pre-determined themes in mind, and with the aim of understanding how perceptions on risk are reproduced in legal text. Legal text analysis was then supplemented by interviews with experts from the scientific community in the field of banana research, some of whom had been working directly on the issue of genetic modification of banana. These interviews were conducted over a period of two years, in the course of the author's interactions with expert scientists.

\section{Chapter breakdown}

This research is divided into four chapters.

The first chapter looks at how the risk of Panama disease is understood and acted upon within transnational governance mechanisms. We seek primarily to understand how actors in global governance networks and international regulatory bodies perceive and frame the risk of Panama disease, and the role of scientific knowledge within global political arrangements. Using a framework of Global Public Goods (GPG), we identify the dilemmas embedded in global governance processes that constrain the delivery of Panama disease interventions as a public good - the question of space and the spatial boundaries of intervention, the underlying tensions between plant protection and the requirements of a neoliberal trade regime, the conflicting claims of divergent scientific knowledge - and analyse how these affect risk decision-making in the global sphere.

In the second chapter, we investigate the dynamics between smallholder banana farmers and big corporations under the contract farming arrangement and analyse how asymmetric economic institutions create an enabling environment for uneven risk distribution in production processes, specifically the risk of destructive crop disease that can annihilate commercial production. Drawing from political ecology, which looks at the way claims about environmental systems are outcomes of the structures and arrangements that produce them, we examine the phenomenon of blaming of small farmers for the spread of Panama disease and reflect on this in the context of literature that investigates the blaming of small farmers and the rural poor for various agroecological phenomena. 
In the third chapter, we analyse how risk decision-making is played out in the context of a highly-privatised agriculture and agriculture extension system reflective of a larger pattern of the withering of the state from economic activity. We situate our research in the Australian context, where biosecurity has been framed as a "shared responsibility" between government and industry, which are both obligated to devote resources toward it and agree on an eradication/management framework. We ask the questions: does the transition to a market-led, industry-led approach shift perceptions on who should bear the burden for addressing Panama disease risk, and to what extent does it influence risk decisions taken by the different actors and stakeholders during an agricultural biosecurity emergency?

In the fourth chapter, we turn to one of the dominant solutions being proposed against the onslaught of Panama disease, the proposition of developing genetically modified bananas, and use it as a contextual backdrop to examine the tensions between different understandings of risk at multi-levels of governance. We first investigate global processes designed to harmonise bio-safety norms using science-based risk assessment to create an enabling framework for biotechnology; and second, examine domestic biosafety frameworks in countries that have confirmed positive for Panama disease. We reflect on why there appears to be a consensus in the international community on the 'science-based approach' as a mobilising framework to bring together divergent understandings of how risk is to be perceived and confronted, but within individual states, an analysis of domestic legislation reveals a different set of realities and priorities. To what do we account for this incoherence? Who decides which risks matter, and which risks should be hidden from view?

Read together, this dissertation seeks to make a modest contribution towards deepening the interface between political ecology and risk theory at various scales and levels of governance. By looking at four institutions/structures of power, all of which can be viewed as reproductions of essential features of neoliberal governance, and all of which have the capacity to govern relationships between actors within their orbits (i.e., the global governance regime and international regulatory networks, the contract farming agreement in the Philippines, the privatised agriculture model in Australia, and the biosafety legal system), we explore and interrogate the threads that connect systems of power to risk perceptions and decisions, in an ecological context where such perceptions and decision-making processes lead to material ecological consequences. 
I.

\section{NEOLIBERAL GOVERNANCE AND GLOBAL PUBLIC GOODS: CAN MARKET-BASED SOLUTIONS RESPOND TO AN EPIDEMIC PLANT DISEASE?}

\section{Chapter overview}

Biological invasion risks have been denominated as a public good problem (see for example, Perrings et al. 2002). Consequently, strategies against transboundary biological invasion risks - such as plant pest diseases that pose issues beyond the legal capacities of national governments to solve, or that are transboundary in scope so that international governance is required - are typically considered a Global Public Good or GPG (Birdsall and Dufasi 2015). In an increasingly interconnected world, under-provision in one region can compromise the whole, thus collective action on a global scale is necessary to ensure adequate provision of GPGs. This, however, has been easier said than done. Why should global public goods be financed, who should finance them, and what mechanisms and institutions should be used to optimally provide for them on a global scale, are persistent questions that pose both theoretical and operational dilemmas. This Chapter uses the example of Panama disease, an incurable disease affecting Cavendish bananas caused by the virulent pathogen fusarium wilt, to analyse and unpack the dilemmas that underlie the delivery of plant disease management strategies in the global governance regime.

Can market-based solutions effectively and efficiently deliver public goods? This question strikes at the heart of the public good debate and lies at the ideological epicentre of neoliberalist thought. Complicating the question in the context of Panama disease as a biological risk is the fact that the recent epidemic targets the Cavendish, primarily a commercial commodity and a high-value export crop, while at the same time, there is evidence to demonstrate that Panama disease also attacks other banana cultivars, including those that are grown primarily for food security.

At the foreground of this research is our interest in investigating the neoliberal global governance infrastructure and how it addresses the public good problem of Panama disease. Our main research questions are as follows: (1) To what extent can market-based solutions provide global public goods? and (2) What are the elements of the current neoliberal global governance regime that constrain and enable the delivery of Panama disease management strategies as a global public good?

A survey of the actors in the banana supply chain present a tableau that is at once complex and heterogeneous: banana multinational corporations developing large swathes of land for banana production (Read 1993), subsistence farmers in banana plantations in the global south (Tadem 2007), developing countries with no technical expertise and relying on bananas for food security, and developed countries that shape and define global political and economic agenda. Against this tableau is a powerful soil- 
borne pathogen that rapidly moves across regions and national jurisdictions, and targets the Cavendish banana, the most important commercial variant for global trade (Arias 2003).

It is the heterogeneity of the actors in the banana supply chain that complicates considerations on the public good characteristics of Panama disease management, and it is the speed and power of this rapidly-moving soil-borne pathogen that makes these considerations urgent. To date, there is no consensus on whether or not Panama disease control and management may be considered a GPG. At a practical level, denominating Panama disease control as a GPG may help provide the imperative for mobilising public good organisations such as the Food and Agriculture Organization (FAO), and pressuring governments to cooperate with each other in the search for transboundary solutions.

At present, different regulation strategies are being employed and proposed at various governance levels and domains - from quarantine measures, organic agriculture, changes in farm management strategies, to genetic modification. International rules such as sanitary and phytosanitary standards and provisions in international conventions such as the International Plant Protection Convention interact with domestic legislation and local ordinances. In turn, these hard laws interact with non-binding rules, local practices, and industry prescriptions to form a multi-governance policy infrastructure that evolves with and is constantly interrogated by scientific expertise, market compulsions, and consumer behaviour. In the case of the Panama disease, there is the World Banana Forum under the FAO and regional bodies in Africa and Latin America. Powerful banana multinationals support research and participate in international fora. At the same time, there are banana smallholder communities that provide the labour in banana plantations worldwide, and who serve as the default 'first responders' in the event of an incursion.

Amid this panoply of unharmonised and at times discordant mechanisms, and given the transnational nature of the disease (Singh et al. 2011), there is an emerging collection of voices calling for an integrated global response so that solutions to Panama disease can be provided at the scale and scope required, including the coordinated mobilisation of resources and expertise (FAO 2014). The effective management of pathogen threats, after all, needs a suite of interventions that match the scale of problem (McAllister et al. 2015). An example of a global coordinated response is the response of the FAO to the Desert Locust, said to be one of the most dangerous pests threatening crop production because of its ability to travel long distances, and currently affecting a total of 29 million square kilometres in 64 member nations.

This Chapter is comprised of the following sections: First, we provide our theoretical frame, grounding our work in the literature on GPGs, particularly on marketbased provisions. Second, we lay out our methodological approach. Third, we examine historical patterns of international plant disease protection and provide an overview and structure of the international governance regime on plant disease prevention, to determine whether the trend has been to move towards or away from a public good 
conception of plant disease management. We also examine how neoliberalism has influenced global governance in plant protection. Fourth, we surface the dilemmas and contradictions that attend the delivery of Panama disease control as a GPG, in order to determine whether or not key structural elements within the neoliberalist model constrain the delivery of Panama disease interventions as GPGs. It is our hypothesis that these elements within the neoliberalist model are at tension with key features of Global Public Goods.

\section{Theoretical framework}

Public goods

For economists, a public good is one wherein the use by one entity does not diminish the optimal availability and enjoyment by another, and where it is impossible or impractical for one entity to prevent another from using it (Brookes and Wahhaj 2001). The former describes the concept of non-rivalry, and the latter the concept of nonexcludability. A vast array of goods considered as public goods only partially meet the standards of non-rivalry and non-excludability and yet retain the characteristics of a public good, including many of its implications (Kaul et al. 1999). These are called 'impure public goods'.1

Public goods may be further classified into models; two of the more common are the 'weakest link' model and the 'best shot' model. The weakest link model of public goods holds that the aggregate benefit is determined by the contribution of the weakest member (e.g., Hirshleifer 1983), whilst the 'best shot' model holds that the aggregate benefit is determined by the contribution of the member who 'fires the best shot' and solves the problem facing the community in the best way. Crop protection and pest eradication have been denominated to be a weakest/weaker-link public good (Arce et al. 2001), since the weakest participant (the one unable to detect or treat disease) becomes responsible for the spread. Therefore, an effective provider of transnational plant disease control as public good must explicitly target assistance toward the weakest link.

\footnotetext{
${ }^{1}$ Impure public goods can be further broken down. One category covers goods that are non-rivalrous in consumption but excludable; these are considered club goods, meaning they are non-rivalrous only within the members of the club. Goods that are mostly non-excludable but rivalrous in consumption are considered common pool resources; these are finite in nature, i.e., overconsumption can lead to an undersupply of the resource. An example would be fishing grounds.
} 


\section{Global Public Goods}

Expanding this definition, GPGs are those whose non-rivalry and non-excludability are not confined within a state but instead cross national borders. We foreground our research on a GPG framework to investigate how the public good characteristics of transnational plant disease control are reflected in the international coordination and multi-stakeholder collaborations around Panama disease. According again to Brookes and Wahhaj (2001) "global public goods can be supplied adequately only through international co-operation (and) whether international co-operation is feasible or not will depend, in turn, on the benefits of the global public good and the costs of co-operation to each nation state." The control of new environmental threats, including the transboundary movement of a destructive soil-borne pathogen, can well be considered a GPG (McMichael and Haines 1997). Even policy questions that were traditionally contested at the local domain, such as communication and transportation, now require some level of international coordination (Kaul et al. 1999). Intervention for GPGs is traditionally provided by global public organisations such as the United Nations (UN) for collective security and international peace (Mendez 1999), the Global Health Fund for HIV-AIDS in Africa (Kaul 2001), and the Consultative Group on International Agricultural Research (CGIAR) for international agricultural research (Dalrymple 2003). These organisations offer a platform by which both state and non-state actors can collaborate and engage with each other towards common goals. Similarly, transnational plant disease control relies heavily on well-functioning disease monitoring, quarantine, and information-sharing platforms between countries and stakeholders. These enable awareness of the disease to be disseminated along vertical and horizontal chains as well as tracking of its movement and spread. The lack of commercial/market-driven incentives to provide this platform on the scale required for it to operate optimally further supports the GPG characteristics of Panama disease control.

Based on the literature, we have extrapolated key features of weak-link models of GPGs, and we use these key features to analyse the global governance infrastructure of Panama disease under the neoliberal framework: (1) creation of incentives for cooperation and disincentives for defection, (2) explicit targeting of weakest-link solutions, and (3) bias towards non-excludable and non-rivalrous knowledge streams.

\section{Neoliberal approaches to public goods}

We now come to neoliberal or market-based approaches to public goods, which is the main theme of this research. Whether or not the market can provide a public good is a question that has been asked before. Geoffrey Heal (1998) suggests that market-based mechanisms can address 'public bads', and that a robust international regulatory framework that promotes market efficiency can promote an optimal environment for the distribution of GPGs. For example, he argues that global pollution levels can be reduced through a global market in pollution permits that will also efficiently distribute the costs of emission reductions. Looking at ecosystem services on agricultural lands, on the other 
hand, Kroeger and Casey (2007) state that without a functional regulatory framework, commodification of ecosystem services cannot deliver public good outcomes.

Underpinning the question on whether or not the market can provide public goods is the debate on how best to respond to 'market failure'. One argument for government intervention is the 'free-rider' problem - the difficulty of private producers to prevent the free consumption of the public good in question by other actors that effectively disincentivises private enterprise and leads to underprovision (Samuelson 1954). In order to address this underprovision, government - or, where global public goods are concerned, international organisations formed on the basis of collective agreement among states - steps in through the use of regulation or subsidies. The neoliberal counterargument to that, however, is that, while market failure is problematic, government intervention will lead to worse outcomes (Palley 2005), owing to its inherent inefficiencies and its potential to create new market failures.

Extending this debate to global public goods and international organisations, we engage with the question of whether or not international plant protection as a global public good is best provided through market-driven solutions, as opposed to interventions from international organisations or regulatory bodies.

\section{Methodology}

This research was developed primarily through semi-structured interviews with three groups of key actors. The first group is composed of international actors within the World Banana Forum, the Committee on Commodity Problems under the Economic and Social Department, the International Plant Protection Convention, and the Emergency Prevention System - all of which are under the auspices of the FAO. Interviews were conducted in Rome, Italy in September 2015.

The second group consists of national actors. These include representatives of the National Agricultural Research Organisation of Uganda, the Plant Protection Office of the Philippines, and the Department of Agriculture, Fisheries and Forestry in Queensland, Australia. Uganda is one of the centres of scientific research on bananas in the African region; while not yet infested with TR4, it is highly concerned about banana diseases given the centrality of bananas to rural livelihoods and its proximity to Mozambique (which has the disease). The Philippines has had Panama disease for more than a decade, while Australia had a recent outbreak of TR4 in March 2015. Interviews in Australia were conducted in July 2015, interviews in Uganda in September 2015, and interviews in the Philippines in October 2015.

The third group consists of expert scientists working on banana research and representing various research organisations and universities. Scientists interviewed came from Bioversity International, the International Institute of Tropical Agriculture, the Association for Strengthening Agricultural Research in Eastern and Central Africa, the Centre for Tropical Crops and Biocommodities - Queensland University of Technology, 
and Wageningen University in the Netherlands. Interviews were conducted from 2012 to 2015 , in various locations, in the course of the research process.

These interviews were supplemented with analysis of official documents of the FAO, research documents and statements of international organisations, and the text of various conventions, particularly the International Plant Protection Convention.

\section{Evolution of plant disease control and Panama disease regulation: How neoliberalism shifted the terrain of plant protection governance}

This section looks at the historical trends of plant disease management in international governance. We look at how neoliberalism recasts the terms of plant protection governance from a framework that emphasised international cooperation to one that facilitates the imperatives of a global free trade regime.

The terrain upon which we examine Panama disease Tropical Race 4 is completely different from the terrain of the earlier variant Tropical Race 1. During the early part of the previous century, corporations were the major driving force of regulation. There was no sense of the necessity of collective action. This was made clear in the example of United Fruit Corporation's struggle with Panama disease in Central America. It was the corporation that dealt with the ramifications of the spread of the disease with hardly any government intervention.

The first undertaking that recognised the need for a multilateral effort to control plant and agricultural diseases took place in 1914: the Phytopathological Conference in Rome, Italy. Thirty countries attended the conference, and each was asked to enumerate the pests that it wanted to be protected from. To quote MacLeod et al. (2010), "(i)n order to justify being placed on such a list, it was agreed that host plants must be present in the country; that the pest could not be widespread; the pest must be able to survive on a trade pathway; and finally that the pest should be injurious to the plant, where injurious meant destructive to the commercial value of the crop."

In 1929, the International Convention for the Protection of Plants came into fruition, but the imminence of World War II made it difficult for the Convention to gain much traction. After World War II ended, the FAO was created as a specialised agency of the UN to address issues of food and agriculture on a global scale. FAO is a conduit for the sharing of critical information on agricultural resources, and this information is considered by the FAO as Global Public Goods. Like the UN, the FAO was founded squarely on a GPG framework, illumined by the ideals of international cooperation. From the postwar era until the 1970s, the whole world was in rebuilding mode, and interventionism was seen as critical for rehabilitating economies fractured by the war and periods of economic recession or depression.

The 1970s, however, was marked by a crisis of 'stagflation' (a combination of high inflation and economic stagnation). A persuasive narrative emerged that stagflation was the result of too much government regulation and too high taxes on the wealthy (Hay 
2004). In response, the 1980s ushered in 'Reaganism' and its mirror in Great Britain, 'Thatcherism'. Buoyed by recommendations from the so-called Chicago group composed of economists from the University of Chicago, US President Ronald Reagan increased interest rates and introduced a 'flat tax system' that bore down heavily on the poor and increased the wealth of the rich. This had ripple effects on developing countries who were recipients of loans from the United States and thus affected by the fluctuations in interest rates. Countries in Latin America were in danger of default; in order to avert a debt crisis, the United States used the International Monetary Fund (IMF) to ensure that debtor countries would repay their loans. The IMF used the loans of these countries to compel them to embark on 'structural adjustment programs' characterised by cutting government subsidies and rolling back regulations on labour, environment, and resource use - in short, agreeing to privatisation, regulation, and liberalisation which are the ideological core of neoliberalism as we know it today (Smith et al. 1994). For agriculture and plant protection, this meant a rollback in government financing for agricultural services and agricultural research and development. All these contributed to massive rural poverty (Kay 2006).

The watershed moment for neoliberalism and globalisation took place in 1995, with the establishment of the World Trade Organization. The WTO solidified neoliberalism as the dominant ideology of our time; it did not see any other viable alternative to globalisation. Where plant protection was concerned, the creation of the WTO was accompanied by the establishment of the Sanitary and Phytosanitary (SPS) regulations that aimed to balance the need to protect against legitimate risks to plant, animal, and human health with the goals of trade liberalisation. These were seen as a response to regulatory diversity through international harmonisation of standards (Büthe 2008). The SPS rules effectively say that sanitary and phytosanitary restrictions unsubstantiated by scientific evidence cannot be the basis of a trade barrier. Article 5 of the SPS agreement states that risk assessment protocols developed by relevant international bodies should be used, as appropriate to the circumstances, to determine the risks associated with trade and to develop protective measures to mitigate the risks.

Just as the IMF was repurposed from its previous function of using its own money in order to help countries with balance of payment problems, the establishment of the WTO and the dominance of the neoliberal ideology led to a 'repurposing' of other international organisations and global platforms to serve the interests of globalisation.

This included the International Plant Protection Convention (IPPC). When the IPPC was founded in 1951, plant protection was its foremost consideration. Under its present reformulation, the IPPC works in tandem with the SPS rules to formulate harmonised standards based on a 'uniform science', with the end in view of eliminating regulatory diversity. An important 'new' role of the IPPC is therefore to aid the WTO in determining whether or not a measure is an unjustified trade restriction. Consequently, it may be said that the IPPC had since followed the WTO's neoliberal framework. The IPPC's principles are meant to balance plant protection aspirations with free trade commitments. For 
example, phyto-sanitary measures are to be applied only when necessary; the measures must be technically justified, transparent, and applied equally to countries of equivalent plant health status; these should be the least trade-restrictive (FA0 2002).

At present, there are 182 contracting parties to the Convention. Today, the IPPC Secretariat is hosted by the FAO and provides information on pest risks as well as technical assistance to developing countries that are signatories of the IPPC. Its primary focus continues to be plant products that have international trade movement, with an explicit policy to ensure the protection of crops with the least interference to the international movement of goods and people. The IPPC works with regional plant protection organisations and other international organisations to address transnational plant risks and to promote the need for harmonised international standards.

This is not to say that the neoliberal framework for plant protection has not been challenged. In 1992, the Convention on Biological Diversity (CBD) was formulated to protect biological diversity against invasive alien species. Whilst the primary purpose of the CBD and the IPPC are different (the IPPC protects plant health and the economic potential of crops, while the CBD concerns itself with ecological damage), both deal with the containment of pathogens like fusarium wilt, the spread of which can wreak havoc on the host or receiving country. The CBD, however, crucially posed a frontal challenge to the IPPC/SPS framework by containing an iteration of the precautionary principle in its preamble: "Where there is a threat of significant reduction or loss of biological diversity, lack of full scientific certainty should not be used as a reason for postponing measures to avoid or minimize such a threat." Countries from Europe and most parts of the developing world rallied to the CBD/precautionary principle framework. However, while enactment of the precautionary principle within the Convention on Biological Diversity could already be considered a victory, global realpolitik has made it hard for the Protocol to make much headway. For example, the WTO decision on the European Union ban on geneticallymodified crops from the United States underscores the body's bias for the science-based risk assessment paradigm of the Americas (Bridgers 2003).

By and large, therefore, the IPPC/SPS framework remains the governing framework for plant protection. Its determination of what constitutes a quarantine pest to warrant trade restriction binds even bodies like the FAO. FAO's Plant Production and Protection Division (AGP) works on the sustainable intensification of crop production as a means to meet food security goals and protect natural resources for future use. One of the core themes of the AGP is Pest and Pesticide Management, which aims to prevent cropdestroying pests whilst reducing reliance on pesticides. The AGP leads the international normative work in pesticide risk reduction and provides technical assistance to states in capacity-building. Also under the FAO is the Emergency Prevention System (EMPRES), created in 1994. EMPRES Plant Protection focuses on outbreaks of transboundary plant pests and diseases and coordinates at local, regional, and international levels. Monitoring and early warning are two key strategies used by EMPRES, which developed specialised 
tools to this end. However, denominating a plant disease as a quarantine disease still cannot be done without the IPPC.

Barring trade-restrictive mechanisms, there is presently a rich array of tools for plant protection and surveillance of plant diseases. Specific to bananas, the FAO hosts the Inter-Governmental Group on Bananas and Tropical Fruits, which provides a forum for exchanges on banana production and consumption, among others, as well as the global trade of the same, with an emphasis on national policies. The Group also links memberstates with international experts and organisations, as well as with the private sector. In 2009, the World Banana Forum was established as a permanent platform to bring together stakeholders along the banana supply chain and experts in banana research. Its main goal is to create best practices for banana production and trade, and it operates through several working groups: sustainable production systems and environmental impact, value distribution along the chain, and labour rights, unions, and gender equity. The Trade and Markets Division of the FAO hosts the World Banana Forum.

In 2014, a proposal was crafted within the FAO for a framework for a global programme on Panama disease (hereafter, Global Programme), with three overarching goals: the prevention of future outbreaks, the management of existing incursions, and the strengthening of international collaboration and coordination among stakeholders such as researchers, governments, producers, and corporations. The Global Programme hopes to engage and collaborate with actors on three levels of governance: national bodies (e.g., national governments and research institutions), regional bodies and groups (e.g., African Consortium for Foc TR4), and international institutions and networks like Bioversity International. It will also coordinate with universities, non-governmental organisations, and members of the private sector. Proponents cite the work on food security and agriculture-based livelihoods as its strategic advantage in the management of transboundary plant pests and diseases, as well as its capacity to bring together the World Banana Forum, the IPPC, and EMPRES under its auspices. As of the writing of this Chapter, however, the Global Programme has not been approved.

This research was conducted amidst discussions and debates preparatory to the creation of the Global Programme, and while international organisations were building a consensus on how the risk of Panama disease is to be addressed. It is our contention that the discourses that emerged in the course of discussions on the risk of Panama disease speak to the success of the neoliberal framework in 'repurposing' international plant protection organisations to promote its agenda. 


\section{Arguments}

We now analyse the dilemmas and issues identified in our research. We draw from three elements of neoliberal ideology: first, private financing, which asks the question of who bears the burden of Panama disease; second, elimination of barriers to trade, which looks at how policies are crafted using the lexicon of the market; and third, market-led agriculture research and development (R\&D). In the first, we use the case of Panama disease to answer the classic question of who bears the burden for plant disease. We then discuss the issue of disclosure as conditionality of collective action, and proceed to demonstrate how this conditionality might be co-opted as a strategy against trade barriers. Finally, we examine competing expert scientific claims and the privileging of corporations in agriculture R\&D.

Who bears the burden for plant disease?

Should public goods be privately financed? Proponents of this argument believe that direct beneficiaries of the crop protection strategies should be primarily responsible for the cost of these strategies, so that public good organisations (states and international organisations) can focus their limited resources elsewhere (Marsh and Pannell 2000).

This perspective has been observed within the FAO. During an interview, an economist at the Intergovernmental Group (IGG) on Bananas within the FAO asserted that the problem should be primarily borne by corporations because Cavendish is a commercial crop. Given the scarcity of resources, he thinks the FAO should channel its funds towards less commercial crops (interview, IGG official, 7 September 2015, Rome). Other interviewees from the FAO took a middle ground position: whilst stating that government should take the lead role versus plant disease, they also said there should be some degree of cooperation or collaboration with the private sector.

Likewise, another respondent within the FAO shared that perceptions within national jurisdictions point to Panama disease as primarily a private sector problem in countries like the Philippines and Indonesia, where the banana industry is characterised by the presence of large transnational corporations engaged in export production of Cavendish. Interestingly, in Uganda, where the banana industry is primarily for domestic production and not characterised by the presence of transnational corporations, the head of the National Banana Program maintained the position that producers should primarily be liable for shouldering the cost of disease management. "If your child is sick, who should pay so that he can get well? Should it not be the parents? Let us not pamper the farmers. They are producing bananas like Coca-Cola is making soda. If something is wrong in the soda factory, Coca-Cola pays for it." (interview, Head of National Banana Program Uganda, 23 September 2015, Kampala) Uganda does not have TR4 yet of Panama disease, but the country is the research hub for bananas in East Africa and has several decades of experience in other banana diseases. 
The position that plant disease management for commercial crops like Cavendish bananas should be borne by the commercial producer is fraught with challenges.

During interviews with both government officials and executives of multinational companies in the Philippines, they revealed that corporations are reluctant to disclose the extent of the infestation of Panama disease in their farms. In the Philippines, there is no mechanism to compel the disclosure of invasive pests; there is, as well, no incentive for corporations to do so (see Chapter 2). Amidst this lack of transparency, leaving Panama disease management solutions to market-driven solutions will not sufficiently arrest the spread of the disease.

In some situations, it is a case of 'cannot', rather than 'do not'. Some governments in developing countries lack capacity to provide management and control strategies for the disease. Many countries in Africa face multiple constraints, not least of which is a weak quarantine infrastructure and limited means to detect and diagnose plant diseases (see for example, Ntawuruhunga and Legg 2007). There have been efforts to facilitate exchange of disease-resistant plant varieties in the region, particularly those plants critical for rural livelihoods.

Even in less problematic but still developing countries like the Philippines and Indonesia, the technology for detection and identification of Panama disease is still very inadequate. Philippine government officials acknowledge that while government cannot compete with the technical expertise of companies, it can play a role for smallholders. "The multinational companies should take care of themselves; government can take care of the smallholders." (interview, Provincial Agriculturist, August 2013) The problem with this formulation is that it suggests interventions for the companies and interventions for smallholders can take on two parallel unrelated tracks. On the contrary, research conducted in the Philippines suggests a dense and complex web of relations between the multinational companies and the smallholder farmers such that independent interventions with clear dichotomies are impossible. For example, a common arrangement is for smallholders to enter into contractual arrangements to supply bananas to multinational companies; these contracts require the smallholders to foot the bill for the disease (see Chapter 3).

The Philippine example surfaces the problematic assumptions embedded in the notion that 'public good'-type interventions should not be mobilised for Cavendish bananas, a commercial commodity. The nature of the disease itself, spreading as it does through the soil and moving from farm to farm, requires the enforcement of regulatory powers. In wealthier Australia, for example, while biosecurity efforts against Panama disease are framed as a shared responsibility between the government and the private sector, evidence suggests that government intervention is still sought by industry and the producers, and the government has been responding through emergency cash injections to arrest the spread of the disease. 
Moreover, there is evidence that other banana cultivars are also susceptible to the disease (Ploetz 2006). Therefore, if no efforts are undertaken to manage the disease in Cavendish farms, it may threaten other cultivars, including those planted for food security and critical to rural livelihoods. If so, a public goods approach becomes even more crucial, because absent market-based incentives to deliver solutions to the threat of Panama disease, underprovision of solutions is imminent and collective action must be mobilised from the community of nations. However, without a consensus on the public good nature of Panama disease prevention, even by the states that have confirmed infestations, the imperative of public sector interventions remains under question. Since institutions like the FAO operate at the behest of member-states, international platforms unfortunately cannot be maximised.

\section{Protection or protectionism? The balancing act between plant protection and free trade}

This section looks at the tensions between collective global action and free trade imperatives under the current neoliberal global governance regime, and argues that these contestations imperil the provision of public goods, in this case, Panama disease interventions.

Proponents of the Global Programme ${ }^{2}$ - the initiative by some officials and stakeholders within the FAO to push for international collaboration for Panama disease, which came at the heels of the confirmation of an infested farm in Mozambique - suggest that international collaboration through an organisation like the FAO is key to finding a solution to Panama disease. This position is shared by international non-governmental organisations, for example the International Institute for Tropical Agriculture during an interview with their East Africa hub in Uganda, and Bioversity International, which hosts the Banana Research Network for Eastern and Southern Africa (BARNESA). "We need global platforms for dialogue and to share experiences," said an expert scientist from Bioversity (interviews, IITA official and Bioversity project manager, 25 September 2015, Kampala).

The felt need for international collaboration is also expressed in the emergence of various regional partnerships focusing on Panama disease. For example, for sub-Saharan Africa, the African Consortium for Tropical Race 4 (AC4TR4) was organised in 2014, on account of TR4's discovery in Mozambique and the critical importance of bananas on rural livelihoods. The African Consortium brings together national governments through their

\footnotetext{
${ }^{2}$ According to the Draft Document of the Global Programme, " $(\mathrm{t})$ he magnitude of numerous independent international activities, and the challenges associated with addressing the global spread of Foc TR4, require proper coordination and synergies among research groups, extension scientists, national plant protection organizations and national government institutions to warrant an apt and useful conclusion to prevent significant losses to a crop that is providing food and income to millions."

3BARNESA was founded in 1994 by 10 Eastern and Southern Africa countries to facilitate cooperation among the respective national agricultural research programmes. Bioversity International is coordinating BARNESA.
} 
national agricultural research organisations, international organisations like the CGIAR networks, and universities such as the University of Stellenbosch. ${ }^{4}$

However, within the FAO, opinion is more divided. Some international actors are less convinced that such a global platform is necessary for Panama disease. A senior official within the FAO himself admitted there were some reservations and internal resistance to elevating the discussions on the disease (interview, FAO senior expert, 7 September 2015, Rome). While all interview respondents acknowledge that serious measures are required to control the spread of the pathogen, there is some disagreement on the spatial dimensions by which these efforts are to be undertaken. Ostensibly, a major reason is the failure of member-countries to raise the issue of Panama disease to the international community and the conventional belief that international organisations can only act when there is a national trigger. Respondents from both the EMPRES and the IPPC were clear that the FAO cannot - and should not - act without any member-state raising the issue, nor should their organisations within the FAO be involved in global actions against the disease (interviews, IPPC and EMPRES officials, 7 September 2015, Rome).

A critical point that surfaced during the interviews is that before a pest or pathogen can fall within the realm of regulation by the IPPC, it must first be denominated as a 'quarantine pest'. The IPPC defines a quarantine pest as "a pest of economic importance to the area endangered thereby and not yet present there, or present but not widely distributed and being officially controlled" (ISPM No. 5, Glossary of Phytosanitary Terms, 2010). Fusarium wilt, the pathogen that gives rise to Panama disease, cannot be denominated a quarantine pest without an official finding, the trigger of which should result from notification by a member-state. Denominating a pest as a quarantine pest, aside from making it fall within the realm of regulation by the IPPC, also allows importing countries to impose phyto-sanitary measures that may be trade-restrictive. The IPPC Secretariat member was firm in laying out the consequences of labelling it as such without having undergone appropriate pest risk assessment procedures. He likewise said that the FAO is duty-bound to follow standards set by the IPPC, and cannot undertake collective action without the imprimatur of the IPPC.

The argument therefore, being posited to reject collective global action against Panama disease can be distilled in this wise: collective global action can only be undertaken if the pest has been denominated as a quarantine pest in accordance with the standards of the IPPC; however, a pest cannot be denominated as a quarantine pest without a formal notification coming from a member-state with a confirmed infestation. Underscoring this point, the IPPC representative stated that international organisations cannot act, even amid data from non-state actors (such as expert scientific communities and civil society organisations) on the threat of the pathogen and the need for urgent

\footnotetext{
${ }^{4}$ According to the Stellenbosch declaration released in June of 2014 by the AC4TR4, the members agreed to "(r)ecognize that Foc TR4 is a continental issue that requires coordination and collaboration between NPPOs, RECs, ICPs, research institutions, universities, governments and other relevant stakeholders throughout Africa by means of regular meetings and consultations."
} 
action, without notification from a national government through their national plant protection office.

The argument is problematic on two levels: first, on the requirement of transparency and disclosure; and second and more importantly, on the privileging of free trade strictures over plant protection.

Indeed, an important area of cooperation is in the area of disclosure. Information is a critical part of plant protection under both the SPS Agreements and the IPPC. Member-countries are obligated to inform other countries of changes in sanitary and phyto-sanitary requirements that have the potential to affect trade, and to immediately provide information on SPS measures if necessary. It is also perhaps a recognition of state sovereignty as an overarching principle of international law that international organisations cannot mobilise global collective action without a national trigger.

The failure or inability of national governments to report the disease has been one of the major difficulties faced in mobilising collective action for Panama disease, and why the Global Programme under the FAO had not been officially launched. When asked why national governments were not reporting the disease, an FAO official identified the weak links between institutions and the lack of capacity and interest in plant protection institutions as the main issues. "Ignorance, lack of interest, simply not knowing what to do." (interview, FAO senior expert, 7 September 2015, Rome). An IPPC official however, suggested that some countries may also be deliberately not disclosing the infestation. "If countries do that more than once, then they will get found out. Their credibility disappears, and it will be difficult for them to trade." (interview, IPPC official, 7 September 2015, Rome). He gave the example of Zimbabwe, which hid the existence of a plant pest and suffered the devastating impacts on their trade. "The impact on your country is far, far bigger than if you were open and honest in the beginning." (ibid.)

However, the failure to disclose and to comply with transparency requirements may also result from the lack of capacity to make accurate diagnostics. In Africa, one of the main constraints in dealing with national governments, according to international organisations, is the lack or unevenness of technical expertise and capacity. In Mozambique, for instance, the corporation was said to have bypassed the National Plant Protection Office and coordinated directly with the University of Stellenbosch to confirm the diagnosis of fusarium wilt (ibid.).

This now leads to the second problematic assumption of the argument. The argument that the market will penalise the dishonest - i.e., "countries who do it often will get found out and will find it difficult to trade" - not only suggests that dishonesty is the reason for non-disclosure, but also shifts the focus to transparency in trade instead of the overarching concerns of plant health and plant protection. The more important priority, it appears, is to compel countries to be transparent in trade and to have uniform disclosure standards across jurisdictions - key ingredients for international free trade instead of mobilising pro-active and purposive solutions to critical threats to plant health 
and agriculture. Because the labelling of a pest as a quarantine pest or as a regulated pest has the net effect of a trade barrier, if there is any question as to whether or not a pest qualifies as a quarantine pest, such question is resolved against quarantine and regulation.

What is surfacing is a possible tension between the neoliberal framework that upholds the primacy of the market and decides on interventions in terms of how these can best facilitate trade, and the goals of plant protection and long-term agriculture priorities. Given the limited capacities of member-states, but also considering the rapid spread of various pathogen and its damaging impacts on livelihoods, economies, and the environment, a plausible case might be made for a global governance regime that is more pro-active in responding to plant pests and diseases. There is evidence that plant pest control is a public good that requires higher-level governance systems, and cannot be reliant on market-driven interventions (Toleubayev et al. 2007). As it stands, however, the free trade principles that undergird the global system dis-incentivise global collective action as this might conflict with the market and the free movement of goods.

\section{Market-based solutions and the neoliberal toolbox: The road to GMOs}

A market-based approach to public goods delivery will necessarily rely predominantly on a market-based toolbox of instruments. Interventions by international organisations like the FAO rely primarily on an interface between scientific knowledge and policy, and on crafting a packet of strategies that are sustainable for and relevant to agricultural communities.

A contentious debate in banana research is the issue of genetically modified bananas versus somaclonal variants. Proponents of GMO suggest that the use of genetic modification to create resistant varieties is the only feasible solution, given the vulnerability of the Cavendish to Panama disease TR4 and the absence of any long-term eradication solution to Panama disease. Genetic modification will protect the cultivar from commercial extinction, proponents claim (Koeppel 2008). These scientists cite field findings that conventional breeding methods cannot be used to introduce improvements (i.e., resistance) into the Cavendish cultivar (Aguilar Moran 2013). Scientists like the Australian biotechnologist James Dale suggest that GMO bananas are inevitable; if biotechnology can bring to the market safe, cheap bananas, then consumer preferences will evolve towards eventual market acceptance (interview, Dale, 16 July 2015, Brisbane). A similar view is echoed by molecular biologist Serge Remy from KU Leuven, who said "genetic modification is the only way to maintain the supply levels of bananas in the market" (interview, Remy, 12 February 2013, Skype).

Confined field trials on GMO bananas were recorded in Israel in 2006, followed by the USA, Uganda, and Australia (Remy et al. 2013). Previous plant breeding work in biotechnology has generated resistance to FOC race 1 in the Lady Finger variant with the use of anti-apoptosis genes (interview, Dale, 16 July 2015, Brisbane). Near immunity was obtained through one gene Ced9 from the nematode Caenorhabditis. In an ACORBAT 
conference held in Miami in 2016, Dale said that developing a TR4-resistant Cavendish replacement should be part of medium- to long-term goals. He also cited promising inroads for biotechnology, such as the results of a TR4 field trial in a banana plantation in the Northern Territory of Australia, where transgenic lines demonstrated high levels of resistance.

However, another strand of thought within the banana research community supports tissue culture as a means for developing a resistant variety as part of an integrated approach to disease management (Interview, Molina, April 2016, Miami, Florida). Supporters of the tissue culture somaclonal variation suggest that the adaption of Giant Cavendish Tissue Culture Variants (GCTCV) has managed to rehabilitate severely affected farms of small-scale Cavendish growers in the Philippines. In his presentation at the ACORBAT Conference in Miami, Dr. Augustus Molina said that severely affected areas can be totally rehabilitated with GCTCV 219, describing the somaclonal variation selection as a "practical and efficient banana improvement approach".

The relationship between those in support of GMOs and those in support of somaclonal tissue culture is understandably antagonistic. The latter group calls efforts to push for fusarium-resistant GMO bananas as a 'pie in the sky', whilst the former group insists that no true resistance can be developed without the use of biotechnology.

While it is too early to say which viewpoint has gained dominance, current international regulatory structures appear to create an enabling framework for the legitimacy of biotechnology. Research in GMO bananas is receiving financial support from wealthy organisations like the Bill and Melinda Gates Foundation. The discourse of 'GMO bananas or no bananas' is gaining credence, and is often accompanied by a derisive attitude towards other modes of Panama disease control and management. Viewed in the context of policies in Europe and the Americas that allow relaxed restrictions for GM crops, there appears to be a concerted effort not only to 'normalise' GM technology, but in the case of the Cavendish, at least - to present it as the only viable solution against Panama disease. Given the massive corporate interest in Cavendish banana as a major export crop, and in the light of a policy regime that allows the patenting of GM crops (see Torrance 2007), the dilemma is that already-expressed fears over monopoly ownership and corporate control in GM crops in general are finding re-articulation in the issue of GM bananas. We suggest that this goes into the heart of the public good debate. It may not be difficult to envision a future where Panama disease management strategies, or indeed resilient bananas, become a 'club good' or an 'excludable public good' available only to those with the means to access the technology.

\section{Conclusion and reflections}

The terrain that plant protection interventions navigate today is a much more complicated terrain than it was decades ago, before neoliberalism influenced the structures of international governance and the ways by which governments relate to each other. Indeed, the complexity of responding to Panama disease TR4 is not just about a 
pathogen with devastating effects, but also the policy landscape in which it operates. Actor/stakeholder networks today have to reckon not only with finding phyto-sanitary solutions and strategies, they have to do so while navigating neoliberal strictures and structures. Meanwhile, the pathogen remains in constant motion, destroying livelihoods and local economies along trade pathways.

This research reflects some of the key issues and challenges that influence and, in some ways, complicate the provision of Panama disease solutions as a Global Public Good. At the onset of this Chapter, we identified three key features of weak-link models of global public goods: the creation of incentives for cooperation and disincentives for defection, the explicit targeting of weakest-link solutions, and the bias towards non-excludable and non-rivalrous knowledge streams. We find that these features of weak-link models of public goods have inherent tensions with features of neoliberal global governance.

The first involves the question of who should bear the burden for Panama disease. It links to the debate on whether or not public goods can be privately financed, and is complicated by perceptions in both international and domestic spheres that the primary target of the disease is a cultivar of economic importance to corporate agriculture. We argue that framing Panama disease management as a responsibility of corporate agriculture ignores the dense and complex web of social relations that tie large corporations to smallholder farmers, and therefore, the many ways by which the latter can be disadvantaged by a purely market-driven approach. It also encourages and sustains a 'pass the buck' mentality, where cooperation is discouraged and responsibilities are not shared.

The second issue surfaces the tensions between the neoliberal imperatives of free trade, and considerations of plant health and plant protection. It discusses the problematic intertwining of disclosure transparency requirements and collective action, whereby the absence of the former is used to justify withholding the latter. While transparency and disclosure may ensure the smooth workings of global governance mechanisms, the case of Panama disease demonstrates the latent difficulties of imposing the same requirements on actors in differentiated positions. This may be true not just for Panama disease but for a host of other issues. Without the benefit of surveillance systems and quarantine processes enforced by developed countries, compliance with transparency and disclosure under the SPS and the WTO remains difficult for developing countries. This demonstrates that 'weakest link' solutions are not prioritised, as a higher premium is placed in ensuring the smooth workings of the free trade model, with possible repercussions on the global state of plant health. How to balance the multiple considerations of plant health and crop protection, a consciousness towards unevenness of global development, and the necessities of disclosure and transparency, remains an unresolved question.

Third, we looked at how current efforts to address Panama disease, imbued as they are by corporate interests, now reflect a bias towards biotechnology and towards 
genetically modified bananas. We argue that given current policy directions supporting GMO patenting, Panama disease strategies may soon partake the nature of 'club goods', where enclosures are erected to keep out those without means to pay. While weakest-link model solutions are characterised by a bias towards non-excludable and non-rivalrous knowledge streams, GMO-based solutions lead us to an opposite direction: one where solutions are forthcoming only to those who can afford it.

As Panama disease spreads further and continues its pattern of global dissemination, these debates will continue to evolve and crystallise. We might also be able to extrapolate reflections that contribute to the larger question of whether Global Public Goods can be provided using available tools in the neoliberal toolbox, or whether an alternative imaginary is in order. Where the banana disease is concerned, however, there is urgent need to address the dilemmas in the delivery of Panama disease interventions as a global public good, and to create durable solutions for crop disease that are not disengaged from social and political realities. 
II.

\section{PANAMA DISEASE AND CONTRACT FARMING IN THE PHILIPPINES: TOWARDS A POLITICAL ECOLOGY OF RISK}

\section{Chapter overview}

Historians have described how fusarium wilt in banana (more commonly known as Panama disease) shaped the political economy of the Americas in the first half of the twentieth century. The virulent soil-borne disease affected large swathes of land in banana-producing economies, generating a need to control large tracts of land and recasting the power grids that cross and connect social actors in differentiated positions in the banana industry (Soluri 2002, Jansen 2006). United Fruit Company, called el pulpo (the Octopus) in Latin America and long held as a symbol of the banana corporations' pernicious chokehold on Latin American rural economy, was brought to its knees by the disease, the fungus becoming "an unlikely environmental locus of resistance to corporate agriculture's will to power" (Marquardt 2001). The Gros Michel cultivar was wiped out, leaving in its wake a trail of devastation. With the introduction of the Cavendish cultivar, developed to replace the Gros Michel and resistant to fusarium, Panama disease in the banana export sector eventually became a historical footnote. During the last quarter of the twentieth century, the banana research community shifted its focus to a very different banana disease: Black Sigatoka (Córdoba and Jansen 2014).

However, the recent emergence and spread of Panama disease's newest variant, Tropical Race (TR4), again threatens export banana production and may redefine the political economy of this agrarian activity. As their counterparts did a century ago, natural scientists are once more studying the causal agent of TR4 and how it spreads through the world. It seems timely therefore to also resume the study of Panama disease from an agrarian studies perspective and look at inter-linkages and relationships amongst the social actors and the spreading disease in today's context. Aside from re-examining these linkages and relationships under a more contemporary tableau, our specific theoretical contribution is to make explicit the engagement with risk and blame. Who bear the risk of Panama disease? Who are blamed for the spread of Panama disease? On whose hands fall these decisions, and why? Then as now, these questions are relevant in examining the ways by which social relationships influence the disease and its control.

Many experts argue that long-term chemical and physical measures against the disease are not (yet) available (Pérez-Vicente et al. 2004, 2014, Ploetz 2006, Pocasangre et al. 2011). Hence, pesticide spraying against the disease is not practised. Researchers are just starting to understand the genetic diversity of the pathogen itself, in order to develop methods and tools to diagnose the disease in the field before it can destroy a plantation (Ordoñez et al. 2015). 
In this study, we examine the complex social relationships in the banana industry in the Philippines and how these influence responses to the disease in the country. The Philippines is one of the top exporters of banana, trailing only behind countries like Ecuador and Costa Rica, and attracting hefty agricultural investments from transnational corporations. When a new epidemic of Panama disease hit the Philippines and started destroying banana plantations, stakeholders in the banana value chain scrambled for solutions.

In a meeting to discuss the disease problem and possible solutions for the Philippines (in Davao in February 2014), we observed how views about causal processes in the spread of the disease and possible control strategies were highly contested. Major divisive issues concerned the implementation of control practices, the sharing of information, and possible alternatives (e.g., GMOs versus other types of resistant varieties). Some of these fractured agro-technological positions seemed rooted in entrenched oppositions between larger corporations, including banana production companies and international banana trading corporations, and smallholder banana producers, in particular members of agrarian cooperatives who are beneficiaries of the land reform programme.

Another contested issue that this Chapter will discuss is who is to blame for the spread of the disease. On the one hand, the FAO has found that commercial expansion of multinational banana companies to new areas is historically related to the spread of Panama disease (FAO 2014). TR4 also targets Cavendish bananas, the bananas of choice in Western breakfast tables and therefore the most important to multinational corporations and export markets. Large-scale monoculture production of multinational companies amplifies the pathogen's risks (ibid.). On the other hand, interviewees in the Philippines suggest that smallholder farmers, particularly agrarian reform beneficiaries, are responsible for the spread of the disease because they lack technological knowledge and capacity to implement disease management protocols at the farm level. This idea was consistent in interviews conducted with officials of an organisation of multinational banana companies, government officials, and public scientists.

In short, the problem of the spreading disease has been framed within existing contestations embedded in the agrarian political economy and can be seen to reflect some historical continuity of differences. To examine this further, we turn to an important practice within the banana sector: contract farming. Contract farming has long been a site of ideological struggle (Oya 2012). Contractual arrangements not only shape the social relationships between smallholder cooperatives and trading corporations (Zhang 2012), but they also contain technical rulings related to disease control. In the banana plantations of the Philippines, located primarily in the south, contract growership is a common contractual arrangement entered into by buyer transnational banana companies with smallholder farmers in order to minimise production risks. In this Chapter, we analyse how contract farming, as an institutional arrangement, formalises the distribution 
of risk in production processes, specifically the risk of destructive crop disease that can annihilate commercial production.

We borrow from Cultural Theory the insight that risks are always political (Douglas 1992) and that "the poor who carry the brunt often carry the blame for epidemic disaster" (ibid.). We incorporate this idea into a political ecology approach that investigates the dynamics of smallholder farmers and transnational banana companies amid technological and biological risks and analyse how economic arrangements, particularly between social actors in differentiated positions, form the basis of risk decisions.

Our research asks the following main question: To what extent does the nature of relationships between the social actors in a contract growership arrangement influence the possibilities and limitations of disease control? We break down this question further: First, how is the risk of Panama disease distributed under a contract growership arrangement? Second, what is the role of blaming in the uneven distribution of risk in a contract growership arrangement? In answering these, we look at whether or not the specific example of Panama disease control within a contract farming arrangement corroborates existing theoretical ideas on risk and blame (i.e., that risk perception and blame distribution are products of cultural bias and social relations) in asymmetric power settings, such as within an agrarian economy. We use this to reflect on implications for Panama disease and its spread, and elimination and mitigation strategies.

This Chapter contains the following sections. First, the theoretical section develops an enriched political ecology approach in studying the relationship between contract farming and disease management. The second section introduces the methodological tools and the case of the banana sector in the Philippines. Subsequently, in the third section, we analyse how the agrarian political economy in the banana sector influences social relations between smallholder growers and agribusiness and interacts with perceptions of plant disease occurrence and control. In the fourth section, we describe how corporations, smallholder farming communities, and local governments engage with each other and how Panama disease strategies are negotiated and its risks distributed in the context of contract farming. The fifth section examines and explains the importance of control by contracts and blaming as a cultural practice for defining responsibility for handling risks. In the conclusions, we summarise our argument that the dynamics of contractual arrangements and discursive interpretations of risk, blame, and responsibility are products of a fractured agrarian political economy with deep historical roots, and reflect on how these impact on the ways by which causes and solutions to Panama disease are viewed and framed. 


\section{Theoretical framework: Using Cultural Theory to build a political ecology of risk}

Agrarian scholars studying contractual relations between smallholder farmers and transnational corporations have demonstrated how processes and contestations embedded within agrarian relationships have resulted in social differentiation that privilege the latter and prejudice the former. Drawing from the same intellectual well, political ecology analyses how power asymmetries in relationships between and among social actors can produce different ecological outcomes that reinforce existing inequalities (Bryant and Bailey 1997, Jansen 1998), and how societal compulsions bear upon ecosystems (Zimmerer and Bassett 2003). Cultural Theory (Douglas 1992), on the other hand, suggests that human perceptions of risk and blame are not driven by sterile evidence-based assessments, but are outcomes of a combination of social relations and cultural biases, or in the words of Douglas, "a way of life" (ibid.)

\section{Political ecology of risk and blame}

In this Chapter, we are interested in the direction of political ecology that looks at how corporations as actors operating within local settings and establishing relationships with local communities shape environmental narratives of risk and blame, with resultant consequences on environmental change. In the context of banana plantations in the Philippines, how do political economic relationships between corporations and smallholder farmers, as embedded in their contract farming agreements, impact upon the actors' views of risk, and how do these views in turn affect how environmental risks are redistributed.

A latent topic in political ecology has been the issue of blame, whereby political ecology criticises how mainstream conservation approaches 'blame the victim'. Since Blaikie (1995), political ecology aims to take away such blame from smallholder farmers by pointing at larger processes of capitalist development that render people's resource use as environmentally destructive.

The social distribution of risk and the relationship between blaming and perceptions of justice and responsibility have also been a theme in Cultural Theory, in particular in the work of Mary Douglas. The study of how people cast blame may reveal or illustrate divisions in society, as ways of blaming are "symptoms of the way the society is organized" (Douglas 1992). Blaming is a social and political activity (Hood 2011), and examining who blames what, for which phenomenon and why, can provide a window into understanding how political and economic relations bear upon policy outcomes. The interesting take of Douglas is that (1) she shows how blaming as a cognitive activity that assigns responsibility can be connected to the study of society's responses, or the lack of it, to environmental risks, and (2) she demonstrates how a major crisis "digs more deeply the cleavages that have been there all this time" (Douglas 1992). These twin notions find iteration in a growing body of literature that looks at blaming as connecting risk issues with social organisation. Ríos-González et al. (2013) examined how the low-schooled rural people in Mexico are blamed for not using pesticides properly, mainly because they 
purportedly possess the 'Mexican idiosyncrasy' of being traditional and reckless. Other literature investigate the blaming of small farmers and the rural poor for various agroecological phenomena (e.g., Fox 2007, Jansen 2008). Drawing from this approach, we combine Cultural Theory's emphasis on casting blame with a political ecology-informed analysis of social organisation, in this case the contractual arrangements, to examine the extent to which blaming practices reflect how actors experience differences between groups and how they draw boundaries between groups.

\section{Contract farming: Indirect or direct control}

Contract growership or contract farming is an agreement between farmers and marketing firms under forward agreements, usually at predetermined prices for the production and supply of agricultural products. It is an institutional arrangement whereby smallholder farmers are integrated into agricultural value chains (Barrett et al. 2011). The advantages of contract growership arrangements have been written about extensively. Proponents suggest that contract farming provides smallholder farmers access to markets and credit that would otherwise not have been available to them (Simmons 2002), as well as ensures price stability (Guo et al. 2007). While contract farming has been lauded as an opportunity to efficiently organise labour and land (Hayami et al. 1998) to maximise economies of scale in a formalised arrangement, critics point out that asymmetries in the relations between buyer and grower make contract farming a formalised arrangement of financial dependence and exploitation (see for example, Porter and Phillips-Howard 1997, Quitoriano 2008) and create social differentiation (Glover and Kusterer 1990).

Early critical accounts of contract farming that examined the connections between contract farming and globalising circuits of capital and how contracts obscure the degree of economic compulsion (e.g., Watts et al. 1990) were later considered to have fallen short of understanding the full, nuanced, and diverse breadth of practices and agency in agricultural areas under contract growership arrangements (Grosh 1994, Grossman 2000, Vellema 2002, Imbruce 2008). However, the recognition that contract farming as a generic concept is problematic does not mean that we cannot analyse, for a given context, the levels of control and relative bargaining power (Singh 2002). In particular the balance between indirect and direct control in relation to Panama disease is relevant for our issue. The emergence of contract farming has been associated with a shift from direct to indirect control of the labour process (Clapp 1994). However, depending upon context, buying companies may shift back to direct control. For example, in a case of asparagus contract farming in the Philippines, Dole shifted contract arrangements from a focus on commercialisation and quality control to direct interventions in labour management practices and the introduction of technologies (Vellema 1999). The direct control over input use has also been observed in many other contract arrangements (e.g., Singh 2002). Below we will examine how the presence of virulent plant diseases and the responses to it may interact with forms of control by large companies as governed by contractual arrangements. 
We find in the interface of political ecology studies and Cultural Theory a useful lens with which to examine how risk is distributed, assigned, and perceived (1) in the context of a virulent plant disease, and (2) in a starkly-asymmetrical agrarian economy where there are clearly differentiated groups, as in a contract farming agreement. Using the case of Panama disease (the identified risk), we are interested in finding out whether the structural asymmetry embedded within a contract farming agreement has led to, first, an uneven distribution of risk whereby the weaker social group (smallholder farmers) bears a greater risk burden than the strong social group (banana companies), and second, a situation whereby the weaker social group is blamed or held 'morally-liable' for the risk besetting their shared community.

There is no dearth of evidence to demonstrate that agrarian studies and political ecology can/should contribute significantly to an understanding of plant diseases. Where the natural sciences study the nature and spread of a disease, agrarian studies can reveal how the responses to a disease are embedded in the dynamics and history of agrarian social relationships, and in turn also impact on the disease and its control and spread. We zero in on two specific responses: how the risk of the disease is distributed, and how blame for the disease is assigned.

\section{Methods and cases}

The case study method was employed in this research, focusing primarily on contract growership arrangements with two major corporations: Lapanday Foods Corp. and Sumitomo Fruits, Inc. (SUMIFRU). In both cases, we used a combination of focus group discussions (FGD), expert interviews, and document analysis.

FGDs were conducted in Davao and Compostela Valley in August 2013 and January 2014 with banana farmers' cooperatives that have contract growership agreements with Lapanday and SUMIFRU.

These discussions were conducted to understand perceptions, behaviour, and attitudes of the banana farmers working within these cooperatives. Moreover, semistructured interviews were conducted with key informants including local government officials such as the Provincial Agriculturist of Davao, representatives of multinational corporations such as Unifrutti Philippines, Inc. and NEH Philippines, officials from the Pilipino Banana Growers and Exporters Association (PBGEA) ${ }^{5}$, and workers from nongovernment organisations that assist small banana growers.

Data collection also involved document review of various issuances and laws passed by the local government of Davao and the national government of the Philippines, and growership and lease contracts between the farmers' cooperatives and the corporations. We did text analysis of the farmers' cooperatives' contracts with Lapanday

\footnotetext{
${ }^{5}$ Created in 1998, PBGEA is the biggest organisation of banana growers and exporters in the Philippines (with 31 companies and covering 15 provinces).The aggregate export volume of PBGEA was valued at US\$552-M and accounted for $71 \%$ of the industry's total.
} 
and SUMIFRU. We were supplied these contracts by farmers who entered into these contracts. We were also able to sit as participant-observer in a contract negotiation between a large buyer and farmers' cooperatives.

The cases were studied against a background of 1) an expanding banana sector up to 2012 and 2) an expansion of the Panama epidemic. Table 1 shows an expansion in area, a more than doubling of the production volume, and a steady increase in yields between 2003 and 2013, dipping only in 2012 and 2013 as a result of Typhoon Pablo.

In an interview with the Provincial Agriculturist of Davao in 2014, she surmised that the reason why there has been no drastic production dip despite the onslaught of Panama disease is because corporations move or expand to other land areas when Panama disease is detected. In 2015, PBGEA reported a 5.1\% loss in the total area planted with banana. The total land area for bananas in Mindanao amounted to 42,316.41 hectares in 2015, down from 44,479.65 hectares in 2014. This means that at least 2,163.24 hectares was lost, which PBGEA contends was due primarily to El Niño (drought caused by weather patterns) and to Panama disease.

Table 1. Cavendish production in the Philippines (2002-2013)

\begin{tabular}{llll}
\hline Year & $\begin{array}{l}\text { Volume } \\
(\text { x1000 metric tons })\end{array}$ & $\begin{array}{l}\text { Area } \\
\text { (x1000 has.) }\end{array}$ & $\begin{array}{l}\text { Yield } \\
\text { (metric tons/ha.) }\end{array}$ \\
\hline 2002 & 1,810 & 44 & 41.1 \\
2003 & 1,900 & 46 & 41.2 \\
2004 & 2,128 & 50 & 42.5 \\
2005 & 2,490 & 52 & 48.3 \\
2006 & 2,811 & 68 & 41.5 \\
2007 & 3,323 & 74 & 44.9 \\
2008 & 4,329 & 75 & 57.6 \\
2009 & 4,480 & 78 & 58.0 \\
2010 & 4,601 & 80 & 57.8 \\
2011 & 4,686 & 80 & 58.4 \\
2012 & 4,695 & 83 & 57.0 \\
2013 & 4,230 & 83 & 51.0 \\
& & & \\
\hline
\end{tabular}

(Based on data from Bureau of Agricultural Statistics) 
The export of Philippine Cavendish involves five major players: four transnational corporations - Dole, Del Monte, Unifrutti (a Chiquita subsidiary), and SUMIFRU - and one Filipino corporation, Lapanday Foods Corp. (Quitoriano 2008). These are only the direct exporters, but there are also several local corporations involved in local production and supply to the international players. Smallholder farmers either transact directly with transnational corporations like SUMIFRU, or work with the local corporation (e.g., many agrarian reform beneficiaries have existing leaseback agreements with Marsman Estate Plantation, Inc., which in turn supplies to Unifrutti). According to latest available data, there are 5,141 agrarian reform beneficiaries in Cavendish banana plantations in the Region 11 Davao region (De Leon and Escobido 2004).

While Cavendish is said to be the most economically-important banana cultivar in the Philippines, it accounts for only $50 \%$ of total banana production; saba accounts for $30 \%$ and lakatan 11\% (Philippine Statistics Authority 2015). The two latter cultivars are often grown by smallholder farmers in their backyards for domestic consumption.

A recent release of the government's Philippine Information Agency reported that 15,500 hectares of banana plantations have been infested with Panama disease. The same release also said that all varieties of banana are affected by the disease. ${ }^{6}$ Table 2 shows the extent of the current disease problem, which was not clearly visible in Table 1 since it does not show the shifting to new production areas and does not count area loss.

Table 2. Areas covered with Panama disease 2015

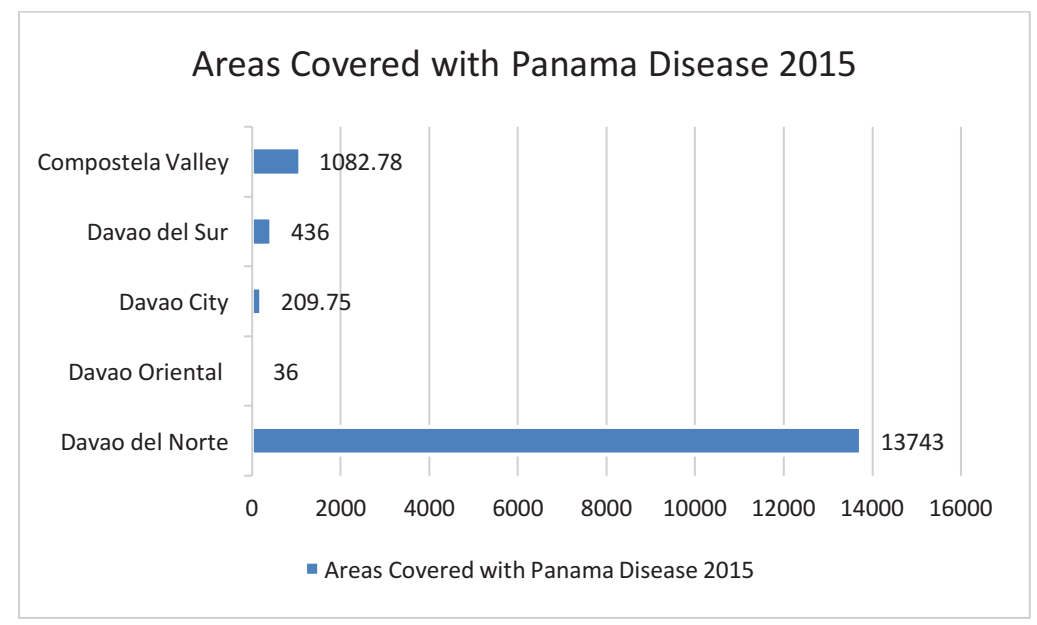

Source: Department of Agriculture

\footnotetext{
6 "Fusarium wilt disease continues to wreck (sic) havoc on banana plantations in Davao region. Available at http://news.pia.gov.ph/article/view/2381457937502/fusarium-wilt-disease-continues-to-wreck-havocon-banana-plantations-in-davao-region
} 


\section{The importance of the political economic history for current perceptions of Panama disease}

What came across in many interviews and the focus group discussions, and what one can also read in some of the scholarly literature and NGO advocacy campaign material, is a distrust between smallholder farmers (and supposedly organic intellectuals) and large banana companies. This section explores the historical roots of this distrust. Some historical elements that appear to play a role in the distrust are the institutions of deferment, the leaseback arrangement, the organised opposition, and the ways by which this opposition has been systematically subdued. Together these institutional arrangements and political relationships leave an impression of inequality and power difference upon people.

The large tracts of land in Mindanao, coupled with agro-ecological conditions suited for commercial agriculture, has made the region a hub for agribusiness plantations. Mindanao's physical terrain must also be seen against its distinct historical context (Tadem 1992, Vellema and Lara 2011) and ethnic configuration that has led to a diverse combination of Muslim inhabitants, non-Muslim indigenous groups, and Christian settlers from Luzon and Visayas (Quitoriano 2009). Pre-colonial Mindanao's tenurial regime was characterised by structures of communal land ownership woven into governance institutions of Muslim and indigenous tribes, but these structures were diluted by the arrival of the Spanish colonisers who imposed the Regalian doctrine, and the American colonisers who imposed the Torrens system of land titles. The latter in particular resulted in the effective nullification of land grants and ancestral rights issued by Sultans, Datus, and Chiefs of non-Christian tribes (ibid.). With Christian settlers further increasing in number as part of a concerted economic policy of government, ownership of land by Muslims was reduced to 30\% in 1972 (Che Man 1990) and 17\% by 1982 (Jubair 1999).

On the other hand, public lands consolidated by the State were used to build largescale commercial plantations. The National Development Corporation (NDC) served as the vehicle for plantation ventures. According to Quitoriano (2009), the first 10,000hectare pineapple plantation run by Philippine Packing Corporation as a subsidiary of Del Monte Corporation in Bukidnon was under a lease agreement with NDC. By 1983, NDC had managed to lease 117,000 hectares to eight foreign-owned companies to develop pineapple, rubber, palm oil, and banana (Ofreneo 1987). Because these large-scale plantations needed farm workers, non-Muslim farm workers were drawn into the region, further changing the ethnic configuration of the communities there (Quitoriano 2009).

The set-up of large-scale plantations and hired farm workers persisted well into the 1970s and the 1980s. By 1982, there were 23,000 hectares of Cavendish plantations controlled by four transnational corporations: United Brands, Dole, Del Monte, and

Sumitomo (ibid.). In the meantime, peasant struggles for land and rural social unrest resulted in what Borras and Franco (2005) describe as "partial concessions from the 
state", with the dictatorship of Ferdinand Marcos imposing a limited land reform decree over rice and corn lands and issuing so-called emancipation patents to landless tillers.

When the Marcos regime was toppled by an uprising now known as the EDSA People Power Revolution, a new Constitution emerged and alongside it, the establishment of the Comprehensive Agrarian Reform Program (CARP) - the new vehicle for smallholder title generation. Coming at the heels of the two-decade dictatorship, CARP was supposed to be the centrepiece of the new administration's thrust towards redistributive justice and democratisation. While critics assail agrarian reform as causing uncertainties that have "constrained investments in agriculture and reduced market valuation of land" (Digal 2007) and credit accessibility (Adriano 2008), advocates consider it a programme that was long-overdue. Scholars like Borras and Franco (2005) take a more balanced perspective:

CARP is thus best understood as a liberal type of land reform: it contains some powers to expropriate private lands (and therefore includes opportunities for redistribution), but as a voluntary scheme it is open to evasion by unscrupulous landowners, especially in the absence of public scrutiny and counter-mobilization. And it contains some outright anti-reform concessions to the most powerful segments of the landed elite.

The first contested issue in the Agrarian Reform Law for commercial farms was the so-called "deferment period". The banana corporations through PBGEA had worked for the insertion in the law of a 10-year deferment, which was a compromise because the banana corporations had initially demanded to be exempt from CARP (PCIJ 2006). For example, Checkered Farms and Diamond Farms, prior to 1988 owned by the multinational company Dole-Stanfilco, and Twin Rivers Farm and Hijo Plantations, owned by Lapanday, applied for a ten-year deferment period (Digal 2007).

The granting of deferment of land redistribution triggered a second mechanism: retrenching farm workers. The corporations knew that while they had managed to delay the land reform process, distribution was still inevitable. Knowing that their farm workers could become the agrarian reform beneficiaries, they opted to retrench farm workers who were hostile to their interests and replace them with those who were friendly to their agenda, i.e., those willing to enter into leaseback arrangements (see below) with them. The FGDs and interviews with key informants revealed that the ten-year period was difficult for the farm workers. According to the worker of an NGO engaged in agrarian reform advocacy in Mindanao, the corporations "tried to bribe the farmers with promises of favours and job security, and if the bribing did not work, they tried to scare them into believing that they would not manage to farm on their own, and if that did not work, then the harassment starts" (interview with NGO worker, 1 February 2014, Manila). "Mahirap, masakit, kumplikado (difficult, painful, complicated)" was the description of one farmer (FGD, 22 August 2013, Compostela Valley) who used to be employed by Dole-Stanfilco. By virtue of a Department Order, those who had been terminated for cause (i.e., for deliberate 
acts done by the worker) in commercial farms are no longer qualified to be agrarian reform beneficiaries. This led to a rise in illegal dismissal cases at the end of the deferment period (mostly between 1998 and the 2000s), as landowners wanted to ferret out the more recalcitrant among the workers, knowing that they would soon have to deal with them as agrarian reform beneficiaries (interview with NGO worker, 1 February 2014, Manila). They also filed inclusion and exclusion cases to exclude certain farmerbeneficiaries and include those sympathetic to the interests of the corporation. Critics estimate that around 20,000 banana farm workers were retrenched during the deferment period (De Leon and Escobido 2004). Quitoriano (2009) characterised the ten-year deferment period as resulting in "tremendous farm worker losses of land rights and incomes".

Yet another contested issue is the so-called lease or leaseback arrangement. Under a lease agreement, companies lease the land from the agrarian reform beneficiaries, usually for twenty-five years, and exercise control over the property and over production therein. In a leaseback arrangement, the company is the original owner of the land before the imposition of agrarian reform. In both a lease and leaseback arrangement, the company may or may not hire the beneficiaries as workers, although the automatic hire clause is sometimes added as sweetener. Some of the corporations that employed leaseback were Lapanday Agricultural Development Corporation (also known as Mampising), Marsman Estate Plantation, Inc., Saranggani Agricultural Corporation, Inc., and Worldwide Agricultural Development Corporation (WADECOR) (PCIJ 2006). While Certificate of Land Ownership Awards were given to the farm workers who became landowners on paper, it seemed that their servant-master relationship with former employers remained unchanged. Bacon (1999) and Quitoriano (2009) have both suggested that direct-wage banana workers in the employ of companies like Dole, Del Monte, and Mampising did not enjoy a betterment of their lives. Some former workers opposed the leaseback and formed themselves into organisations. One of these organisations was the WADECOR Employees and Agrarian Reform Beneficiaries Association, Inc. A growing consensus emerged among land reform advocates that the leaseback scheme was conceptualised as a way to thwart the goals of the land reform programme and allow the former landowner-corporations to reconsolidate control over their landholdings even post-distribution (interview with NGO worker, 1 February 2014, Manila). So discredited was the leaseback arrangement that when Republic Act 9700 or the CARP Extension with Reforms law was passed, leaseback arrangements were prohibited.

The reproduction of asymmetries, despite or within the land reform programme, informed subsequent contractual arrangements entered into by both parties and, as will be later argued, the ways by which they attempt to confront the scourge of Panama disease. This is what appears when we look more closely at the relations between growers and corporations on the ground. 


\section{Post-land reform and current-day iterations of political economic history}

The ways by which contemporary collective memories continue to creep into present-day relations between the smallholder farmer beneficiaries and the banana corporations reflect the asymmetrical nature of contract growing arrangements. On paper, a contract growing agreement between farmers and marketing firms appears to be an agreement on the production and supply of agricultural products. However, Vellema (1999) states that one of its objectives is to "control and coordinate a whole range of agricultural activities" of the farmer. As narrated by the respondents in the case studies, the narrative and patterns of a contract growership arrangement are the same, with few variations: an organised group of agrarian reform beneficiaries enters into a contract with a multinational banana corporation for the exclusive use of their land and labour to produce export bananas.

In Compostela Valley, we conducted FGDs with farmers under contract growership arrangement with SUMIFRU. Respondents of the FGD represented five groups of banana growers: Selecta Farms, Best Liberty Farms, United Banana/Goodwill Farms, Davao Fruits Corporation Agrarian Reform Beneficiaries Cooperative (DFC-ARBCO), and Davao Fruits Corporation Agrarian Reform Beneficiaries Association. Of these five groups, only Selecta Farms and Best Liberty Farms have not been given Certificates of Land Ownership Awards, meaning they still do not own the land that they till. The remaining three groups are composed of agrarian reform beneficiaries. All five groups are banana growers supplying bananas to SUMIFRU, a Mindanao-based corporation that exports Cavendish bananas to China, Japan, Korea, the Middle East, New Zealand, and Russia. SUMIFRU began its operations in 1970, focusing primarily on bananas. Priding itself on the quality and volume of its fruits, it claims to be the number one player in its chosen market (Davao Chamber 2017).

There are two main classes of contracts governing SUMIFRU's relationship with the smallholders. A Farm Management Contract is the legal instrument that SUMIFRU executes with farmers when the land to be used is not yet distributed under the land reform programme. Upon distribution of the land reform titles, the Farm Management Contract is terminated and replaced with an Exclusive Production and Sales Agreement (EPSA).

In a focus group discussion (FGD, 22 August 2013, Davao del Norte), a banana grower who entered into contract growership with SUMIFRU described how the negotiations were undertaken relative to the 2008 EPSA. He was not shown a copy of the contract. When it was time to sign the contract, only the former chairman of the cooperative signed, not all the members. They were only told that the price per 13.5 kilo box of bananas was US\$3, less a processing fee of 0.41 cents, and with production costs and development costs deductible. Before the lands were distributed and they were still under the Farm Management Contract, the price was \$2 per 13.5 kilo box. From 19941997, they incurred debts amounting to 1.4 million pesos, which they were able to pay only when the peso went down against the dollar in 1998. He said their lives did not 
improve as much as he expected - "katamtaman lang (average improvement only)". Another banana farmer from Best Liberty Farms said they too were bound to an identical contract with similar terms, and echoed the sentiment that $\$ 3$ per 13.5 kilos minus production costs leave them with an almost negligible amount.

Such feelings about low prices and the lack of influence to set prices compound other critical issues. The contracts are written in English and are not translated into the local dialect prior to signing. Copies of the contract obtained by the authors were indeed written in the English language. It was only when the contracts were being executed that the full breadth of their implications and effects were understood, and their grossly disadvantageous nature revealed. An overwhelming majority of the respondents of the FGD stated that if it were legally possible to unilaterally rescind the contract, they would have done so.

This asymmetry shows that the land reform programme - desirous as it was of restructuring agrarian relations - had not completely succeeded in reducing the power imbalance between parties, and only provided another framework within which these unequal parties engage.

The 'takeover' clause provides yet another example of historical iniquity shaping modern-day relations. In Davao City, we conducted FGDs with members of Hijo Agrarian Reform Beneficiaries Cooperative (HARBCO) and key informant interviews with HARBCO officers. The corporation has 724 members and is the registered owner of 579.206 hectares of agricultural land in Brgy. Madaum, Tagum City. The said land, consisting largely of banana plantations, formed part of the vast landholdings of Hijo Plantation, Inc. (HPI) which were acquired and redistributed by the government. Since its creation, HARBCO has entered into three major contracts with corporate partners or investors. The first, a Memorandum of Agreement with HPI, was executed in January 1997, shortly after HARBCO was created and almost a year prior to the issuance of the land title under agrarian reform. The Memorandum of Agreement covered a period of two years, from 1 January 1997 to 31 December 2008, and was essentially a contract farming agreement where the cooperative exclusively sold its Cavendish bananas to HPI.

On 28 December 1998, the parties entered into a Banana Sales and Marketing Agreement (BSMA), which would replace the former agreement that was about to expire. The agreement was essentially another contract farming agreement whereby HARBCO agreed to exclusively sell, and HPI agreed to buy, all Cavendish bananas produced by the cooperative in the land. Less than a year after the BSMA was signed, HARBCO was informed by HPI that the latter had assigned all its rights under the contract to Lapanday Foods Corp. From then on, the cooperative transacted with Lapanday and continued to do so until the end of the ten-year contract in December 2008.

According to an officer of HARBCO (FGD, 24 August 2013, Davao City), they were pressured to accede to the agreement, which pegged the price of the bananas at $\$ 2.10$ per box, when their salaries and wages were withheld. Withholding of advances intended for 
the salaries and wages of HARBCO members and employees, said the same worker, was a frequently-used strategy whenever Lapanday sought to pressure HARBCO to accept disadvantageous terms or drop its demands for renegotiation. According to an NGO worker interviewed, this practice is not unique to Lapanday (interview, 2 February 2014, Manila).

A little over a week before this contract expired, however, Lapanday invoked its rights under a takeover clause ${ }^{7}$ in the Agreement, and a third contract - the General Framework on Farm Handling (GFFH) - was executed on 23 December 2008 to govern the takeover. The takeover was initiated by Lapanday, purportedly as a solution to HARBCO's financial situation. According to HARBCO officials, Lapanday demanded from the cooperative the amount of Php114,963,256.55 (around EUR2.3 million), representing the unpaid value of farm inputs supplied by Lapanday to HARBCO from 1999 to 2008. Four years after the third contract was executed, all 579 hectares of HARBCO's banana plantation continued to be under the operational control of Lapanday, with the latter managing all aspects of farm operations, from support services to actual field operations.

The historical pattern of inequity in the formation of current position in the agrarian structure, and the ways by which this iniquity is institutionalised in existing contractual arrangements entered into by the corporation and the cooperatives that are prejudicial to the latter, provide an unfavorable climate for working together to address plant disease.

\section{Who bears the burden for plant disease control?}

The issue of who bears the burden for plant disease control will be approached firstly in terms of the political economy of the contract, which institutionalises inequality in the control over technology and the distribution of costs, and secondly as a discursive construction of blame and responsibility.

\section{The terms of the contract and farmers' assumption of risk}

The farmers who participated in the FGDs feared that if the bananas are eradicated and the soil contaminated, they will lose their only source of livelihood. At the same time, they said that the real problem for Panama disease control lies with the contract farming agreement which made them liable for plant diseases. There was a unanimous agreement in both focus groups that the onslaught of banana diseases created big financial setbacks for the agrarian reform beneficiaries. For instance, to arrest the spread of the Panama disease, they would have to surround the infected banana plant with bamboos and then

\footnotetext{
${ }^{7}$ Art. X (Miscellaneous Provisions) Para. 1 of the BSMA states:

1. Should the SELLER fail to follow the prescribed cultural policies to the extent, in the opinion of the BUYER, that the success of the crop is endangered, the BUYER shall have the right, upon one week's notice in writing to handle the operation of the SELLER's farm. The BUYER shall continue to operate the FARM until such time the loans or other financing agreements guaranteed by the BUYER as well as all advances and moneys due to the BUYER shall have been FULLY LIQUIDATED.
} 
burn the plant to the ground, costing them Php 250 per infected banana plant, not including lost profits and loss of land as the area around the infected

plant should not be replanted and kept in quarantine. The farmers stated that their lack of resources and their increasing debts to the corporation make it difficult for them to address Panama disease in any sustainable way. As further elaborated by a farmerleader, the farmers are bound by contract to pay for disease eradication but have no say as to what materials will be used and which technical provider will be hired. It is the banana company with whom they have a marketing contract that decides what eradication strategy to employ, and they are made to pay for it. This farmer's view seems to be confirmed in the contract itself. Section 7.02 of the Exclusive Purchase and Sale Agreement (EPSA 2008) between SUMIFRU and the farmer-leader's cooperative, DFCARBCA, states, as follows:

The GROWERS agree that the COMPANY shall be the exclusive provider of aerial spray, ground spraying machine or any other method of application for fertilizer, crop protectant, or chemicals against pests and plant diseases, such as Sigatoka control, and the materials, chemicals and other supplies for use thereon which the COMPANY may implement in accordance with the need of the locality. The costs of said equipment, materials, chemicals, supplies and services, and other necessary inputs to the GROWERS in support of production activities, shall be for the account of the GROWERS. (emphasis supplied.)

The contract thus provides the company with the power to control the supply and use of agricultural technologies. The contract does not stipulate how the procurement process for these materials is to be undertaken. Without the company having much interest in keeping the costs down, the growers simply have to accept the service or materials provider endorsed by the company. There is a potential for abuse because the company may set up a subsidiary business to provide the inputs at high prices and charge them to the growers. There is also nothing in the contract to hold the company liable if there is damage to the crops because of substandard eradication materials or if the pesticides are ineffective.

Besides this control over technology and possible profits derived from it, the terms of the contract include an even more drastic form of control. The company may 'take over' the farm, pursuant to the so-called 'takeover clause':

13.01. If the situation so warrants, as when a violation of any provision of this Agreement has been committed, or there is a need to protect the COMPANY's volume commitment to the international market, or when the GROWERS fail, refuse, or are unable to follow the COMPANY'S prescribed practices and/or manage the project to such an extent that the success of the crop production or compliance of the crops with international standards is endangered, or when the condition of the crops or the GROWERS' operations are such that losses are imminent, or other similar situations, without need of court proceedings or further authorization, but with prior notice of 
at least seventy two (72) hours to the GROWERS, the COMPANY may intervene by entering the Land/Farm, and -

a. Take over the management of the operations at the Farm, Land, Project, or portions thereof,

b. Appoint an interim manager or administrator; or

c. Assign said operations and management to a third party

without prejudice to final accounting and liquidation of all accounts payable and reimbursements that may be due to the GROWERS or to the COMPANY.

It is hereby understood that the GROWERS shall maintain ownership of the operations at the Farm and all expenses and costs of production shall be for their account, including the costs of labor. (emphasis supplied)

This means that the company can take over the plantation and the operations for virtually any reason, introduce any technology that they want, whilst all expenses and costs of production will still be borne by the growers.

One might argue that a provision of this sort may actually help in the mitigation of Panama disease TR4 because the company, with its toolbox of mitigation techniques and strategies, can step in and prevent the further spread of the pathogen. But the catch-all conditions for takeover - note the phrase "or other similar situations" make the power of the company to resort to this mechanism a blanket and unilateral one. It is also to the advantage of the company to maintain the takeover status quo because Section 13.04 states that, " $(t)$ he intervention shall continue for a period of not less than ten (10) years or until the COMPANY determines that its volume commitment has been assured, loans or other financing agreements guaranteed by the COMPANY as well as all advances and monies due to the COMPANY shall have been fully liquidated and paid, the situation is rectified, and/or that the GROWERS have ceased committing the violation and have shown irrevocable proof that they will not commit the same and/or any other violation under this Agreement." (EPSA 2008) Because debts are deductible from the income of the farmers, it is to the interest of the companies to interminably maintain the takeover.

During the negotiations between DFC-ARBCA and SUMIFRU, which we were able to observe, it was the takeover clause that the farmers had the biggest problems with. One of the farmer-leaders asked, "How can we even think about diseases of plants, when it feels like they are choking us to death with this takeover clause?" (FGD, 22 August 2013, Davao del Norte) On the one hand, the takeover clause can serve as a check and balance mechanism to ensure that the banana growers comply with protocols set by the multinational companies on Panama disease. On the other hand, it breeds so much resentment among the growers that coordination and cooperation is hampered. According to a farmer in the FGD, those with exclusive growership/exclusive purchase contracts with banana growers have to comply with the strict agricultural practices imposed by the banana company. Those who do not have these contracts are not bound by the rules imposed by the multinationals, thus their production costs are lower and they 
earn more. The farmer candidly shared that he and his peers in growership/exclusive purchase contracts are jealous of their more independent counterparts who make more money. At the same time, he shared the growers' general perception that the spread of Panama disease is likely caused by these 'independent contractors' who are not bound to the strict protocols of the company.

In contrast, for the Lapanday Foods Corp. which entered into a contract with the cooperative HARBCO, the contractual provisions had the effect of granting Lapanday utmost flexibility in the performance of its obligations to HARBCO. Flexible wording (i.e., non-mandatory phraseology) in the provisions on Lapanday's obligations to HARBCO not only softened its obligations but also reduced Lapanday's liability for non-performance. Lapanday's obligations under the contract are often qualified and described to be performed by Lapanday on a "best effort" basis. It is important to analyse this notion of best effort. Under the Banana Sales Marketing Agreement (1998), for example, the provisions which set forth Lapanday's obligations to HARBCO are preceded by a blanket qualifier, as follows:

\section{RIGHTS AND OBLIGATIONS OF THE BUYER}

For and in consideration of the SELLER's undertakings under this AGREEMENT, the BUYER shall, among other things, undertake and perform at a best effort basis the following. (emphasis supplied)

The use of the best effort qualifier is repeated in both the main contract farming agreement and the takeover agreement (GFFH 2008), always in reference to major obligations of Lapanday. It is reiterated in describing Lapanday's obligation to provide emergency materials whenever HARBCO's farm experiences a high degree of pest and disease infestation. ${ }^{8}$ The same best effort qualifier is also employed in the takeover agreement to soften LFC's liability in its takeover of HARBCO's farm operations. ${ }^{9}$

What these two case studies show is air-tight responsibility clauses for farmers on plant disease, and malleable provisions for the banana companies. Tellingly, multinational companies resist state regulation on contractual arrangements with smallholders. In a news article on proposed legislation in the Philippines seeking to regulate agribusiness venture agreements and shield smallholder farmers from risks, the President of PBGEA, which represents banana companies, was quoted as saying "the bill negates the autonomy of contracts by providing mandatory provisions that will deter investors into entering into contracts with ARBS (agrarian reform beneficiaries)" (Fresh Fruit Portal 2015).

Blaming is used to reinterpret Panama disease risks in terms of oppositions in agrarian relationships

\footnotetext{
${ }^{8}$ BSMA Art. V (e) On a best effort basis, the BUYER shall advance to the SELLER pest and disease materials over the normal requirements in the event the SELLER experiences a high degree of pest and disease infestation in the FARM.

${ }^{9}$ GFFH 2008 Para 9. LFC will not post performance bond but will handle farm operations on a best-effort basis.
} 
As a legally-binding instrument, the contract itself is a 'hard' law that sets rules and dictates behaviour among parties. Earlier we showed that enforcing the contracts reproduces inequalities and creates tensions between different actors in the banana sector. However, difference and opposition is not only created through formal arrangements institutionalised through the contract. Difference is also created through a second, more fluid and often implicit cultural layer in which narratives tell us who behaves well or badly. We already described that farmers link the problem of controlling Panama disease to the nature of the contract. In narrating such links, farmers also mention, in a somewhat accusatory style, their differences with the companies. For example: "The corporations can leave Davao and find another location that is not infested with Panama disease. For us, we have nowhere else to go," rued a 41-year-old farmer-leader who is under contract with SUMIFRU (FGD, 22 August 2013, Davao del Norte).

Subtle forms of blaming are also expressed by the larger companies through the PBGEA President who stated that agrarian reform had the effect of cutting up swathes of agricultural land into smaller parcels, and cutting up legal ownership. "Instead of multinationals having control of the farms and being able to fully implement their protocols, now smallholder farmers with less capacity and technical know-how have control over the land. This could be one of the reasons for the rapid spread of Panama disease." (interview, 21 August 2013, Davao City). Large scale here is equated with protocols, hinting at a more rationalized, knowledge-intensive approach, versus the knowledge-poor control options of smallholders. Similarly, a local government official in Davao stated that "Smallholder farmers are used to their old ways and are careless, and these characteristics cause the spread of the disease." (interview, 20 August 2013, Davao City). The smallholder farmers in the FGDs admit to feeling blamed for the disease - "Sabi nila hindi kami maingat (they say we are not careful)" - but at the same time blame the multinational companies because they are not being paid enough and are being made to bear the cost of production. In turn, we heard claims that many multinational companies also cause the problem because they do not disclose the degree of infestation in their farms (e.g., in an interview with a Provincial Agriculturalist, 20 August 2013, Davao City).

These are micro-forms of blaming embedded in otherwise analytical remarks about the spread and technicalities of the disease. But what they do is to differentiate in identifying major causes for spread and lack of control. In fact, from a technical point of view, it may be surprising how a single disease that potentially affects all Cavendish bananas, regardless of the size of the plantation, and which requires a sector-wide response, is reinterpreted by social actors in terms of differences and oppositions. But this is what the social domain does. It reinterprets risks and links these to other risks in different ways. In the Philippine context, the technicalities of the spread and control, through assigning blame, are being related to existing oppositions resulting from the land reform process and the history of agrarian relationships. This rather new risk is approached with older schemata of what is the better form of production (farm size), who has the best capacity to practice agriculture, and who should be supported by the state. 
This also means that blaming is directly connected with assigning responsibility. The role of large companies is often referred to in this respect.

Complementing the trope of the smallholder farmers as the cause of the spread of Panama disease is the trope of the multinational banana companies as 'leaders' of Panama disease protection. According to its president, PBGEA "takes the lead" in disease protection. It has formed its own Technical Committee, composed of scientists in the research and development units of its member corporations, that is a primary forum to discuss crop disease management, including fusarium wilt. The PBGEA President recalled how the mayor of Santo Tomas once wrote asking him for help to combat Panama disease, when the more appropriate thing to do would have been for the mayor to contact the Department of Agriculture (interview, 19 August 2013, Davao City). The Head of Research of Unifrutti Philippines cited the multinational companies' training manual which they provided the Department of Agriculture, because the government simply did not have enough resources to conduct its own research on proper Panama disease protocols. "We considered it our responsibility to do it," said the expat scientist (interview, 20 August 2013, Davao City). The division of labour, therefore, appears to be that the production of content for the Panama disease training manuals is generated by the multinationals, and the government assists in its dissemination to the smallholders. According to PBGEA's president, the government's lack of resources and technical skills impedes its ability to arrest the spread of Panama disease. The Provincial Agriculturist of Davao agrees that the government cannot compete with the technical expertise of the private sector (interview, 20 August 2013, Davao City). ${ }^{10}$

With the companies being seen as the 'saviours' and the government contributing to this perception, there is very little incentive for the companies to improve behaviour, enter into more equitable contracts, or accept more risk where Panama disease is concerned.

\section{Conclusions}

This Chapter has investigated the spread and control of Panama disease in the Philippines using the lens of political ecology. We sought to investigate the extent to which the nature of relationships between the social actors in a contract growership arrangement influence the possibilities and limitations of disease control. We broke down this question further by asking two sub-questions: First, how is the risk of Panama disease

\footnotetext{
10 The following quotes reflect how PBGEA views its responsibility vis-á-vis smallholders. “We gave several millions of pesos to smallholder farmers as donation when Typhoon Pablo devastated the region, even our own companies were hit" (interview with PBGEA's president, 19 August 2013, Davao City), referring to the destructive super-typhoon of 2012 that resulted in agricultural losses in the billions of pesos to Mindanao. He also said that PBGEA consistently gives scholarships to the children of banana farmers. The Head of Research of Unifrutti likewise notes that the multinational companies also had no choice but to help the smallholder farmers. "Considering that the disease is soil-borne and could travel to our farms from some of the smaller farms, it is also in our interest to teach Panama disease prevention strategies to the smallholders."
} 
distributed under a contract growership arrangement? Second, what is the role of blaming in the uneven distribution of risk in a contract growership arrangement?

In navigating those two questions, we examined the agrarian history of these relationships and its effects on contemporary arrangements. An analysis of the growership contracts between the farmers and the corporations reveals evidence to support the contention that smallholder farmers are being made to bear the risk of Panama disease through legally-binding contractual stipulations. Likewise, we also demonstrated how smallholder farmers are being blamed for Panama disease. Such blaming of smallholders creates the hostile discursive environment that reinforces the arrangements created by the contract: employing soft pressure to bolster the hard pressure of the legally-binding agreement. What we then see is a synergetic relationship between the cultural layer, as it were, and the legal infrastructure articulated in the contract, both reinforcing the trope of the small farmers causing the spread and the large companies helping prevent it. Moreover, it feeds into the common dominant descriptions of smallholder farming, e.g., inefficient, romantic, ideal but unsustainable, by inserting 'dangerous' and 'more prone to the spread of the disease', thereby creating even more disincentives to smallholder agriculture. Ultimately, it has the strategic value of allowing inequitable structural arrangements to remain unquestioned and functioning.

Second, while smallholder farmers have been described as causing the spread of Panama disease because of their low awareness and low technical expertise, this research suggests that a deeper alternative formulation might be possible. It looked at the contracts involved in contract growing and theorised that (1) by allowing farmers to assume the risk of the disease when they do not have the resources or wherewithal to pay for adequate plant protection, and (2) by depressing smallholder incomes so much, the spread of Panama disease increases in likelihood. There is room for further study on this, especially through a more thorough investigation of disease control practices on the ground. Furthermore, the current contracts reintroduce the mechanism of direct control over agricultural production (through the takeover clause) by large companies, subsuming smallholder farmers. This mechanism may be triggered by the argument of needed capacity to control plant disease. It creates resentment among smallholders. This may well lead us to reflect that perhaps social relations of production under contractual farming and not smallholder farmers are what put banana farms at risk; contract farming is an institutional arrangement that unevenly distributes risk.

Third, we find that a political ecology of risk, one that incorporates Cultural Theory elements of risk and blame, is a useful tool in looking at how economic arrangements - in this case, contract farming - can bear upon decisions on disease management and control. In turn, these may result in hastening the spread of the pathogen and creating bio-physical patterns that provide an enabling, instead of constraining, environment for Panama disease. While political ecology has always been used as a lens to examine the ways by which practices of corporations and their relationships within local communities impact on resource use and environmental change, an explicit interface with Douglas's Cultural 
Theory contributes a how: by shaping narratives of risk and blame through discursive processes and contractual stipulations, risk is unevenly distributed and blame asymmetrically cast against the party in the weaker economic position, thereby resulting in environmental change and shifts in resource use and access. We posit that this framework of political ecology of risk can be used to examine a wider range of phenomena involving asymmetric relationships within local settings.

Finally, we posit that the dynamics of contractual arrangements and discursive interpretations of risk, blame, and responsibility have implications for the technical feasibility of disease management in the long term. The trope that farmers are the weakest link and the multinational companies are the strongest link allows government to depend on the companies for research and development and rely on their disease management models. This would then privilege corporate-driven solutions that might be agnostic to power relations. Conversations around how agrarian communities are responsible for the spread of Panama disease ignore not just the importance of agrarian reform as a social justice measure for local people, but also the reality that they have for the most part been bearing the cost of Panama disease and making risk decisions that are invisible to the rest of the players.

Indeed, by leaving uninterrogated the structuring arrangements such as contracts that, as this Chapter has tried to demonstrate, contribute to the spread of the disease, and by failing to see how inequitable relationships might impact on the degree to which Panama disease is addressed on the ground, proposed solutions might prove to be mistargeted or irrelevant, or worse, dangerous. There is room for further study on the particularities and extent of these consequences. 
III.

\section{PUBLIC-PRIVATE COLLABORATIONS AMIDST AN EMERGENCY \\ PLANTDISEASE OUTBREAK: THE AUSTRALIAN EXPERIENCE WITH PANAMA \\ DISEASE}

\section{Chapter overview}

The retreat of government from agriculture and agricultural extension (Rivera 1996), reflecting as it does a larger pattern of the withering of the state from economic activity, is a consistent thematic strain in the Western world in the last twenty to thirty years (McKenzie and Lee 1991, Risse 2007). The past decade has seen a steady transitioning from a framework where the state has been the provider of productionoriented agricultural services to a 'user pays' philosophy that emphasises the role of the private sector and the market (Marsh and Pannell 2000, Mullen et al. 2002).

Biosecurity, defined by the Food and Agriculture Organization (FAO 2007) as a "strategic and integrated approach that encompasses the policy and regulatory frameworks (including instruments and activities) for analysing and managing relevant risks to human, animal and plant life and health, and associated risks to the environment", is traditionally considered as belonging squarely in the public sphere as a public good (Waage and Mumford 2008). The trend towards the privatisation of public agricultural services and the adoption of the market-driven approach, however, has extended to biosecurity.

This Chapter aims to analyse the contours of public-private collaborations in agricultural biosecurity services and research and development (R\&D) in the context of an emergency outbreak of plant disease. We situate our research in the Australia model, an agricultural model considered one of the least supported sectors in the world (Botterill and Fisher 2003), and currently facing the threat of its massive Cavendish banana industry being decimated by a virulent and incurable pathogen.

Like in many parts of the world, the retreat of government from Australian agriculture has had implications on R\&D trajectories and extension services. Driven by the 'new public management' paradigm, the central argument is that since Australian primary producers are the sole beneficiaries of technical support from the government, reallocation of resources to other purposes resulting in a wider public benefit will be a more efficient use of these public resources (Cook et al. 2012). Agriculture R\&D is now financed jointly by industry and government through production-based levies collected from individual farmers and channelled into the rural research and development corporations (RRDC), with matching funds from the federal government. The Australian 
biosecurity policy has consistently been framed as a 'shared responsibility'11 model, whereby government and industry are equally responsible for biosecurity risk, are obligated to devote resources towards it, and agree to an eradication and/or management framework in the event of infestation.

The confirmation of Panama disease Tropical Race 4 in a farm in Northern Queensland, and the steps undertaken by Australian officials and industry stakeholders to arrest the spread of the disease, provide an opportunity not only to interrogate Australia's present biosecurity policy and agricultural research and development and extension (RD\&E) model, but also to revisit larger questions on public and private collaborations in agriculture.

As described in previous chapters, commercial production of Gros Michel was eradicated by Tropical Race 1 (TR1) of the disease (Stover 1962), completely devastating farms in Latin America until scientists were able to develop the Cavendish, a cultivar resistant to TR1. Cavendish became the commercial banana of choice, providing livelihood once more to banana plantations, including those in Queensland. After several decades, however, TR4 was discovered and with the discovery, the realisation that Cavendish was no longer resistant to this new strain (Ploetz 2006). Panama disease TR4 has been in the Asia Pacific for decades (Ordoñez and García 2015), and has in fact already been in the Northern Territory of Australia since 1997 (Hennessy et al. 2005). However, $90 \%$ of banana commercial farms are in Northern Queensland - an AUS\$600 million industry that produces 372,000 tonnes of bananas for domestic consumption (Australian Bureau of Statistics 2013). Thus, the confirmation of Panama disease in a Northern Queensland commercial farm created shock waves in the industry.

This Chapter is interested in investigating how the 'user pays' model responds in this kind of crisis scenario. We ask the following research question: To what extent does the 'user pays'/industry-driven model influence Panama disease strategies in research and extension services and biosecurity?

The structure of this Chapter is as follows: we first situate our research in the existing literature on the influences of privatisation on agriculture policy and agricultural extension, and the diminishing role of the state and its consequences on the delivery of public goods, particularly biosecurity. Second, we describe the methods employed for the collection of our data. Third, we present an overview of Australia's agriculture model and overall plant disease management strategy, with emphasis on RD\&E and biosecurity. Fourth, we examine the banana industry in Australia: its structure, the actors, and its RD\&E and biosecurity policies. Fifth, we describe the efforts in Australia following the detection of Panama disease in Northern Queensland in March of 2015, the interactions between and among the different actors, and the actors' perceptions regarding these

11 The phrase 'shared responsibility' first came out in a report entitled Australian Quarantine: A Shared Responsibility by the Australian Quarantine Review Committee. The report was commissioned by the Federal Government as part of a pre-election promise to overhaul the quarantine system. 
interactions. Finally, we tease out insights on the influence of the industry-driven model on Panama disease strategies and reflect on the implications of the same on wider debates on government intervention, public-private collaboration, and the delivery of public goods.

While there are many different actors in the Australian banana industry who shape its biosecurity policy (e.g., universities, particularly the Banana Program of the University of Queensland), the focus of this Chapter is primarily on actors in the government and industry.

\section{Theoretical framework: Problematising agricultural privatisation}

The question of how an industry-driven agricultural framework responds to the threat of a bio-physical incursion such as Panama disease in bananas is at heart rooted in classical debates on the virtues of the free market vis-à-vis government intervention in agriculture. Proponents of the former suggest greater economic efficiency may be gained from greater reliance on the logic of a functional market; on the other hand, proponents of the latter argue that market failures demand regulatory responses which only the state can provide. Experiences from an evolving and increasingly complex world demonstrate that the dichotomy between market and state is very rarely clear and unyielding (DattaChaudhuri 1990), and institutional arrangements are increasingly being created on the basis of a 'collaboration' between the private sector and public sector. While this collaboration has many permutations, a key feature is the decrease in government spending and the emergence of industry and the private sector as new sources of financing - also known as the user pays model. This has been the Australian experience (Marsh and Pannell 2000). Another key feature is the limited intervention of the government only in instances of 'market failure', where the target of the intervention is imbued with public good characteristics (Rivera and Cary 1997).

Policy-makers in the developed world argue that as farming has increasingly become more specialised and technical, publicly-funded agriculture extension can no longer be justified. Using data from India, Ferroni and Zhou (2012) argue that rising appetites of farmers for technology as a result of rising rural wages create growth opportunities for the private sector, and government needs to readjust in order to fill in the gaps in extension services left by industry. Le Gouis (1991) enumerated three major policies that he observed were adopted in privatisation of extension schemes: (1) public financing by the taxpayer only for the kinds of services that are of direct concern to the general public, (2) direct charging for some individual services with direct return (in the form of improved income), and (3) mixed funding shared between public and private contributions. The Australian model is closest to the third, with the Australian government providing nearly dollar for dollar matching of levy-generated industry expenditure on R\&D, up to a limit of 0.5 percent of each industry's Gross Value of Production (GVP). 
While privatisation in agriculture has been lauded by some (see for example, Prinsley et al. 1994) who argue that industry's wider influence in determining policy priorities results in more efficient, transparent, and accountable service delivery, other researchers suggest that this transition to a market-oriented agriculture paradigm has resulted in failures or weaknesses (see for example, Cook et al. 2012 and Hunt et al. 2012. Critics also point out that the user pays model privileges precisely those who can afford to pay, a tendency that was documented by Walker (1995) in New Zealand and Labarthe and Laurent (2013) in the European Union. Marsh and Pannell (2000) also suggest that an industry-focused extension system leads to a decline in the government's ability to influence outcomes that commercial enterprises are agnostic to - for example, environmental protection and social cohesion. Data from New Zealand suggest that privatisation reforms in horticulture in the 1980s led to undesirable biosecurity outcomes, with biosecurity surveillance capacity compromised (Warrington et al. 2004). Its neighbouring country Australia, however, continued its transition to a shared responsibility framework, putting forward a public-private collaborative model for biosecurity issues.

Our theoretical contribution is to look at the public sector and private sector dynamics in the context of an emergency plant disease situation where some public good characteristics are present, but where an a priori agreement of a shared responsibility model has been set in place. We look at what kinds of conclusions can be drawn by analysing how government and industry interact and collaborate in addressing Panama disease, and identify the tensions and contradictions in such a model that may contribute to current thinking on public-private engagement.

\section{Methods}

This Chapter is based on research carried out primarily in Brisbane, Australia in July 2015, as well as a review and analysis of documents obtained from government instrumentalities and research organisations.

Interviews were conducted with key representatives of the government (Biosecurity Australia, Department of Agriculture), university researchers (University of Queensland and Queensland University of Technology/QUT), representatives of the Australia Banana Growers Council, an independent contractor and consultant on plant protection, and two farmers in Northern Queensland. Interviewees were selected for their expertise, and appointments were made with them primarily through the assistance of the head of the Banana Plant Protection Program. Individual growers were also interviewed. Transcripts from the interviews were analysed and triangulated with documents procured in the course of the fieldwork. Most interviews were conducted faceto-face; however three interviews were conducted over the phone due to distance and logistical constraints. A storyline was then developed based on details provided by interviewees that were corroborated either by document or another interviewee. A second aspect of the interview was asking for perceptions and opinions on specific issues. For example, interviewees were asked to describe interactions with the other 
stakeholders or groups, or to render their assessment of the future of the Australian banana industry in the face of Panama disease. The data and documents collected from the interviews were then arranged into thematic clusters for analysis.

\section{Overview of Australia's agriculture policy and plant disease protection framework: The march to privatisation}

\section{Australian agriculture policy: A brief historical overview}

In 1986, the Australian government shepherded nineteen other agricultural exporting nations into an interest bloc to force agriculture onto the agenda of the Uruguay Round. The bloc was named Cairns Group, after the Australian city where the group first met, and its aims were clear: to present a unified objection to the European Union's Common Agriculture Policy and other protectionist policies in agriculture (Tyers 1993) and to liberalise agricultural trade. Australia's leadership in this bloc underscores the dramatic transition in its national agricultural policy from interventionist until the early 1970s to ardently supportive of the free market in the 1980s (Botterill and Fisher 2003).

Botterrill identifies four main triggers and turning points for the policy shift in Australian agriculture. The first was the election of the Labor Party in 1972, and the subsequent release of the Green Paper which supported market-driven resource allocation. The second was the formation in 1979 of the National Farmers' Federation, which became a unifying voice of agricultural producers and which supported a free market philosophy. The third was the Balderstone Report, commissioned by the Minister for Primary Industry, which sought to identify the key policy issues in the agriculture sector and which took into account emerging global trends. Citing oil price shocks of the 1970 s and the laggard pace of the farm sector, the Balderstone report proposed greater liberalisation and privatisation to achieve economic efficiency. The fourth was the release of the Economic and Rural Policy Statement in 1986 by the Commonwealth of Australia, which explicitly supported deregulation of agricultural industries and shifts in government spending, and called on farmers to have a more business approach in their cultivation. Thus, the leadership position taken by Australia of the Cairns Group during the Uruguay negotiations was reflective of a neoliberal policy position that was as firmly entrenched as it was recent.

\section{The R\&D framework: Rural Development Corporations and the levy system}

These policy changes, particularly the shifts in government financing, had major impacts on RD\&E and facilitated the creation of the Rural Development Corporations (RDC). ${ }^{12}$ The RDCs are a partnership of the government and industry to finance research

\footnotetext{
12There are currently fifteen RDCs catering to a wide range of industries in agriculture, fisheries, and forestry. Six of these industries have been denominated as 'statutory RDCs' and nine have been denominated as 'industry owned companies'. The difference between these two classes is that only industry-owned companies are allowed to do marketing activities. Moreover, statutory RDCs are governed by the Primary Industries Research and Development Act 1989, while industry-owned companies adhere to industry-specific legislation. Both classes of RDCs are prohibited from engaging in agro-political activities
} 
and development of Australia's rural-based industries. According to the Department of Agriculture website, the government-industry partnership model that is now the backbone of the RDC provides more than AUS $\$ 470$ million in annual R\&D expenditure. Of this amount, around AUS\$247 million is from industry and AUS\$218 is from government. ${ }^{13}$ The industry share comes primarily from levies collected from members of industry (e.g., individual growers), based on a percentage of production.

The fund collection roughly follows this basic principle: the government collects compulsory levies from individual members of industry based on production (for example, based on a certain measurement unit, like cents per carton) through the Levies Revenue Service. These levies are then turned over to the relevant RDC, minus the levy collection cost. Each RDC, guided by its own R\&D priorities and investment needs which were drawn up after consultation with industry bodies, then allocates funds to specific $\mathrm{R} \& \mathrm{D}$ projects. If the RDC is an industry-owned company, it can also allocate funds to marketing activities; however, the government only matches the funds of research and development projects. These R\&D projects are typically bidded out to various service providers, for example, universities. While criticism plagued and continues to plague the RDC framework, chiefly on the point that government spending is too high at AUS\$83 for every AUS $\$ 100$ spent by industry, the government-industry financing model still remains the backbone of the research and development companies.

\section{Plant biosecurity}

The framework priorities of the national biosecurity system of Australia are as follows: (1) to prevent exotic pests from entering and establishing in Australia, (2) to manage the pests that are already established in Australia, (3) to understand and quantify the impacts of pests, and (4) to demonstrate the absence of pests (Nelson et al. 2014).

Up until the 1990s, biosecurity in Australia was seen as a government public good. However, in 1997, efforts to revisit and overhaul the country's biosecurity system led to the creation of the Nairn Committee Report, which focused primarily on the quarantine framework. A cornerstone of the report was the need to transition to a shared responsibility model in light of the pressures from world trade and international obligations, and to adopt risk-based approaches while sharing the cost of risk along the production chain through public-private partnerships. This led to the creation of Plant Health Australia in 2000, the peak industry body for biosecurity. It is funded by the federal and state governments, together with industry, to develop industry-specific biosecurity plans, lead surveillance and monitoring activities, and initiate emergency plans and management when necessary.

\footnotetext{
such as lobbying and advocacy. While more independent than statutory RDCs, industry-owned companies are made accountable through a Statutory Funding Agreement (SFA) signed with the Commonwealth government, in which they commit to ensure that the funds collected are used in a manner consistent with the needs of the industry and the principles and the policies of the government.

13 Information on the website of the Department of Agriculture, Fisheries and Forestry, quoting 2009 figures.
} 
A key point of collaboration for plant biosecurity is in the area of co-financing for emergency response. Peak industry bodies and the state and federal governments are signatories to the Emergency Plant Pest Response Deed (EPPRD), which requires all signatories to contribute to funding in the event that a response plan is approved against a pest incursion. Ratified in 2005 after three years of negotiation, the Deed classifies a disease based on the public and private effects of eradication and uses this standard to determine the percentage of costs borne by government and borne by industry. ${ }^{14}$ The emergency management framework is laid out under a document called Australia Emergency Plant Pest Response Plan or Plant Plan ${ }^{15}$, which is based on the terms of the EPPRD. Proceeds from the co-financing arrangement primarily go to reimbursement of growers for crop destruction in infested farms, on the principle that "no one should be better or worse off as a result of reporting an incident" (Plant Plan 2007).

\section{The Australian banana sector: When government and industry collaborate}

Banana is an important part of the Australian diet and an important commercial commodity in the country. Thus, the banana industry in Australia is a big one. Cavendish bananas are currently grown in 14,000 hectares, primarily in the northern part of Queensland but also south in New South Wales and west in Western Australia. Banana plantations are also located in the Northern Territory, but production there declined as a result of the emergency plant protection response to banana freckle disease (Plant Health Australia 2009). Australia does not import fresh bananas, and the banana industry primarily services the domestic market.

According to figures of the Queensland Department of Agriculture, Fisheries and Forestry (QDAFF), there were a total of 584 banana growers across the country, $51 \%$ of which were in Far North Queensland. This region produced $90 \%$ of the national volume, where the average farm size was 40 hectares per enterprise. In contrast, in New South Wales and Western Australia, the average farm size was 5.4 hectares (QDAFF 2014).

In this section, we look at the Australian banana sector; we explain its structure and map out its important actors. Understanding the contours of the industry and the relationships among actors provides a context to understanding the response to Panama disease when it was confirmed.

\section{Horticulture Innovation Australia}

The RDC under which the banana industry falls is Horticulture Innovation Australia (HIA), an industry-owned company governed by the Horticulture Marketing

\footnotetext{
${ }^{14} \mathrm{~A}$ category 1 pest, whose eradication would have very high public benefits (for example, the pest causes significant ecological damage), attracts $100 \%$ government funding; on the other end of the spectrum, a category 4 pest where eradication would have mostly private benefits, attracts only $20 \%$ government funding, with $80 \%$ shouldered by industry.

${ }^{15} \mathrm{~A}$ copy of the Plant Plan is available in http://www.planthealthaustralia.com.au/biosecurity/incursionmanagement/plantplan/ Last accessed 21 September 2016.
} 
Research and Development Services Act 2000. The horticulture industry in Australia is worth AUS $\$ 9$ billion and, according to its website, HIA invests more than AUS\$100 million yearly in $R \& D$ and marketing activities.

The levy collected from banana growers amounts to 1.7 cents per kilogram of bananas (equivalent to 22 cents per 13 kilogram carton). Based on the Levy Industry Financial Statement of the banana industry, for the year 2013 to 2014, the banana industry received a net levy income ${ }^{16}$ of AUS\$6,241,797. According to figures for 20122013 procured by the Consultation Paper, based on financial accounts submitted, the banana industry had the fourth highest expenditure for $R \& D$, following vegetables, apple and pear, and avocado.

The growers interviewed generally support the levy-funded RD\&E framework. According to one of the growers who used to sit on the Industry Advisory Committee, "The levy system keeps the research focused, and makes sure it is from the ground up" (interview, 18 July 2015, Brisbane). Another grower, however, the owner of a banana company that funds the research of QUT on banana genetic modification, raised an issue with levy-funded research, saying that since it is geared to the interests of the growers, it has a tendency to be too focused on 'immediate needs', and there is no incentive to finance explorative research. "The industry is not daring enough," said the grower (interview, 19 July 2015, Brisbane). The Principal Plant Scientist of Biosecurity Queensland also flagged some contradictions between the research outcomes of the industry-funded levy system and the biosecurity priorities of Biosecurity Queensland. According to him there is some disconnect between the agency's biosecurity needs and what researchers submitting projects for funding to HIA think it needs. "So they get funding to do a biosecurity project, but with not a lot of engagement with us" (interview, Principal Plant Scientist, BQ, 21 July 2015, Brisbane).

\section{The peak industry body}

The Australian Banana Growers' Council (ABGC) is the peak industry body representing commercial banana growers in the country. It was formed in 1962 with a full-time national secretariat based in Brisbane, field personnel in north and south-east Queensland, and contractor field staff in northern New South Wales. It has a Board composed of eight directors: five from Queensland, two from New South Wales, and one from Western Australia/Northern Territory. ABGC receives levies from its RDC, Horticulture Innovation Australia, which sustains the ABGC's research function. ABGC also collects voluntary membership fees from its members, amounting to 3 cents per $13 \mathrm{~kg}$ carton of bananas sold. Proceeds from the membership fee go to agri-political functions, which includes lobbying and advocacy to promote the interests of banana growers.

ABGC is signatory to the Emergency Plant Pest Response Deed and, aside from cofinancing biosecurity initiatives, is responsible for "biosecurity planning and

\footnotetext{
${ }^{16}$ Net levy income = levy income from growers minus levy collection costs
} 
implementation at the national and farm levels, liaising with federal and state governments on trade issues, participating in national committees and response efforts in an emergency" (PHA, 2014).

ABGC claims a solid relationship with the farmers, built through council meetings and an attitude of candour and transparency. "We have a long-standing relationship with the growers, and we perhaps have more trust and connection with them than the government has" (interview, BGC manager, 19 July 2015, Brisbane). This appears to be confirmed by the growers, who all say that they believe ABGC is sincere in representing their interests and is doing the best that it can amidst the Panama disease situation.

\section{Biosecurity Queensland}

With respect to biosecurity, the main government agency is Biosecurity Queensland (BQ), which is under the auspices of the Department of Agriculture, Fisheries and Forestry (DAFF), and brings together the resources and functions of the former Queensland Primary Industries and Fisheries, Department of Natural Resources and Water, and the Environmental Protection Agency.

The work of BQ cuts across a large spectrum of biosecurity activities: prevention, preparedness, diagnostics, surveillance, and response. It also includes smaller incident responses and large-scale emergency responses; those that cannot be eradicated go into ongoing management (interview, Principal Plant Scientist in Plant Biosecurity, BQ, 21 July 2015, Brisbane). BQ works within the structure of Biosecurity Australia and cooperates with the Biosecurity agencies of other states, but enjoys a fair degree of autonomy. The Principal Plant Scientist in Plant Biosecurity of BQ explained it thus:

We cooperate with other states. But if Queensland wanted to do something and the other states do not support it, we can decide on our own. Cooperation however builds confidence: we give them confidence that we can manage the disease. We need their confidence because these states are also our trading partners. (ibid., interview).

$\mathrm{BQ}$, however, does not enjoy the full trust of banana growers. A banana grower interviewed said that the government was ineffective in handling biosecurity services (interview, grower, 19 July 2015, Brisbane). Many of the growers interviewed attributed the phenomenal growth of the banana industry to industry efforts.

Indeed, before the outbreak, the banana sector in Australia was thriving. The peak industry body was powerful, levy-funded research was driven by the needs of the industry, growers had their complaints about government's bureaucratic processes, and there was no reason to question both the privatised model of Australian RD\&E or the shared responsibility model of Australian biosecurity. If anything, the confidence enjoyed by the Australian Banana Growers Council, along with perceptions of government inefficiency, seemed to confirm the wisdom of privatisation. 


\section{Outbreak of Panama disease}

The infestation of Tropical Race 4 on a farm in Tully was first discovered during a routine twice yearly inspection by a liaison officer of properties in North Queensland to check out the Sigatoka levels in the banana plantations and ensure that growers were keeping below the $5 \%$ leaf spot level. The liaison officer was an ABGC employee paid through levy funds. When alerted by a grower to an abnormality in the leaves, the liaison officer obtained some samples and turned these over to BQ, which then did diagnostics primarily through VCG testing in its own laboratory and molecular diagnostic tests in partnership with the University of Queensland. A confirmatory diagnosis was made with a laboratory in the Northern Territory. The confirmation was made official on the $4^{\text {th }}$ of March 2015, at which date BQ put a quarantine order on the property, as well as another property related to the infested one.

According to the Principal Pathologist who made the confirmation, before TR4 was confirmed, the laboratory operation had only three personnel who were also in charge of other plant diagnostics. As a result of the positive confirmation, the DAFF decided to scale up laboratory operations: they were allowed to open six new positions in their department, and were given new laboratory equipment (interview, Principal Pathologist, 24 July 2015, Brisbane). The objective was to contain all diagnostic tests in one laboratory, thus the laboratory had to be equipped for 'surge capacity'.

Events unfolded quickly after the official confirmation, as it was the first confirmation of the disease in a major banana-producing region in Australia. BQ set up three physical centres: the state coordination centre which coordinates activities across the state and national levels, the local control centre which plans and conducts operational activities, and the command post in Tully, to manage specific field level activities. A response strategy was soon developed, with the following elements: (1) disease control and containment, (2) surveillance to delimit the extent of the disease, (3) prevention of further disease spread from known infested sites, (4) education and awareness, (5) on-farm biosecurity, (6) research and development, and (7) building capacity and capability (QDAFF 2015). The federal and state governments were also called upon to make cash injections. ${ }^{17}$

ABGC immediately called for growers meetings. A voluntary levy was immediately proposed, the aim of which was to reimburse the grower family whose farm was infested, as they were asked to suspend operations and their farm put under quarantine. According to the R\&D manager of ABGC, the objective of the levy was to 'bridge the gap' because no funding for reimbursement could be obtained from the Emergency Plant Pest Response Deed, which authorised this only if the disease is technically or economically feasible to

\footnotetext{
${ }^{17}$ As of this writing, the federal government has injected AUS $\$ 230,000$ to the 'Stronger Biosecurity and Quarantine Initiative' to fund diagnostic equipment and augment manpower. An extra $\$ 330,000$ has been pledged. The Queensland government has committed $\$ 130,000$ for the Tully Support Centre. ABGC is lobbying for more emergency cash injections.
} 
eradicate. This is because the Deed itself classifies pests according to the public or private benefit of eradication. Currently, reimbursements to the affected grower in Tully are derived from the voluntary levy collected by ABGC, and funds from the state and federal governments.

In interviews, the growers raised complaints about the pace with which government, through $\mathrm{BQ}$, has responded to the situation. One of the interviewees, a second-generation banana grower, said "Biosecurity Queensland seems to be held down by red tape." Another banana grower said "BQ is not in touch with the reality of banana growers, they are government employees who won't lose their salary." An independent consultant who provides scientific advisory services to the growers had even stronger words: "BQ is a disgrace. DAFF is a disgrace." The scientist from the University of Queensland said the problem was one of "effective leadership to do things in a costeffective and rapid manner", and BQ was always hiding behind regulatory issues. In more colourful language, the independent consultant said that BQ was not willing to "bite the bullet" and was "too legalistic".

All respondents who shared these sentiments about BQ cite the issue of the fence as an example of government's 'ineptitude'. After confirmation of the infestation in the farm in Tully, an action point was the erection of a fence around the infested property in order to prevent the movement of animals that could hasten the spread of the organism on the soil. Growers said it took more than two months for the fence to be erected. BQ does not dispute this, but enumerated many reasons for the delay, including difficulties in hiring a contractor who was willing to go to the infested area, weather disturbances, the need to resurvey the property in order to ensure that the demarcation was properly identified, and potential conflicts with environmentalist groups.

An insight made by ABGC is that in an emergency pest situation, industry wants government to be more pro-active and desires more - and not less - regulation. This opinion appears to be shared by the growers, as gleaned from interviews with them. "We want more regulation to make sure that the disease is contained" (interview, grower, 19 July 2015, Brisbane). Another said, "Growers are generally responsible, but the risk of Panama disease spreading is just too great. One irresponsible grower can ruin it for all of us" (interview, grower, 19 July 2015, Brisbane). When asked whether they would cooperate if BQ issued stricter protocols, they all answered in the affirmative. According to $\mathrm{BQ}$, however, government has no intention of stepping back. "My understanding is that government has no intent of stepping back because industry does not have the regulatory tools that are critical to maintaining quarantine on properties."

In the absence of enforcement powers, ABGC has been providing workshops for banana growers on on-farm biosecurity measures, and helps in information dissemination through the Farm Biosecurity Manual for the Banana Industry and the risk assessment tool. Extension officers hired by ABGC through funds made available by HIA 
are also assisting DAFF and BQ workers in the command centre close to the infested farm in Tully.

A significant observation made during the interviews is the importance being given by industry and government in their relationship with each other. In many instances, there was no legal obligation to collaborate or institutional linkage to compel a dialogue, but the different actors still sought each other. It has also been observed that ABGC's legitimacy is sustained by the fact that it has a regular feedback mechanism with the growers, which by and large has resulted in a degree of trust between the peak industry body and its constituents. In contrast, Biosecurity Queensland does not have direct lines with the growers.

While BQ does not have much direct contact with growers except for encounters at various meetings, it has a close relationship with their peak industry body, ABGC. BQ and ABGC both categorise their relationship as healthy and constructive, particularly for emergency response issues. The BQ official said, "It is taken as a given that we consult ABGC, even if there is no institutional requirement." She further said, "Throughout the response, they have been well-engaged. They have a good understanding of what our role is, why and how they do things" (interview, BQ official, 19 July 2015, Brisbane). The R\&D manager, on the other hand, said, "As best we can, we work with Biosecurity Queensland. Good relationship, sharing information. Sometimes, we agree to disagree" (interview, ABGC manager, 19 July 2015, Brisbane). Even the scientific experts under DAFF not directly involved in biosecurity and emergency management suggest that work relations with industry are smooth. When asked about the influence of industry - through BG - on government biosecurity, the Principal Plant Scientist of BQ said that the ABGC has direct influence over BQ: "We don't do this for ourselves, we do this for industry."

Currently, there is only one confirmed infested farm in Northern Queensland, but the gravity of the disease and the seriousness of the threat appear to be appreciated by all sectors. Projections on the future of the industry as a result of the disease, however, appear to be more varied. Industry and the growers seem more optimistic about the future of the industry and the country's capacity to protect itself against a full-blown outbreak. Some of the positive responses from the growers and from industry are: "As long as there are regulations and they are enforced, it will not spread further"; "Through good management and the use of suppressive systems on the farms, we can stay in good shape"; "In Australia, we still have a lot of land to move to"; and "We have large resources to fund the diagnostics and response". On the other hand, Biosecurity Queensland, through the Principal Plant Scientist, suggests a bleaker perspective. "Given the nature of the banana industry, there is a lot of movement. From an epidemiological perspective, it is unlikely that it is contained in one farm, and also because Tully is one of the wettest places in Australia so rainwater can cause the spread."

While Panama disease management in Australia remains an evolving narrative, with many turnings in the months and years to come, some themes emerge. The first is 
that while Australia's plant disease management strategy clearly shows a collaborative model among state, industry, and university, there are remaining tensions and disharmonies that result in gaps in service delivery and constant revision in policy. The second is that the levy-driven R\&D system, while largely working, still finds itself navigating tensions between responding to the direct and immediate needs of the industry ('user pays' therefore 'user decides') and supporting more long-term and explorative research trajectories. The third is there appears to be a greater trust in industry than in government, particularly in rapid emergency response - an assessment that appears to be based on past experiences. However, and this is the fourth point, while there is more trust in industry apparatuses, both the growers and the peak industry body want more, and not less, government regulation, and appear to be clear on the central role of the state in attaining biosecurity objectives.

\section{Conclusion and reflections}

Using its experience with Panama disease, we find that the industry-driven model in Australia does influence crop disease strategies in research and extension and in biosecurity strategy, but in largely different ways. In research and development, influence is more frontal as the levy system of $R \& D$ financing provides a mechanism by which research priorities are guided by industry and research outcomes accountable to the same. The data we gathered show support among farmers for the levy system of funding research, largely because of a sense of ownership generated by it. In the same vein, we saw how the current levy-driven research system remains imperfect, and revisions are being made on the basis of the experience of peak industry bodies becoming too influential and inviting criticisms of conflicts of interest. Further, there have also been questions raised on the capacity of the user-driven model to address long-term exploratory research that may have no immediate benefit to the banana grower paying for the research, but are necessary for future outlooks of the industry.

This supports the idea of Toleubayev et al. (2007) and Córdoba and Jansen (2014) that explorative crop protection research may have public good characteristics, and government funding for broader agricultural priorities may be necessary to accompany levy-funded industry specific research, which remains equally essential and important. Interestingly, however, the explorative crop research in this case is biotechnology - a proposition that may compel us to revisit contentious issues on biotechnology as public good.

In biosecurity response, however, the role of the industry is more tangential, and government has a more central role. While industry is involved in every step of the biosecurity process, the inherent nature of biosecurity calls for the rule-making and enforcement powers of the state, which are not transferrable to industry. In reality, the notion of 'shared responsibility' as operationalised during an agricultural biosecurity is not a genuine 'privatisation' of biosecurity, nor can biosecurity policy be considered 'industry-driven' the way RD\&E policy might be. While there is perhaps cooperation and collaboration on biosecurity extension services, regulatory mechanisms have largely 
remained within the ambit and sphere of Biosecurity Queensland, and industry's contribution has largely been to leverage its influence in order to pressure government to work faster and more efficiently. Government response has been criticised by growers as slow, bureaucratic, and unresponsive. But the fact that better government intervention as opposed to no government intervention - is sought may be seen as indicative of a common understanding among banana growers and the banana industry at large that biosecurity remains primarily a public function.

We argue that the tension between the Australian government's clear policy bias towards the 'user pays', market-oriented approach, illumined by the ideological principles of the 'new public management' paradigm vis-à-vis the public good characteristics of biosecurity, must be played out, analysed, and ultimately resolved within the context of a rapidly-evolving epidemiological landscape.

Amidst this complex landscape, what should be the role of the government, given the tensions between the entrepreneurial interests of industry and the government's desire to cut spending where it can while fulfilling its mandate? Based on the Australian model, what are the conditions by which the goals of biosecurity and plant protection can be served in the context of public-private collaborations?

First, given that the production-based levy gives farmers a sense of ownership over the agricultural RD\&E emanating from the industry, this system works best when there is no great differentiation among producers, and the industry is propelled by a more or less homogeneous profile of producers with similar interests. A public-private collaboration between two distinct groups of participants is easier to navigate than in a context like the Philippines with smallholder farmers and large multinational corporations (see for example, De los Reyes and Pelupessy 2009), with the latter leveraging its levy contributions.

Second, the representative body of industry (in the case of Australia, the peak industry body) must enjoy trust and political capital from the producers it represents, so that in the event of an emergency quick decisions can be made without dividing the base. In this case, the producers' trust in the Australian Banana Growers' Council made it possible for the industry body to collect an additional voluntary levy to reimburse the owners of the infested farm in Tully. ABGC also was able to credibly liaise between the government and the growers to transmit information on disease management strategies.

Third, the relative success of the collaboration in Australia between the private sector and the government owes largely to the fact that government was both willing and able to make emergency cash injections as well as devote government resources to address the outbreak. This wherewithal and largesse might not be available in other countries confronting the disease. We note that Australia is the only developed country so far confirmed to have the disease. 
The storyline in Australia, however, continues to unfold. Stakeholders in Australia are divided when asked about long-term projections on the disease. It should provoke insight that while the banana industry maintains an optimistic outlook on the fate of the Cavendish banana amid the incursion of Panama disease, public scientists offer a more bleak prognosis. At an age of heightened biosecurity risks owing to globalisation and rapid transboundary movement of goods, peoples, and services, a pathogen invasion should be seen less as an exceptional emergency situation where dormant government resources are to be rallied and activated, but as something that can be anticipated and prepared for with long-term strategic tools. What this portends for shifts in perspectives and attitudes on the role of government in agriculture extension, as well as on biosecurity measures as public goods, remains to be seen. 
IV.

\section{GENETICALLY MODIFIED BANANAS AGAINST PANAMA DISEASE: A SILVER BULLET IN A DIFFERENTIATED WORLD?}

\section{Chapter overview}

The restrictions on research and development have been framed as a problem resulting from the "lack of a proper and functional bio-safety system" (Remy et al. 2013) - understood in the main as the absence of a globally-coherent and harmonised set of rules and regulations to provide the necessary enabling environment for biotechnology. The confirmation of new fusarium wilt infestations, a virulent soil-borne disease threatening the commercial production of Cavendish bananas in major banana-producing areas of the world, reopens conversations on GM banana and the regulatory gaps that confront it. Scientists who support biotechnology believe that a harmonised, enabling, and functional regulatory framework will spur the development of biotechnology to its maximum potential. As one claimed, "We need to make rules, we need to make sure these rules are science-based, and then we get everyone to follow the rules" (interview, expert scientist of the University of California Berkeley, 4 November 2012, Berkeley, California).

That statement frames the problem of biotechnology regulation as primarily one involving divergent, incoherent, disorganised, and unscientific rules. A harmonised legal infrastructure is therefore viewed as the solution, where the 'rules of the game' are predetermined and a single set of science-based standards applies to all participants. It echoes global efforts towards harmonised regulatory standards that are often mobilised around and justified by the notion of a 'universal science' valid across jurisdictions and context, and insulated from political vagaries. The central logic underpinning neoliberal aspirations for a global regulatory framework for bio-safety and biotechnology, where considerations of health and environment are balanced with free trade imperatives, is that science is a neutral risk arbiter with neither agenda nor history. As such, the argument goes, mobilising consensus is justified and member-states are required to harmonise their legislation to conform with the framework.

Critics, however, point out the contradictions and tensions within this model, chiefly that scientific input is not devoid of political interests (Sarewitz 2000), that science can also be a product of framing, where dominant values are privileged (Jasanoff 1998), and that regulatory harmonisation that does not take into account political and economic process on the ground will fail (Zwanenberg et al. 2011). They assail proponents of the model for being remiss in ensuring that these 'neutral' and 'scientifically-driven' harmonised standards remain legitimate across variegated contexts (Gupta 2004) and rooted in local realities (Jansen and Roquas 2008). 
This Chapter analyses the current global regulatory infrastructure for geneticallymodified organisms (GMOs). We analyse this in the context of the proposal for GM bananas as a response to a recent epidemic of fusarium wilt of banana (fusarium oxysporum f.sp. cubense), caused by the so-called Tropical Race 4 (TR4) of the fungus. It seeks to determine whether or not harmonisation at the global level has translated into legitimacy in the local contexts, and investigates the extent to which science-based standards in global regulations are reproduced in domestic legislative frameworks. We examine the divergence and differentiation between global regulatory standards and domestic legislative outcomes by employing some ideas of Mary Douglas's Cultural Theory of Risk, which uses cultural constructions to explain competing interpretations of environmental and technological risks. We consider that risk decisions are influenced by institutional arrangements, belief systems, identities, and interests.

The outbreak of TR4 creates new entry points for discussions on genetic modification of the fruit. It also provides a backdrop for our analysis of the ways by which GMO risk is framed and understood within the legal frameworks of selected countries that have tested positive for Panama disease. Law, it is often said, mirrors the priorities and interests of the society to which it belongs (see for example, Tamanaha 2001). By connecting it to a study on risk perception, we hope to derive some reflections on the ways a society perceives risks, what it considers a threat, which solutions it considers viable, whose opinions it values, and how it orders what it needs to protect first. From these analyses, some contributions might be made both to risk theory and projections for GM bananas.

This Chapter has two overarching research questions: First, what efforts have been undertaken within the global governance regime on bio-safety in harmonising domestic legislation, and to what end? Second, how do countries with Panama disease construe biosafety risk, and how are these constructions articulated and reproduced within their biosafety legislation? From these two questions, we reflect on the possible implications on proposals to introduce fusarium-resistant modified bananas.

The structure of the Chapter is as follows: we begin by providing a short overview of the progress made in GM bananas and a description of the two broad groups in the scientific community who have taken on the issue of GM bananas. We then present our theoretical framework and describe the state of the art. Next, we describe the bio-safety global governance infrastructure and its harmonising features, and argue that the insistence towards harmonised bio-safety norms is linked to the overarching agenda of framing science as an objective and irrefutable hegemonic anchor. Proceeding from this, we then show that this framing is contested, and we surface tensions and contradictions between this international regulatory framework and domestic legislation demonstrating the subversions that result when legal harmonisation on the global level does not attain legitimacy on the national level. Finally, we reflect on these tensions and contradictions, and what these might portend for the future of GM bananas. 


\section{Panama disease and GM bananas}

Amidst the onslaught of Panama disease, conversations on the importance of developing resistant bananas often turn toward genetic modification as a possible solution (Ploetz 2015). Field findings that improvements in export-quality Cavendish bananas cannot be introduced using conventional breeding technologies provide traction to this inclination (Aguilar Moran 2013). For many scientists, genetic modification is the only way to save the Cavendish from disappearance as a commercial crop (Koeppel 2005). An emerging but increasingly pervasive narrative paints the GM banana as a proverbial 'silver bullet' that provides not just disease resistance, but also addresses a host of other problems such as Vitamin A deficiency and food insecurity. These narratives echo earlier 'biotechnology for the poor' narratives that look to biotechnology as "feeding a hungry world" (Scoones 2002). Critics, however, charge these narratives do not engage with alternative perspectives or provide democratic spaces for debate (Jansen and Gupta 2009), and only serve to provide purpose and direction to a technological process that is marked by "profound uncertainty" (Glover 2010).

Most bananas and plantains are clones, propagate asexually, and thereby render cross-hybridisation difficult (Morpurgo et al. 1997). Classical breeding methods, e.g., for purposes of breeding for disease resistance, are difficult because of the high sterility as well as the lengthy generation times of most edible cultivars (Rout et al. 2000). Research on the introduction of beneficial genes intensified only after year 2000 (Remy et al. 2013). Most of the work has focused on resistance to Black and Yellow Leaf Streak Disease (BLSD and YLSD) and Panama disease (ibid). Other research objectives have been to determine the viability of bananas as carriers of vaccine (Kumar et al. 2005), and to introduce resistance to bacteria (Vishnevetsky et al. 2011). Confined field trials on transgenic bananas were reported in 2006 in Israel, followed by the United States, Uganda, and Australia (Remy et al. 2013.) These countries are known for promotional positions on biotechnology, with regulatory frameworks that promote biotechnology research. Uganda, in particular, is an important research and development hub for GM bananas. The confined field trial in Uganda in 2007 was a project to develop East African Highland bananas that are resistant to Black Sigatoka and nematode (Okeno et al. 2013). In June 2014, it was announced that human trials of pro-Vitamin-A enriched bananas would commence in Australia, and subsequently in the United States. The project would be led by Prof. James Dale of the Queensland University of Technology - Centre for Tropical Crops and Bio-commodities and funded by the Bill and Melinda Gates Foundation. Later, these trials were put on hold due to logistical constraints. Prof. Dale characterised the work in banana bio-fortification as a contribution to public health because of Vitamin A deficiency in Ugandan children (interview, Dale, 5 February 2014, Davao City).

The current thinking on genetic modification in bananas as a response to Panama disease is mainly divided into two strands: the first strand holds that biotechnology is only one of several viable options, but that we cannot close the door on genetic 
modification; and the second strand asserts that GM banana is the only solution, given the magnitude of Panama disease and the nature of the banana.

An example of the "Keep the door open" position is held by Charles Staver, research coordinator for banana production of Bioversity International, who said he was not opposed to genetic modification, but that people should also talk about "managing and strengthening quarantine" (interview, Staver, 7 February 2013, Skype). This thinking tends to be critical of the crisis narratives that pervade genetic modification of bananas. "How big a threat is fusarium? The literature uses the language of inevitability. It is exaggerated to say the industry will be wiped out" (ibid.). A similar view is shared by the Principal Horticulturist of the Department of Agriculture, Fisheries and Forestry in Queensland, Australia, who worked directly on Panama disease in the country. He called GM bananas a "last resort" and said that farm management might still provide the necessary solutions to Panama disease (interview, 20 July 2015, Brisbane).

Another strand of thinking propounds the idea that without GM bananas, the Cavendish is on its way to commercial extinction as a result of TR4. To quote a proponent of this position, "Genetic modification is the only way to maintain the supply levels of bananas in the market" (interview, Remy, 12 February 2013, Skype). This view also holds that the importance of banana as an agricultural crop and the pervasiveness of the threat of fusarium wilt will change the minds of those currently opposed to GMOs (interview, Dale, 16 July 2015, Brisbane). Proponents of biotechnology further suggest that research on genetic engineering of banana remains underdeveloped (Remy et al. 2013). One of the reasons for this is "the lack of a proper and functional bio-safety system" in the bananaproducing countries (ibid.). This view was also shared by a biotechnology expert based in University of California Davis: "We urgently need coherent and harmonised rules" (interview, Richard Michelmore, 22 February 2013, California).

Understanding these two strands of thinking among those involved in GM banana research surface the divergent risk narratives and perceptions even among expert scientific communities. The absence of any consensus among scientists and biotechnology researchers on whether or not GM bananas is the only solution against Panama disease offers interesting preliminary insight, as we begin looking into multiple understandings of risk and science within the global biosafety regime.

\section{Theoretical framework}

There is no dearth of academic literature on the global bio-safety framework and how it engages with the free trade principles underpinning the World Trade Organization (Isaac and Kerr 2003, Oberthür and Gehring 2006). The onslaught of trans-border plant diseases and the hazards that these bring to global agricultural trade appear to make a persuasive case for a uniform and binding set of phyto-sanitary standards. The neoliberal model of biosecurity has been described as attempting to regulate the movement of pests and diseases, whilst ensuring that the markets remain as free as possible, and believing these two objectives to be mutually-compatible in one political project (Maye et al. 2012). 
Eckersley (2004) describes "disciplinary neoliberal governance" as the irresistible and compulsive force that whips states and non-state actors to comply with free trade norms, even over environmental protections using regulatory science.

'Science-based', in itself, is a loaded term, framing those in the opposite side of the fence as 'unobjective', 'primitive', or 'non-evidence based'. Jasanoff (1998) describes the deployment of the word science in contested settings as offering "an especially powerful discursive and institutional framework for creating globally-convergent understandings about environmental problems". Wynne (2001) challenges the blithe dismissal of the sceptical public reactions to new technologies by their proponents - i.e., labelling sceptics as ignorant or unaware, or fooled by irresponsible activists and their media platforms by suggesting that these public reactions are in large part representative of negative public perceptions of scientific and policy institutions.

The dimension to which this Chapter hopes to contribute is the effects and influences of regulatory harmonisation built on 'scientific universality' on individual countries, using Panama disease and the prospect of GM bananas as background. There has already been some academic discussion on the contradictions between the notions of scientific universality that underpin global regulatory systems and local institutional arrangements and negotiations (Atik 1996, Irwin et al. 1997, Rothstein et al. 1999). Zwanenberg et al. (2011) has looked specifically into the area of agricultural biotechnology, calling attention to how regulatory harmonisation has in some cases led to mismatches in how international norms envision transgenic technologies on the ground and the local realities of end-users. Our specific and small contribution is to interface this discussion with a socio-legal analysis of risk approach, which looks at risk subjects as actors in differentiated positions whose risk decisions are influenced and ordered by belief systems, institutional pressures, identity politics, and economic interests (see for example, Simon 2005) and reflects on how some risk accounts are privileged over others (Scott 2008).

We use this approach to investigate existing legal regulatory systems for GMOs in banana-producing countries affected by Panama disease, compare with the global governance regime, and to compare these systems with each other. Risk theorists (see for example, Beck 1992) suggest that society orders itself in accordance with the ways that subjects within it perceive, mobilise against, and mitigate risk. The Cultural Theory of Risk proposed by Mary Douglas expands this further and seeks to explain competing interpretations of environmental and technological risks by looking at "cultural ways of life". Douglas proposes a grid to explain how risk choices are determined by the cultural groups that people fall into. This Chapter hopes to make a contribution to the literature on the Cultural Theory of Risk by looking not only the myriad and differentiated ways that cultural groups perceive risk. Our approach forwards the idea that social, economic, and political compulsions, in addition to the cultural constructions, shape how individuals are grouped and subsequently, how they make decisions on risk: which risks should be avoided at all costs, which risks are worth taking, which risks can be managed by human 
capacity, and so on. We interface this with Wynne (1992), who postulates that dominant institutions that gain authority from 'scientific knowledge' aim to control the social worlds to whom this knowledge is transmitted.

A legal approach is employed in that the primary methodology is an analysis of legal text, but it is an analysis that proceeds from the assumption that legal rules cannot be disembedded from the social order to which they belong, and policy prescriptions are rarely simple outcomes of sterile scientific experimentation but are imbued with and mediated by the values, biases, and strategic considerations of policy actors. This coincides with socio-legal thought which believes "legal and social practices are reciprocally constituted and that law operates routinely to control or reproduce the social order" (Durham 2001).

\section{Methodology}

Of the eleven countries found to be infested with Panama disease, we selected Indonesia, Jordan, Mozambique, Pakistan, and the Philippines as units of analysis - a criteria based on geographic spread, availability of legal texts in English, and a decision to focus on developing countries.

The authors obtained the National Bio-safety Frameworks and/or copies of national legislation of all of these countries from the United Nations Environment Program, the FAO, and from their respective government websites. We also obtained the countries' submitted National Reports to the Bio-Safety Clearing House of the Cartagena Protocol on Bio-Safety. All the Tropical Race 4 countries are signatories to the Cartagena Protocol, with the exception of Australia. The requirement to submit a National Report begins from the time a state becomes a party to the Protocol. To date, there have been three National Report cycles, the last of which was in 2015.

We analysed the legal texts with pre-determined questions in mind. These questions relate to the following themes: (a) risk perception and risk trade-off (i.e., what are the perceived risks of biotechnology seen against the risk sought to be addressed by biotechnology); (b) the approaches underlying biotechnology decision-making (i.e., science-based vs precautionary); (c) degree of development of regulatory regimes; and (d) socio-economic considerations. Legal text analysis was then supplemented by interviews with experts from the scientific community in the field of banana research, some of whom work directly on the issue of genetic modification of banana. These interviews were conducted over a period of two years.

\section{The bio-safety global governance regime: A case of harmonisation at the top?}

There are three important bodies of law applicable to plant disease regulation and consequently to any conversation on Panama disease management: the International Plant Protection Convention (IPPC), the Sanitary and Phyto-Sanitary (SPS) Agreement, and the Convention on Biological Diversity/Cartagena Protocol. The IPPC deals with coordination mechanisms and standards for plant health, where quarantine and trade- 
restrictive mechanisms are one of several mechanisms/regulations against pathogens. The SPS Agreement deals with all forms of trade barriers of a sanitary and phyto-sanitary nature. It is composed of a three-part approach: risk assessment, risk management, and risk communication similar to its progenitor, the GATT-SPS Agreements (Hooker and Caswell 1999).

In 1992, the Convention on Biological Diversity (CBD) was formulated, to counter invasive alien species and protect plant diversity and ecology. Whilst the primary purpose of the CBD and the IPPC are different (the IPPC protects plant health and the economic potential of crops, while the CBD concerns itself with ecological damage), they overlap in one crucial respect: they deal with the containment of pathogens whose spread can wreak havoc on the host or receiving country.

Emanating from the CBD is the highly-contentious Cartagena Protocol. It was spawned by an incident in 1986, wherein the United States tested a genetically-modified rabies vaccine in Argentina without having informed, much less obtained consent from, the Argentine government. This raised fears that with without an international legal framework for bio-safety, developed countries would use developing countries as laboratories, thus putting citizens of the latter at great risk (Gupta 2000). The Cartagena Protocol expressly adopted the precautionary principle that was first crystallized in the Rio Declaration. Environmentalists all over the world, including the European Union, lauded the inclusion of the Precautionary Principle in the Cartagena Protocol in 2000.

To allay fears that the Protocol would result in unwarranted trade restrictions and be used as an excuse for protectionism, the preamble states that parties recognise that trade and environment agreements should be mutually supportive, "emphasise that the Protocol is not interpreted as implying a change in the rights and obligations under any existing agreements", but also that the parties "understand that the above recital is not intended to subordinate this protocol to other international agreements". Gupta (2004) describes with great colour the protracted negotiations involved in the crafting of the Cartagena Protocol, even the wrangling over wording and phraseology. For example, the term 'genetic modified organism' was changed to 'living modified organism' to create distance between genetic engineering and the special regulations under Cartagena. However, the Cartagena Protocol is hampered by the fact that it does not have the support of free trade-supporting and GMO-advocating powerhouses like the United States. In fact, the United States and Canada are not signatories to the Protocol at all.

One of the most recent significant developments in the international policy regime governing liability for damage caused by biotechnology is the Nagoya-Kuala Lumpur Supplementary Protocol on Liability and Redress to the Cartagena Protocol on Biosafety (NKLSP). It was adopted on 16 October 2010, but as of October 2016 lacks four more signatures to enter into force.

While inroads have been made in global legislation, decisions taken by the World Trade Organization (WTO) with respect to disputes on the restrictions of genetically- 
modified foods reveal a scorecard favouring science-based risk assessment over the Precautionary Principle.

Table 3 summarises the three agreements and their key features, as well as their interactions with each other. We see that while the compliance mechanism under the SPS is clearly fleshed out, the Cartagena Protocol - sans the Nagoya Protocol, which has not yet come into force - is wanting in an enforcement framework. 
Table 3. Summary of agreements

\begin{tabular}{|c|c|c|c|c|}
\hline Agreement & $\begin{array}{c}\text { Countries } \\
\text { Covered }\end{array}$ & $\begin{array}{l}\text { Scope of application/ } \\
\text { regulatory goals }\end{array}$ & $\begin{array}{l}\text { Compliance } \\
\text { Mechanisms }\end{array}$ & $\begin{array}{l}\text { Relationship with } \\
\text { other Agreements }\end{array}$ \\
\hline IPPC & 181 & $\begin{array}{l}\text { Covers issues relating to } \\
\text { plant protection and the } \\
\text { creation of harmonised, } \\
\text { technically justified, and } \\
\text { transparent phyto- } \\
\text { sanitary measures for } \\
\text { plant protection }\end{array}$ & $\begin{array}{l}\text { Parties can request the } \\
\text { Director of the FAO to } \\
\text { appoint a Committee of } \\
\text { Experts to consider the } \\
\text { question in dispute, } \\
\text { but the } \\
\text { recommendations of } \\
\text { the Committee are } \\
\text { non-binding in } \\
\text { character. }\end{array}$ & $\begin{array}{l}\text { The IPPC will not } \\
\text { affect rights and } \\
\text { obligations under } \\
\text { other international } \\
\text { agreements. } \\
\text { Resolution of the } \\
\text { Committee of } \\
\text { Experts must } \\
\text { complement dispute } \\
\text { settlement } \\
\text { procedures in other } \\
\text { international } \\
\text { agreements. }\end{array}$ \\
\hline SPS & $\begin{array}{l}159 \\
\text { (members } \\
\text { of the } \\
\text { WT0) }\end{array}$ & $\begin{array}{l}\text { Covers all measures } \\
\text { whose purpose is to } \\
\text { protect: } \\
\text { 1. Human or animal } \\
\text { health from food-borne } \\
\text { diseases } \\
\text { 2. Human health from } \\
\text { animal or plant-carried } \\
\text { diseases } \\
\text { 3. The territory of a } \\
\text { country from damage } \\
\text { caused by pests } \\
\text { Primary intent is to } \\
\text { ensure that sanitary and } \\
\text { phyto-sanitary standards } \\
\text { are not used for } \\
\text { protectionist purposes. }\end{array}$ & $\begin{array}{l}\text { Formal and binding } \\
\text { dispute resolution } \\
\text { mechanism under the } \\
\text { WTO }\end{array}$ & $\begin{array}{l}\text { International } \\
\text { standards set by } \\
\text { relevant } \\
\text { international } \\
\text { organisations and } \\
\text { conventions (like the } \\
\text { IPPC) shall be } \\
\text { presumed consistent } \\
\text { with SPS Agreement. }\end{array}$ \\
\hline $\begin{array}{l}\text { Cartagena } \\
\text { Protocol } \\
\text { (under the } \\
\text { Convention } \\
\text { on } \\
\text { Biological } \\
\text { Diversity) }\end{array}$ & 166 & $\begin{array}{l}\text { Covers the safe handling, } \\
\text { transport, and use of } \\
\text { living modified organisms } \\
\text { (LMOs) resulting from } \\
\text { modern biotechnology } \\
\text { that may have adverse } \\
\text { effects on biological } \\
\text { diversity, taking also into } \\
\text { account risks to human } \\
\text { health. (CP) }\end{array}$ & $\begin{array}{l}\text { The Nagoya-Kuala } \\
\text { Lumpur } \\
\text { Supplementary } \\
\text { Protocol elaborates the } \\
\text { rules and procedures } \\
\text { on liability and redress } \\
\text { for damage resulting } \\
\text { from transboundary } \\
\text { movements of LMOs } \\
\text { and is predicated on } \\
\text { Article } 27 \text { of the } \\
\text { Cartagena Protocol. } \\
\text { However, the } \\
\text { Supplementary } \\
\text { Protocol is not yet in } \\
\text { force. }\end{array}$ & $\begin{array}{l}\text { The preamble states } \\
\text { that parties } \\
\text { "recognise that trade } \\
\text { and environment } \\
\text { agreements should } \\
\text { be mutually } \\
\text { supportive", } \\
\text { "emphasise that the } \\
\text { Protocol is not } \\
\text { interpreted as } \\
\text { implying a change in } \\
\text { the rights and } \\
\text { obligations under } \\
\text { any existing } \\
\text { agreements". } \\
\text { However, it also } \\
\text { states that the } \\
\text { parties "understand } \\
\text { that the above recital } \\
\text { is not intended to } \\
\text { subordinate this } \\
\text { protocol to other } \\
\text { international } \\
\text { agreements." }\end{array}$ \\
\hline
\end{tabular}


* "Nothing in this Convention shall affect the rights and obligations of the contracting parties under relevant international agreements." (Art. III, IPPC)

** "The provisions of this article (on dispute settlement) shall be complementary to and not in derogation of the dispute settlement procedures provided for in other international agreements dealing with trade matters." (Art. XIII.6, IPPC)

*** Members shall play a full part, within the limits of their resources, in the relevant international organizations and their subsidiary bodies, in particular the $\mathrm{xxx}$ international and regional organizations operating within the framework of the International Plant Protection Convention, to promote within these organizations the development and periodic review of standards, guidelines and recommendations with respect to all aspects of sanitary and phyto-sanitary measures. (Art III.4, SPS Agreement)

\section{Harmonised international commitments}

Global efforts at harmonisation are evident in the fact that TR4-infested countries are signatories to all three of the major international agreements (the IPCC, the SPS, and the CBD), with only Australia opting out of the Cartagena Protocol.

Table 4. Fusarium wilt TR4 countries and the agreements ${ }^{18}$

\begin{tabular}{|l|l|l|l|l|l|l|}
\hline Countries & IPCC & SPS & CBD & CP & NKLSP & $\begin{array}{l}\text { Has complied with } \\
\text { SPS Transparency } \\
\text { Obligations }{ }^{19}\end{array}$ \\
\hline Australia & $\sqrt{ }$ & $\sqrt{ }$ & $\sqrt{ }$ & $\mathrm{X}$ & $\mathrm{X}$ & $\sqrt{ }$ \\
\hline China & $\sqrt{ }$ & $\sqrt{ }$ & $\sqrt{ }$ & $\sqrt{ }$ & $\mathrm{X}$ & $\sqrt{ }$ \\
\hline Indonesia & $\sqrt{ }$ & $\sqrt{ }$ & $\sqrt{ }$ & $\sqrt{ }$ & $\mathrm{X}$ & $\sqrt{ }$ \\
\hline Jordan & $\sqrt{ }$ & $\sqrt{ }$ & $\sqrt{ }$ & $\sqrt{ }$ & $\sqrt{ }$ & $\sqrt{ }$ \\
\hline Mozambique & $\sqrt{ }$ & $\sqrt{ }$ & $\sqrt{ }$ & $\sqrt{ }$ & $\sqrt{ }$ & $\sqrt{ }$ \\
\hline Pakistan & $\sqrt{ }$ & $\sqrt{ }$ & $\sqrt{ }$ & $\sqrt{ }$ & $\mathrm{X}$ & $\sqrt{ }$ \\
\hline Philippines & $\sqrt{ }$ & $\sqrt{ }$ & $\sqrt{ }$ & $\sqrt{ }$ & $\mathrm{X}$ & $\sqrt{ }$ \\
\hline
\end{tabular}

The significance of this table can be seen in two ways: in intent, and in consequence. With respect to intent, we see clearly the objective of mobilising state actors

\footnotetext{
18 Australia and China are included in this table only as Panama disease-infested countries.

19 Compliance means (1) notified an enquiry point as provided in paragraph 3 of Annex B of the SPS Agreement and (2) identified their national notification authority as provided in paragraph 10 of Annex B of the Agreement as of 8 October 2007.
} 
towards agreeing on a certain set of standards and commitments. Although Gupta (2000) describes the negotiations preceding the Cartagena Protocol as contentious, the Cartagena Protocol was eventually signed by 166 member-states, whilst the SPS Agreement has 159 member-states. As there are 195 countries in the world, a vast majority can be said to be members both of the WTO and the Cartagena Protocol.

With respect to consequence, the ratification of treaties and conventions binds member-countries to reproduce within their domestic legislation the principles embodied in the international commitments entered into. These conventions give rise to rights and duties between country-signatories, and become a basis for the assertion of claims against each other.

Both the Cartagena Protocol and the SPS/IPPC guard against injurious organisms that could compromise plant health. So ostensibly, a GMO that could be injurious to plant health will also have some remedies under the IPPC and the SPS Agreement. However, the difference lies in how to determine whether or not an organism is injurious to warrant barring entry within a jurisdiction. Cartagena clearly follows the precautionary principle; in contrast, Article 5.2 of the SPS Agreement requires members to assess risks to health on the basis of "available scientific evidence" and under Article 5.5 obliges them to avoid arbitrary or unjustified distinctions in the levels of measures, if such measures result in discrimination against other WTO members or "disguised restrictions to trade". This presents a conundrum to countries that are members of both the Cartagena and the SPS. When GMO banana becomes a reality, will it trigger Cartagena or will it trigger SPS? Is Cartagena to be treated as the specific exception to the broad rules of SPS, or will SPS operate to neuter Cartagena? Will precautionary principle-based countries be made to toe the WTO line?

\section{Iterations of the precautionary principle and science-based risk assessment in domestic legislation}

We have found iterations of both the precautionary principle and the sciencebased risk assessment principle in the domestic legislation of Indonesia, Jordan, Mozambique, Pakistan, and the Philippines - all countries with fusarium wilt TR4 and therefore potentially engaged in conversations involving GMO bananas, and all signatories of both the SPS and the Cartagena. 
Table 5. Legislative interpretations of the precautionary principle and sciencebased risk assessment

\begin{tabular}{|c|c|c|}
\hline COUNTRIES & PRECAUTIONARY PRINCIPLE & SCIENCE-BASED RISK ASSESSMENT \\
\hline Indonesia & $\begin{array}{l}\text { "Arrangement applied in this } \\
\text { government regulation is a precautionary } \\
\text { approach in realizing environmental } \\
\text { safety, food safety and or animal feed } \\
\text { safety based on an accurate scientific } \\
\text { method by considering religious, ethic, } \\
\text { socio- cultural and esthetic norms." } \\
\text { Government Regulation } 21 / 2005\end{array}$ & $\begin{array}{l}\text { "Risk assessment of PRG (genetically } \\
\text { engineered product) means assessment of } \\
\text { possible occurrence of influence that can } \\
\text { affect environment, human health and } \\
\text { animal health as a result of PRG } \\
\text { development and use based on correct } \\
\text { scientific method and certain statistics." } \\
\text { Government Regulation } 21 / 2005\end{array}$ \\
\hline Jordan & $\begin{array}{l}\text { "Lack of scientific certainty due to } \\
\text { insufficient relevant scientific } \\
\text { information and knowledge regarding } \\
\text { the extent of potential adverse effects of a } \\
\text { living modified organism on the } \\
\text { conservation and sustainable use of } \\
\text { biological diversity, taking also into } \\
\text { account risks to human health, shall not } \\
\text { prevent the National Biosafety } \\
\text { Committee from making a decision with } \\
\text { regard to the import of a living modified } \\
\text { organism in order to avoid or minimize } \\
\text { potential adverse effects." Draft Law for } \\
\text { Biosafety of Genetically-Modified } \\
\text { Organisms based on Biosafety Framework } \\
\text { 2005 }\end{array}$ & $\begin{array}{l}\text { "Risk assessment should be carried out in a } \\
\text { scientifically sound and transparent } \\
\text { manner, and can take into account expert } \\
\text { advice of, and guidelines developed by, } \\
\text { relevant international organizations." Draft } \\
\text { Law for Biosafety of Genetically-Modified } \\
\text { Organisms based on Biosafety Framework } \\
2005\end{array}$ \\
\hline Mozambique & $\begin{array}{l}\text { "The management of the environment } \\
\text { shall prioritise the establishment of } \\
\text { system to prevent acts which are harmful } \\
\text { to the environment in such a way so as to } \\
\text { avoid the occurrence of negative } \\
\text { environmental impacts which are } \\
\text { material or irreversible, regardless of the } \\
\text { existence of scientific certainty } \\
\text { concerning the occurence of such an } \\
\text { impact." Environmental Law 20/97 }\end{array}$ & $\begin{array}{l}\text { "The risk assessment shall be coordinated } \\
\text { by the NBC and it shall be conducted based } \\
\text { on the information provided by the } \\
\text { applicant, public and any other available } \\
\text { scientific evidences, in order to identify and } \\
\text { evaluate the possible adverse effects on } \\
\text { environment particularly the biological } \\
\text { diversity and human health." Mozambique } \\
\text { Biosafety Regulation } 2007\end{array}$ \\
\hline Pakistan & $\begin{array}{l}\text { "There is a state of uncertainty and in } \\
\text { such a situation the authorities should } \\
\text { observe the rules of prudence and } \\
\text { precaution. The rule of prudence is to } \\
\text { adopt such measures which may avert } \\
\text { the so-called danger, if it occurs. The rule } \\
\text { of precautionary policy is to first } \\
\text { consider the welfare and safety of the } \\
\text { human beings and the environment and } \\
\text { then to pick up a policy and execute the } \\
\text { plan which is more suited to obviate the } \\
\text { possible danger or make such alternate } \\
\text { precautionary measures which may } \\
\text { ensure safety." Ms. Shela Zia and others v. } \\
\text { WAPDA P.L.D. 1994 SC 693. }\end{array}$ & $\begin{array}{l}\text { "Risk assessment, including the auditing of } \\
\text { risk assessments and evaluation of } \\
\text { proposed risk management measures, and } \\
\text { field trials, shall be carried out on a case-to- } \\
\text { case basis in a scientifically sound manner, } \\
\text { in accordance with Article } 15 \text { and Annex III } \\
\text { of the Cartagena Protocol as set forth in the } \\
\text { biosafety guidelines." Article 13(2), Pakistan } \\
\text { Biosafety Guidelines } 2005 \text {. }\end{array}$ \\
\hline Philippines & $\begin{array}{l}\text { 2.6 Using Precaution. In accordance with } \\
\text { Principle } 15 \text { of the Rio Declaration of } \\
1992 \text { and the relevant provisions of the } \\
\text { Cartagena Protocol on Biosafety, in } \\
\text { particular Articles 1, } 10 \text { (par. 6) and } 11 \\
\text { (par. 8), the precautionary approach shall }\end{array}$ & $\begin{array}{l}\text { 5.2.1. Principles of risk assessment. The } \\
\text { risk assessment shall be carried out in a } \\
\text { scientifically sound and transparent } \\
\text { manner based on available scientific and } \\
\text { technical information. The expert advice of } \\
\text { and guidelines developed by, relevant }\end{array}$ \\
\hline
\end{tabular}




\begin{tabular}{|l|l|l|}
\hline & $\begin{array}{l}\text { guide biosafety decisions. The principles } \\
\text { and elements of this approach are hereby } \\
\text { implemented through the decision- } \\
\text { making system in the NBF. Philippine } \\
\text { Executive Order 514. (2006) }\end{array}$ & $\begin{array}{l}\text { international organizations, including } \\
\text { intergovernmental bodies, and regulatory } \\
\text { authorities of countries with significant } \\
\text { experience in the regulatory supervision of } \\
\text { the regulated article shall be taken into } \\
\text { account in the conduct of risk assessment. } \\
\text { Philippine Executive Order 514 (2006) }\end{array}$ \\
\hline
\end{tabular}

A cursory reading of these legal provisions embedded in the domestic legislation of all five countries shows that, despite a narrative of incompatibility at the top, down below, the precautionary principle and the science-based principle of risk assessment are both articulated, and in almost equal measure.

The significance of having both principles reposed in national legislation is that it provides advocates of both camps a basis for lobbying and assertion, creating spheres of contestation in the national level. For example, in the Philippines, where the existing biosafety framework appears to be aggressively promotional in favour of genetic modification, the Supreme Court ruled in 2012 that the field trials for Bt eggplant violated the Filipino people's right to a healthy environment (Greenpeace 2012). Mozambique's decision to accept genetically-modified food aid as long as it was milled first had been seen as an about-face considering its earlier rejection of GMOs, and yet Mozambique is a signatory to the Nagoya-Kuala Lumpur Supplementary Protocol, deemed to be more progressive than the Cartagena in that it establishes liability mechanisms for ecological harm caused by the release of living modified organisms (LMOs) in the environment. It is therefore difficult to adopt a straightforward typology or categorisation of state attitudes on biotechnology because first, states are not monoliths, but are complex amalgams of actors, practices, and interests; second, because there are external political and economic compulsions that bear upon states' decision-making, leading to seemingly-incoherent legislative outcomes. For example, states are required to be members of the WTO and sign on to the principles of trade liberalisation prescribed by the WTO, or face the punitive effects of being left out from the global economic order. But domestic actors (for example, the High Courts in Pakistan and the Philippines) and advocates also influence state decisions and policies, and do so in ways that contradict the prescribed 'science-based' framework of the WTO and question the legitimacy of its prescriptions.

\section{Identical approach in risk and risk trade-off: "Human health" and the "environment" as risk, and "food security" as risk trade-off}

This section looks at the discourses of risk of the Panama disease countries: what they consider to be the risks involved in genetic modification, and how these risks are weighed against the risks that genetic modification ostensibly combats. We find that repeatedly, countries identify 'food insecurity' as the main problem that they believe genetic modification would address - a compulsion that resonates with the idea that economic and not just cultural pressures influence risk choices of social actors. 
Since all of the countries subject of this research are signatories to the Cartagena, all virtually adopted the language of Cartagena with respect to risk, that is to say, "the possible adverse effects of living modified organisms on the conservation and sustainable use of biological diversity, taking also into account risks to human health" (Article 15, Cartagena Protocol).

In the texts of the Bio-Safety Framework Agreements, however, human health was either equal to or more important than the environment or sustainable use of biotechnology. For example, Mozambique defines risk as that directed to "human health and to the environment that could originate from the deliberate release or display of GMO on the market" (Mozambique BSF, p. ix). Jordan's Bio-Safety Framework reads that "The overall objective of Jordan policy on biosafety is to ensure that the risks likely to be caused by the products of modern biotechnology will be minimized to the level as low as possible and to protect human health, biodiversity and the environment in the maximum way" (Jordan BSF, p. 9). The Philippine framework speaks of "risks to human health and the environment based on available scientific information" (Philippines BSF, p. 9), while Indonesia frames the risks of biotechnology as "environmental and food safety risks" (Indonesia BSF, p.18). It can be said, however, that the broad consensus is that risk can be classified into two categories: health risks and environmental risks.

Looking through the texts of the Bio-safety Frameworks and other legal documents of the countries, a common rationale emerged for adopting biotechnology: food insecurity. Jordan and Mozambique's bio-safety frameworks are the most explicit, with the question of food security setting the tone for both countries' framework on bio-safety. The first sentence of Jordan's framework reads:

Jordan is a food deficit country. With an annual growth rate 3.3\%, the population of Jordan is expected to reach 7.1 million by the year 2010 and will exert heavy pressure on the fragile natural resources base of the kingdom (Jordan Bio-Safety Framework, preface).

Similarly, the first sentence of Mozambique's framework reads:

Food and environmental security are on the top of the national agenda for fight against poverty and to ensure sustainable development of the country. In this context, the development and access to adequate novel technology for food and agricultural production is of crucial importance for achieving food security in the country (Mozambique Bio-Safety Framework, preface).

Interestingly, Indonesia frames it as a debate between two 'contending' policies: sustainable biodiversity and food security.

Indonesia is very concerned with the conservation and sustainable use of biodiversity. On the other hand, due to the struggle in providing food for its large population, Indonesia is also extremely concerned with food security (Indonesia Bio-Safety Framework, page 7). 
In contrast, the perspective of Pakistan and the Philippines on biotechnology is one driven by economic reasons. The first sentence of the Philippine Bio-Safety Framework reads: "(a)s early as 1979, the Philippine government has recognized that biotechnology is a driving force for economic development". The first clause of Philippine Executive Order No. 514 recognises that "there is a rapid expansion of the use of modern biotechnology not only for scientific research but also for products for commercial releases and purposes", while the prefatory paragraph of the Pakistan National Biosafety Guidelines (Notification No. F.2(7)95-Bio) contains a clause "recognizing the revolutionary economic potential of the new biotechnology in agriculture, health, industry, environment and energy sectors".

What is apparent is that the five countries with Panama disease investigated here are food-insecure or economically-underdeveloped countries, and food security has been deployed as the explicit rationale (with the exception of Pakistan) for the endorsement of biotechnology.

Drawing from Douglas (1992), which proposes that the cultural filters of social organisations "elevate some risks to a high peak and depresses others below sight", we suggest that some processes of risk selection are in fact 'risk trade-offs'. It is not always the case that certain risks are rendered invisible or depressed below sight; in some cases the risks are visible but are consciously accepted.

The construction suggesting invisibility prompts the question of social biases that hide some risks and surface others. Douglas and Wildavsky (1983), for example, suggest that the risks that are more pronounced than others are those to which the community has attached some sort of moral deficit, and this risk selection is rarely a conscious cognitive assessment. A risk trade-off, on the other hand, provokes analysis of why the accepted risk was accepted by a conscious actor who makes a conscious decision with two or more sets of risks before him or her. It could either be because the benefits of accepting the risk are deemed to be greater (i.e., mitigation of bigger risks), or perhaps the accepted risk is deemed to be manageable by regulation of human conduct or technological expertise. Or it can also be, in fact, that socio-economic compulsions require acceptance of the risk.

In the context of genetic modification, it is not that countries do not see the risks of biotechnology; indeed in every single country studied, the purported risks of biotechnology are spelled out. From all accounts, states appear to be aware of the potential hazards of biotechnology to health and the environment. Countries accept the risks of biotechnology because they believe it is the answer to food insecurity and/or agricultural underdevelopment, and trust that a functional regulatory framework can mitigate these risks. We see an underlying economic compulsion to accept biotechnology: the need to feed its people and the belief that genetic modification is the way to do it.

Whether or not this belief is true, or is foisted upon developing countries through a complex array of political and economic pressures, is a debate that will persist for many years. 


\section{Differentiations from below}

The preceding section looked at the areas in which there has been some harmonisation in the domestic frameworks of the subject countries in the area of biosafety. We proceed to look at the areas of differentiation.

\section{Degree of development of regulatory regimes}

This part looks at specific mechanisms within regulatory regimes of the five countries with Panama disease. There is a large variance in the degree of development of these regimes. Among developed countries, the regulations differ mainly in terms of approaches - e.g., the United States's regulatory approach is based on the end-product, whilst the European Union approach is more concerned with the process - with strict regulatory standards for every step of the GMO development process (Gruere 2006). For developing countries, however, stark differences are also found in how developed or how fully fleshed out their regulatory regimes are.

By far, of the countries investigated, the Philippines has the most experience in biotechnology and has the more advanced bio-safety framework. It is also the first country in the Association of Southeast Asian Nations to have a regulatory system for biotechnology. ${ }^{20}$ The Philippines has approved Bt corn and maize for field trials. Indonesia has not yet planted any GMO seeds, but in 2014 accepted US $\$ 1$.3billion worth of GMO imports from the United States, including corn, soybean, and maize. ${ }^{21}$ Jordan's biotechnology framework remains largely undeveloped, but evolving biotechnology legislation point to a support for genetic modification. No GMO crops have been planted yet, but a Biotechnology Regulation passed in 2001 (Regulation JS 9:2001) that incorporates $\operatorname{Codex}^{22}$ standards into Jordanian legislation is perceived to legalise the marketing of GM crops in Jordan. ${ }^{23}$ Mozambique, on the other hand, has transitioned from its original anti-GMO stance during the controversy over the inclusion of GM maize in food aid to southern Africa. Mozambique requested that the maize be milled before distribution so that farmers would not plant the seed (Zerbe 2004), demonstrating its fears of the risks associated with GMO planting. Since then, field trials were conducted in 2009 for Bt cotton, and in 2010 for maize. Pakistan's experience in genetic modification is with Bt cotton, but the technology was not readily accepted by the farmers because of the higher prices of the Bt cotton seed, perceptions that the seed was vulnerable to viral infections, and the higher requirements for fertiliser (Arshad et al. 2009).

\footnotetext{
${ }^{20}$ Biotechnology Philippines 2015. See http://biotech.da.gov.ph/

${ }^{21}$ Indonesia Agricultural Biotechnology Annual 2014.

http://gain.fas.usda.gov/Recent\%20GAIN\%20Publications/Agricultural\%20Biotechnology\%20Annual_Ja karta_Indonesia_7-15-2014.pdf

22The Codex Alimentarius, or "Food Code" is a collection of standards adopted by the Codex Alimentarius Commission and was established by FAO and WHO to protect consumer health and promote fair practices in food

${ }^{23}$ http://gain.fas.usda.gov/Recent\%20GAIN\%20Publications/Biotechnology\%20-

\%20GE\%20Plants\%20and\%20Animals_Amman_Jordan_6-24-2010.pdf
} 
In the table below, we examine the state of legislative development in Indonesia, Jordan, Mozambique, Pakistan, and the Philippines using the three broad stages in the development of a GMO: (1) contained use, (2) field trials, and (3) large-scale release and commercialisation (Prabhu 2009). For contained use, work is done with physical isolation, for example in a greenhouse or laboratory, to ensure no modified organisms are introduced to the environment. Field trials are experiments done in open environment. Commercial distribution entails the release of GMO end-products into the market.

Table 6. Legislative basis for GMO regulation at every stage

\begin{tabular}{|c|c|c|c|c|c|}
\hline $\begin{array}{r}\text { Stages of GMO } \\
\text { development }\end{array}$ & Indonesia & Jordan & Mozambique & Pakistan & Philippines \\
\hline Contained use & $\begin{array}{l}\text { Yes. } \\
\text { (Government } \\
\text { Regulation } \\
21 / 2005 \text { ) }\end{array}$ & $\begin{array}{l}\text { None. } \\
\text { Proposed law } \\
\text { is Draft } \\
\text { Biosafety Law } \\
\text { by the } \\
\text { Ministry of } \\
\text { Environment }\end{array}$ & $\begin{array}{l}\text { Yes. (Biosafety } \\
\text { Law 2007) }\end{array}$ & $\begin{array}{l}\text { Yes. } \\
\text { (Pakistan } \\
\text { Biosafety } \\
\text { Rules } \\
\text { 2005/ } \\
\text { National } \\
\text { Biosafety } \\
\text { Guidelines } \\
\text { 2005) }\end{array}$ & $\begin{array}{l}\text { Yes. (Executive } \\
\text { Order } 430, \\
\text { Series of } 1990 \text { ) }\end{array}$ \\
\hline Field trials & $\begin{array}{l}\text { Yes. } \\
\text { (Government } \\
\text { Regulation } \\
21 / 2005 \text { ) }\end{array}$ & $\begin{array}{l}\text { None. } \\
\text { Proposed law } \\
\text { is Draft } \\
\text { Biosafety Law } \\
\text { by the } \\
\text { Ministry of } \\
\text { Environment }\end{array}$ & $\begin{array}{l}\text { Yes. (Biosafety } \\
\text { Law 2007) }\end{array}$ & $\begin{array}{l}\text { Yes. } \\
\text { (Pakistan } \\
\text { Biosafety } \\
\text { Rules } \\
\text { 2005/ } \\
\text { National } \\
\text { Biosafety } \\
\text { Guidelines } \\
\text { 2005) }\end{array}$ & $\begin{array}{l}\text { Yes. } \\
\text { (Department of } \\
\text { Agriculture } \\
\text { Administrative } \\
\text { Order No. 8, } \\
\text { Series of 2002) }\end{array}$ \\
\hline Commercialisation & None. & $\begin{array}{l}\text { None. } \\
\text { Proposed law } \\
\text { is Draft } \\
\text { Biosafety Law } \\
\text { by the } \\
\text { Ministry of } \\
\text { Environment }\end{array}$ & $\begin{array}{l}\text { No clear } \\
\text { legislative } \\
\text { framework/ } \\
\text { procedure. }\end{array}$ & $\begin{array}{l}\text { Yes. } \\
\text { (Pakistan } \\
\text { Biosafety } \\
\text { Rules } \\
\text { 2005/ } \\
\text { National } \\
\text { Biosafety } \\
\text { Guidelines } \\
\text { 2005) }\end{array}$ & $\begin{array}{l}\text { Yes. } \\
\text { (Department of } \\
\text { Agriculture } \\
\text { Administrative } \\
\text { Order No. 8, } \\
\text { Series of 2002) }\end{array}$ \\
\hline
\end{tabular}

A look at how countries assess their own regulatory regimes perhaps provides a clearer picture of the divergences among these regimes. Data below was taken from the submissions of Indonesia, Jordan, Mozambique, Pakistan, and the Philippines in their Second National Reports (2011) to the Biosafety Clearing House. ${ }^{24}$ The following table

\footnotetext{
${ }^{24}$ As of writing, five countries have yet to submit their Third Report, due in 2015.
} 
shows a sampling of questions asked to the Cartagena member-countries relating to their compliance with the Agreement, and their respective answers. ${ }^{25}$

Table 7. Robustness of regulatory regimes based on self-assessment

\begin{tabular}{|c|c|c|c|c|c|}
\hline & IND & JORDAN & MOZ & PAK & $\mathrm{PH}$ \\
\hline $\begin{array}{l}\text { Does your country regulate the transit of } \\
\text { LMOs? }\end{array}$ & No & No & Yes & No & No \\
\hline $\begin{array}{l}\text { Does your country regulate the contained } \\
\text { use of LMOs? }\end{array}$ & Yes & Yes & Yes & Yes & Yes \\
\hline $\begin{array}{l}\text { Has your country established a mechanism } \\
\text { for taking decisions regarding first } \\
\text { intentional transboundary movements of } \\
\text { LMOs for intentional introduction into the } \\
\text { environment? }\end{array}$ & Yes & Yes & No & Yes & Yes \\
\hline $\begin{array}{l}\text { Has your country established a mechanism } \\
\text { for monitoring potential effects of LMOs } \\
\text { that are released into the environment? }\end{array}$ & No & No & No & Yes & Yes \\
\hline $\begin{array}{l}\text { Has your country adopted specific law(s) or } \\
\text { regulation(s) for decision-making } \\
\text { regarding domestic use, including placing } \\
\text { on the market, of LMOs used for Food, Feed } \\
\text { or Processing (LMOs-FFP)? }\end{array}$ & No & Yes & Yes & Yes & Yes \\
\hline $\begin{array}{l}\text { Has your country established legal } \\
\text { requirements for the accuracy of } \\
\text { information to be provided by the } \\
\text { applicant? }\end{array}$ & No & No & Yes & Yes & Yes \\
\hline $\begin{array}{l}\text { Has your country established a mechanism } \\
\text { for taking decisions on the import of LMOs- } \\
\text { FFP? }\end{array}$ & No & Yes & No & Yes & Yes \\
\hline $\begin{array}{l}\text { Has your country established a mechanism } \\
\text { for the review and change of a decision } \\
\text { regarding an intentional transboundary } \\
\text { movement of LMOs? }\end{array}$ & No & No & Yes & Yes & Yes \\
\hline $\begin{array}{l}\text { Has your country established a system for } \\
\text { the application of the simplified procedure } \\
\text { regarding an intentional transboundary } \\
\text { movement of LMOs? }\end{array}$ & No & No & No & No & No \\
\hline $\begin{array}{l}\text { Has your country established a mechanism } \\
\text { for conducting risk assessments prior to } \\
\text { taking decisions regarding LMOs? }\end{array}$ & Yes & Yes & No & Yes & Yes \\
\hline
\end{tabular}

25 This is just a sampling of questions that were asked to the member-countries. The comprehensive list of questions with responses of the subject-countries are available from the author upon request. 


\begin{tabular}{|l|l|l|l|l|l|}
\hline $\begin{array}{l}\text { Has your country established and } \\
\text { maintained appropriate and operational } \\
\text { mechanisms, measures and strategies to } \\
\text { regulate, manage and control risks } \\
\text { identified in risk assessments for LMOs for } \\
\text { intentional introduction into the } \\
\text { environment? }\end{array}$ & $\begin{array}{l}\text { Yes to } \\
\text { some } \\
\text { extent }\end{array}$ & $\begin{array}{l}\text { Yes to } \\
\text { some } \\
\text { extent }\end{array}$ & No & $\begin{array}{l}\text { Yes to } \\
\text { some } \\
\text { extent }\end{array}$ & Yes \\
\hline $\begin{array}{l}\text { Has your country established and } \\
\text { maintained appropriate and operational } \\
\text { mechanisms, measures and strategies to } \\
\text { regulate, manage and control risks } \\
\text { identified in risk assessments for LMOs } \\
\text { intended for direct use as food and feed, or } \\
\text { for processing? }\end{array}$ & $\begin{array}{l}\text { Yes to } \\
\text { some } \\
\text { extent }\end{array}$ & $\begin{array}{l}\text { Yes to } \\
\text { some } \\
\text { extent }\end{array}$ & No & No & Yes \\
\hline $\begin{array}{l}\text { Has your country established and } \\
\text { maintained appropriate measures to } \\
\text { prevent unintentional transboundary } \\
\text { movements of LMOs? }\end{array}$ & No & No & No & $\begin{array}{l}\text { Yes to } \\
\text { some } \\
\text { extent }\end{array}$ & Yes \\
\hline $\begin{array}{l}\text { Has your country established a mechanism } \\
\text { for addressing emergency measures in case } \\
\text { of unintentional transboundary movements } \\
\text { of LMOs that are likely to have significant } \\
\text { adverse effect on biological diversity? }\end{array}$ & No & Yes & No & Yes & Yes \\
\hline
\end{tabular}

Source: Data taken from the Biosafety Clearing House of the Cartagena Protocol

The wide disparity among the countries now becomes readily apparent. The only question with a unanimous answer of a complete Yes was the question on regulating the contained use of LMOs. This means that, at the very least, the countries with Panama disease have the regulatory framework for contained experiments. With the exception of Jordan which replied with a "Yes, to some extent", all countries also claim to have documentation for LMOs for contained use, and for intentional introduction into the environment. Thus, for at least two issues, there is both an acknowledgement of the risk of the dangers of LMOs for contained use, for undocumented and unidentified LMOs, as well as the capacity to regulate such risk. In all other cases, there is marked differentiation in the degree and depth of regulation. It must be noted again that all five countries are signatories to the Cartagena Protocol, and thus presumably accede to the principle behind management and regulation of LMOs. Jordan and Mozambique appear to be the countries with the least degree of regulatory mechanisms, and the Philippines with the most developed regulatory framework in place.

Regulatory harmonisation requires some degree of development homogeneity among actors whose regulatory frameworks are to be harmonised. The data above demonstrates a wide differentiation in the robustness of legislation and regulatory experiences. This presents clear challenges to proponents of harmonisation. 
Article $26.1^{26}$ of the Cartagena Protocol allows member-countries to include considerations outside the realm of health and the environment, in decision-making processes where biotechnology is concerned. This provision has generated much controversy (Fransen et al. 2005). On the one hand, socio-economic considerations are believed to be helpful for developing countries and provide buffers to mitigate the effects of, for example, imported GMO seeds on domestic agriculture. On the other hand, some researchers think that socio-economic considerations could be protectionism "in disguise" (Falck-Zepeda 2009) and can hinder the transfer of "beneficial" GMO technology to the poor (ibid.), or be used for political decisions in the absence of any clear and workable framework. In any event, there is some insight to be derived in investigating the various socio-economic considerations clauses (SECC) of the countries. While these considerations may be considered by some as rhetoric that can easily be brushed aside to support a biotechnology regime, these provide clues into how countries analyse their own contexts and some of the social values that illumine decision-making.

\section{Table 8. Socio-economic considerations}

\begin{tabular}{|l|l|}
\hline Countries & Socio-economic Considerations Clause (SECC) \\
\hline Indonesia & $\begin{array}{l}\text { "The utilization of GEAP originating from both domestic and foreign } \\
\text { products must pay attention to and take into consideration the religious, } \\
\text { ethical, socio-cultural and esthetical norms." (Regulation 21 of 2005) }\end{array}$ \\
\hline Jordan & $\begin{array}{l}\text { "Also the decision should touch on and analyze the convention socio- } \\
\text { economic impacts, including effects on people's health, family life, } \\
\text { recreation and quality of life, economic activities, and land uses." (*not in } \\
\text { legislation, but in Biosafety Framework, page 26) }\end{array}$ \\
\hline Mozambique & $\begin{array}{l}\text { 1.1.1. "Apart from scientific risk assessment report, public contribution } \\
\text { and other socio-economic considerations have to be carried out." (Biosafety } \\
\text { Regulation 2007) }\end{array}$ \\
\hline Pakistan & $\begin{array}{l}\text { "The use of GMO's vis a vis religious belief, distribution of seeds to low- } \\
\text { income farmers and product labelling, may give birth to ethical and social } \\
\text { issues which can have serious consequences in the unique socioeconomic } \\
\text { set-up in Pakistan. It is anticipated that the recently concluded International } \\
\text { Treaties on Patent and Intellectual Property Rights such as WTO coupled } \\
\text { with present level of investment by different nations in R\&D in bio- } \\
\text { technology, will aggravate the situation by further widening the existing gap } \\
\text { in the biotechnological capabilities of the developed and developing } \\
\text { countries." (National Bio-safety Guidelines 2005) }\end{array}$ \\
\hline Philippines & $\begin{array}{l}\text { "Socio-economic, cultural and ethical consideration. - Impacts on small } \\
\text { farmers, indigenous people, women, small and medium enterprises, and the } \\
\text { domestic scientific community to be taken into account." (Executive Order } \\
\text { 514,2006) }\end{array}$ \\
\hline
\end{tabular}

${ }^{26}$ Article 26.1. The Parties, in reaching a decision on import under this Protocol or under its domestic measures implementing the Protocol, may take into account, consistent with their international obligations, socio-economic consideration arising from the impact of living modified organisms on the conservation and sustainable use of biological diversity, especially with regard to the value of biological diversity to indigenous and local communities. 
It is interesting to compare the socio-economic considerations above with similar provisions in other countries that have an unambiguous position and historical track record on biotechnology. For example, the GMO Act 1997 of South Africa, a strong proponent of GMO crops, reads: 'The Council may in performing its function in terms of sub regulation, consider the socio-economic impact that the introduction of a genetically modified organism may have on a community living in the vicinity of such an introduction." Immediately apparent is the narrow application of socio-economic impact assessment: only on the population in close proximity to the GMO site. India, another state with a promotional approach to biotechnology, does not have the socio-economic considerations provision in its Environmental Act or Biosafety Guidelines. Rather, it mandates a systematic evaluation of the agronomic performance of LMOs purely on economic terms (Falck-Zepeda 2009).

In contrast, the five countries under study provide a trickier, so to speak, socioeconomic context in which to navigate. The Philippines, seemingly promotional in its approach to biotechnology, cites quite a number of traditionally-marginalised groups to consider: small farmers, indigenous peoples, women, and (while less marginal) small and medium enterprises. While these invocations might appear lofty and rhetorical, small farmers through the organization MASIPAG (Farmers and Scientists for Agricultural Development) have successfully managed to assert their rights under this provision, arguing before the Supreme Court that "despite the acknowledged importance of eggplant as a source of income of our Filipino farmers, no analysis of the effects of Bt talong (eggplant)on the economic security of Filipino farmers has been made or cited by Respondents Project Proponents." 27 As earlier mentioned, the Supreme Court granted the petition and halted the field trials of genetically modified eggplant.

It is likewise important to note the mention of "domestic scientific community" in the Philippines's Socio-economic Considerations Clause: a clear demarcation of endogenous scientific knowledge from exogenous scientific knowledge, with the implication that biotechnology - Western biotechnology - can render endogenous scientific knowledge and the Filipino scientists that generate it vulnerable.

Indonesia, on the other hand, appears to have a different set of priorities. An emphasis on "religious considerations" in predominantly-Islamic Indonesia suggests a foreseeable conflict between religion and genetic modification, and by wording its SECC in such a fashion, reserves its right to reject biotechnology when such a conflict materialises. It must be noted, however, that Islamic scholars still diverge on whether or not the Quran supports genetic modification (Omobowale et al. 2009). In contrast, Pakistan - also an Islamic country - does not lay much emphasis on religion, but its socioeconomic clause is as striking, in that it frames the GM debate in the language of inequality, and anticipates that biotechnology will further widen the chasm between

\footnotetext{
27 Greenpeace Philippines et al. v. DENR et al. "PETITION FOR WRIT OF CONTINUING MANDAMUS AND WRIT OF KALIKASAN." 2012.
} 
developed and developing countries: a framing that goes beyond domestic socioeconomic concerns and comments on unevenness of global development.

Jordan's Socio-Economic Considerations Clause is broad, encompassing many facets of social life and social needs, but such a provision has not yet been reposed in legislation where it could have the force of law. Mozambique's SECC is vague, with no elaboration on what forms of public contribution might be considered and what other socio-economic considerations are contemplated.

Some writers suggest that the SECC is more restrictive than countries might think. This is because Article 26 of the Cartagena Protocol contains the phrase "consistent with their international obligations", thus preventing states from including considerations that would conflict with previous treaties or agreements entered into. We then have to determine how to reckon this with SPS principles that call for science-based risk assessment methods only. The secretariat of the Convention on Biological Diversity indicated, however, that these socio-economic considerations "could include the risk that imports of GE foods may replace traditional crops, undermine local cultures and tradition, or reduce the value of biodiversity to indigenous communities" (CBD Secretariat 2003), and these are risks that fall wider than those contemplated by SPS. How these risks are to be measured, and at what point in the risk assessment process, are left to the determination of the states. In all the five countries studied, there were no clear parameters for the measurement of these non-scientific risks. Be that as it may, as seen in the Philippines, socio-economic considerations clauses can provide platforms by which citizens can engage the state (in the case of the Philippines, through the courts), and these engagements can derail biotechnology-related projects.

What can be concluded is that socioeconomic considerations clauses have the potential to complicate the already murky terrain of biotechnology governance, but studying them gives us clues and indicators on what states value vis-à-vis the potential gains of genetic modification, and indeed how political and ethical stakes shape science and technology (Macnaghten and Chilvers 2012).

\section{Conclusions}

There are some similarities and some differences in the regulatory approaches and regulatory frameworks of the five countries with Panama disease, which provide us with insights on the governance-related challenges that could face GM banana as a potential solution to the disease. All five countries are signatories to both the SPS Agreements and the Cartagena Protocol, and have reproduced in their legislation the key principles of both. The tensions and inherent contradictions present tricky issues that may surface later, particularly in resolving disputes arising from the transnational movement of GM products. More importantly, these contradictions within the domestic legislation of the aforementioned countries point to the dilemmas of harmonisation and demonstrate that there is no easy transition from uniformity to legitimacy. While some harmonisation may 
be gleaned in the way that risk is perceived and how GM products are deemed an accepted risk, a closer look at domestic policies reveal a high degree of differentiation.

While member-states have on the surface accepted the notion of science as a mobilising framework to bring together divergent understandings of how risk is to be perceived and confronted, an analysis of their domestic texts reveal a different set of realities and priorities, and some areas of incoherence. The co-existence of two seemingly incompatible concepts - the precautionary principle and the science-based risk assessment - suggests either one of two things: first, that harmonisation has created absurdly incoherent domestic policy regimes, and second, that these distinctions are largely symbolic, theoretically-robust buzzwords with no domestic operational significance, and that a vacuum still exists for a clearer framework for the analysis of comprehensive risks and harms. We submit that the second appears more plausible. The wide divergence of socio-economic considerations alone opens the idea of some regulatory apparatus, however modest, for wider issues outside the realm of science to be entertained.

For proponents involved in the genetic modification of banana, it is perhaps significant to note that all five countries studied are aware of the potential risks of biotechnology to human health and the environment, but opt to trade these risks to address an ostensibly bigger risk: food insecurity and agricultural underdevelopment. Hunger is the economic compulsion that moves states into accepting biotechnology despite awareness of the risks that it may bring to human health and the environment. Perhaps what we see is not really a fealty to the universality of science and the acceptance of the logic of harmonisation, but a risk trade-off to address the pressing concern of food insecurity. Some might opt to see this as testimony to the relative success of the 'biotechnology to feed the world' narrative that has been used to get developing companies to relax regulations in favour of GM crops, and to argue that 'responsible biotechnology' with welfare-enhancing outcomes for the poor is possible without any substantive and redistributive structural changes. However, a more development-centred perspective suggests that food insecurity and hunger are truly some of the more enduring problems of our time that demand urgent and durable solutions.

For regulators and policymakers, the point this Chapter wishes to make is the high level of differentiation in the regulatory mechanisms for genetic modification beyond confined trials. While many authors believe genetic modification to be a 'silver bullet' to combat Panama disease and arrest the threat of eradication of the Cavendish, more work will have to be done in the regulation aspect before modified bananas are introduced by scientists. Further, attention must be given to the socioeconomic considerations cited by countries in biotechnology decision-making. While bound by WTO strictures, countries do have socioeconomic considerations that are factored into their regulatory processes, and these considerations differ across jurisdictions. 
For social scientists and risk scholars, the evolving and rapidly-shifting landscape of genetic modification provides an opportunity to understand how pluralist cultural understandings of risk are, first, also shaped by socio-economic compulsions and, second, reproduced in law and policy. It also adds to the robust critical literature on harmonisation, which speaks to the tensions and contradictions that arise when global uniformity aspires to domestic legitimacy using a politically-neutered conception of science as a mobilising framework. 


\section{CONCLUSIONS}

\section{Chapter overview}

In a large white building in the centre of Rome, Italy, a senior economist expresses the view that Panama disease in banana is primarily a disease involving a commercial crop - "possibly the most commercially-important fruit crop in the world" - and the burden of responding to the disease should therefore be borne by the corporations that produce and export bananas. His colleague in another agency within the Food and Agriculture Organization says that they have yet to ascertain the magnitude and extent of the disease, as individual countries are not reporting its existence within their boundaries. Consequently, there is no consensus as yet on whether or not Panama disease is serious and widespread enough to warrant global collective action (see Chapter 1).

On the other hand, in laboratory buildings and research centres in Brisbane, Australia, Wageningen, the Netherlands, and Leuven, Belgium, teams of scientists are convinced of the gravity of Panama disease and the eventual extinction of the Cavendish banana in the absence of any effective response to the disease. For many of these scientists, the only effective response to stop the spread of Panama disease and save the Cavendish banana from extinction is the creation of resistant bananas through genetic modification (see Chapter 4).

Thousands of miles away from Europe and Australia, in a small shed in a banana plantation in Southern Philippines, a farmer in his early 50s looks down at his dusty sandals when asked if they are taught proper Panama disease protocols. In his country, the Secretary of Agriculture had reported that 15,500 hectares of banana plantations have been infested with Panama disease. He had entered into a contract farming agreement with a transnational corporation before any talk of Panama disease, and the contract he signed required him to pay for all disease control measures. "They require us to use rice hulls, but sacks of rice hulls are expensive, and they cut into our already very small earnings that we need to feed our family." When asked if that might only cause the further spread of the disease, he shrugs with resignation and says nothing (see Chapter 2).

What accounts for these disparate views on Panama disease, and consequently disparate responses? If plant diseases are but bio-physical phenomena involving the interaction of a plant and a pathogen within a specific environment, why do actors perceive their risks differently and what are the underlying influences of these risk perceptions and risk decisions? Why is a senior expert at the International Plant Protection Convention seemingly reticent about mobilising international mechanisms against Panama disease, even amidst evidence of the transnational nature of the disease and the absence of any effective eradication measure against it? Why are biotechnology scientists forwarding the narrative that the Cavendish banana is on its way to commercial extinction, and all eradication and mitigation measures presently being undertaken will 
not be successful in saving the cultivar, even when some modest success has been reported in somaclonal variants in Taiwan and the Philippines? Why is smallholder farming being blamed for the spread of Panama disease in the Philippines, and why are poor smallholder farmers being made to bear disproportionate risk burdens?

This research is premised on the key idea that 'risk' is a political concept - how it is perceived, responded to, not responded to, and distributed, are products of power relations. Risk decisions are both a driver of power and an effect of power. However, we did not want to study power relations in a vacuum: we wanted to situate our study of Panama disease and how it is perceived by actors within differentiated power arrangements in the time-space constellation of the present. A social science study of Panama disease Tropical Race 1 in the 1890s explored the social effects of the disease amidst the context of powerful banana corporations and weak Latin American states; we were interested in updating this knowledge with a social science study of Panama disease Tropical Race 4 under the present neoliberal governance regime, and the new set of compulsions and pressures that bear down upon actors operating around and affected by the banana disease.

The main objective therefore of this research was to determine whether or not, and the extent to which, features of neoliberal governance influence risk perceptions and decision-making on Panama disease. The question was asked: Do features of neoliberal governance influence risk perceptions and decision-making on Panama disease and, if so, in what ways? The hypothesis was that identifiable features of neoliberal governance influence risk perceptions and risk decisions on Panama disease in local, national, and international scales of governance and interaction.

This Chapter is divided into two main sections. In the first section, we discuss the main points of engagement of our research, spread out over four different chapters. We focus on four main areas of engagement: free trade and global public goods (liberalisation), contract farming in agrarian settings (corporatisation), privatised agriculture and a plant disease outbreak (privatisation), and the GM bananas agenda through a uniform regulatory framework (harmonisation). In the second section, we flesh out and summarise the political ecology of risk framework that was developed in order to analyse relationships between and among actors in the banana industry, and identify the ways by which risk perceptions and risk decisions in different spheres of governance are mediated by neoliberal compulsions. We examine possible theoretical contributions to both political ecology theory, and risk theory. 


\section{Main points of engagement}

Free trade and global public goods: Can international organisations founded on free trade ideals address transnational plant disease?

In the first Chapter of this dissertation, we looked at how the risk of Panama disease is evaluated by international regulatory bodies and actors in global governance networks, and examined the contestations that underlie the question of whether or not Panama disease control and management constitute a Global Public Good. We have found with clarity that adherence to free trade principles influence and constrain the ways by which international organisations perceive the risk of, and how they address, this transnational plant disease.

It has been observed that questions on who should finance Panama disease control and mitigation measures have been factored into decision-making processes within international organisations involving interventions on the disease. Grappling with the question of whether or not Panama disease measures constitute a public good and warrant public financing finds root in existing debates on whether or not financing for plant protection measures for commercial crops (like banana) should be borne by public institutions. Opponents of public financing suggest that those who directly benefit from the crop protection strategies should be primarily responsible for the cost of these strategies, reflecting neoliberal thinking on the rollback of public financing for agricultural services. This trend of thought has been noted in international organisations involved in plant disease. We have data demonstrating that a strong, if not dominant, sentiment within the Food and Agriculture Organization is that since the Cavendish banana is a commercial crop, finding solutions for Panama disease - a disease that affects the Cavendish - should emanate from banana corporations, and that the FAO should better channel its resources on crops less linked to commercial agriculture. While this can be seen as a statement of pragmatism and prioritisation by senior officials within the FAO cognizant of their organization's limited resources, the contention that Panama disease is best addressed through private financing is a common refrain even in discussions with national officials. We quoted in the earlier chapter the head of the Uganda National Banana Program saying, "If your child is sick, who should pay so that he get well? Should it not be the parents?", suggesting that private financing is not just the practicable solution, it is also the morally-appropriate solution - a position that finds coherence with the neoliberal precept of the rollback of public financing in all spheres of human activity.

Moreover, we also demonstrated that the structural framework of international plant protection disincentivises pro-active plant health measures. We began by looking at how international regulatory bodies for plant disease and plant health have been 'repurposed' to facilitate the requirements of a global free trade regime, of which liberalisation is a pillar. From being primarily focused on plant protection, we identify a shift whereby the IPPC became conscripted to formulate harmonised, uniform, and 'science-based' standards to eliminate regulatory diversity. The notion of 'uniform science' is a counter-pole to regulatory diversity, where countries are allowed to institute 
their own regulations based on individual, country-specific assessments of risk. Free trade advocates have generally looked with disfavour upon this, as well as on 'precautionbased' science, for impeding the free flow of trade and allowing individual countries to impose protectionist barriers. Harmonisation of regulatory policy on plant health was therefore necessary, and to this end, the IPPC was a critical vehicle to determine whether or not a plant health measure is an unjustified trade restriction, and for ensuring that phyto-sanitary measures are applied only when necessary, technically justified, and the least trade restrictive. Because of the need to ensure these stringent standards, a host of requirements are then attached before a quarantine pest is labelled such.

We gave the example of uniform transparency and disclosure requirements, which have been met with difficulty by developing states but have been made a prerequisite before global action can be mobilised against the disease, as an example of possible contradictions between plant health and crop protection, and the imperatives of the global free trade regime. Another example that we provided is the seeming prioritisation of biotechnology and genetically-modified bananas as a solution to Panama disease, noting that the 'biotechnology agenda' is a core agenda of corporate agriculture, and expressing the concern that following the GM track might create even more distance from the Global Public Good framework and render Panama disease solutions inaccessible to those who might need it the most.

Contract farming in agrarian settings: Can relationships of asymmetry produce optimal outcomes for plant disease?

In our second Chapter, based on field work in the southern part of the Philippines where a Panama disease infestation has been confirmed and where social relations in rural livelihoods are characterised by a contentious agrarian history, we sought to investigate how asymmetric binary relationships between the social actors in a contract growership arrangement, operating around the logic of the corporate food regime where agriculture commodity prices, are universalised through processes of liberalisation(McMichael 2006), rendering peasants vulnerable to dispossession (ibid.) and adverse incorporation (Borras and Franco 2013), and how these influence the possibilities and limitations of disease control.

We have found in our research that the asymmetric relationships under a contract growership regime produce asymmetric distributions of risk, and this, in turn, produces sub-optimal, if not problematic, outcomes for Panama disease management and control. An analysis of the contract farming agreements between agrarian reform beneficiaries in the Philippines and banana corporations reveals that the former are being made to bear disproportionate risk burdens through one-sided contractual stipulations. Leveraging financial advantage, these corporations through contracts compel the farmers to assume the risk of Panama disease and other plant diseases, even as these contracts do not allow them to have the resources or wherewithal for adequate plant protection. 
We also demonstrated how 'blaming' is used to reinforce the asymmetrical relationships between the smallholder farmers and the corporations, as when smallholders are being held to account for the spread of Panama disease because of their low technical expertise and capacity, in contrast to the corporations which have superior skills and knowledge. Taken together, the hostile discursive environment created by processes of blaming, reinforced by the oppressive legal stipulations in the contract farming agreements, serve to reinforce the narrative of corporate agriculture being the superior vehicle for the delivery of Panama disease management and control strategies in particular, and plant disease protection in general.

Using a political ecology of risk that incorporates Cultural Theory elements of risk and blame into political ecology theory, this research proposes a counter-narrative to the dominant narrative that blames smallholder farming as responsible for a host of negative agro-ecological outcomes and, in this case, for the spread of Panama disease. We assert that the spread of Panama disease is hastened and rendered inevitable by making farmers liable for the risk of the spread of the disease whilst also depressing smallholder incomes such that capacity to finance crop protection is compromised - twin decisions that are products of the social relations of production under contract farming.

Privatised agriculture and a plant disease outbreak: How does a market-led approach respond to a biosecurity emergency?

In our third Chapter, we were interested in looking at how a market-led economy characterised by privatisation in agricultural research and development responds to a biosecurity outbreak involving Panama disease. We situated our research in Australia, a country whose agricultural sector is considered one of the least supported sectors in the world, and whose Cavendish banana industry is being threatened by a virulent and incurable pathogen, We were interested in the tension between the Australian government's explicit adoption of the 'user pays', market-oriented approach, vis-à-vis the public good characteristics of biosecurity in the context of a dynamic epidemiological landscape. Field work in Brisbane, Australia, six months after confirmation of Panama disease infestation in March 2015, yielded data that allowed for preliminary reflections on how a privatised, industry-driven model influences crop disease strategies in research, development and extension, as well as in biosecurity services.

In agriculture research and development, we have found that the industry drives and determines the direction and scope of research funding. This is done through the use of industry levies as the main vehicle for R\&D financing, and thus, research priorities are guided by the industry, and in some cases, determined by it. Farmers in Australia largely support the levy system of funding research because it gives them a sense of ownership over the research and reflects the felt needs of the producers. On the other hand, there were questions surfaced on the capacity of the levy system, or the industry-driven model, to address long-term exploratory research where no benefit to the banana grower might immediately be seen, but are important windows not just into future prospects for the 
industry, but also into looking at non-market aspects of agriculture, such as ecological sustainability. Thus, it may be necessary to supplement or partner levy-funded, industrydriven research with knowledge production with public good characteristics.

It is, however, in biosecurity response that we see more tensions between the industry-driven model and the state-centric traditional conception of biosecurity. This is because the nature itself of biosecurity services necessitates the rule-making and ruleenforcing powers of the state. It is embedded in the compulsive powers of the state, and its mandate to govern. Owing to its laissez-faire economic policy, Australian agricultural policy has instituted a 'shared responsibility' approach in its biosecurity efforts - an approach whereby biosecurity services to address the disease is divided between the government (in this case, the state government of Queensland) and the industry. In reality however, while cooperation and information-sharing is present between government and industry, rule-making and regulatory mechanisms have been largely tethered to the state, and industry leverages its influence to prod government to work faster and better.

We have demonstrated in the Australian example the insufficiency of the neoliberal 'user-pays' model in addressing emergency plant disease outbreaks, particularly when the swift rule-making and rule-enforcing powers of the state are necessary. While the shared-responsibility approach can keep the wheels grinding in a business-as-usual context, within a rapidly-evolving epidemiological emergency, the terms of engagement between government and industry must be recast, and the tensions between the market-oriented approach and the public good characteristics of biosecurity must be re-examined.

Genetically-modified bananas and the global regulatory framework on biosafety: When regulatory harmonisation at the top does not meet local legitimacy below

In the fourth Chapter, we examined the issue of genetic modification - bannered by some scientists as the only solution to the urgent problem of Panama disease - and the current state of the global regulatory framework on bio-safety. We challenged the framing of biotechnology regulation as primarily a problem of divergent, messy, incoherent, disorganised, unscientific rules; where the solution is a uniform and harmonised legal infrastructure based on a single set of science-based standards applicable to all, and insulated from political, social, and economic considerations. A neoliberal approach believes that science should - and can be - a neutral arbiter of risk, and that therefore, science-based standards can be used to mobilise consensus towards one global regulatory framework, a framework that typically endorses genetic modification.

We sought to determine whether or not harmonisation at the global level has translated into legitimacy in local contexts, and investigate the extent to which sciencebased standards in global regulations are reproduced in domestic legislative frameworks. Using the outbreak of Panama disease as a starting point, and keen to find out which of the countries already infested with Panama disease would apply a more promotional 
position towards genetic modification, we embarked on a comparative legal analysis of these countries' legal rules on bio-safety with a focus on risk and risk perception.

We have found that while countries ostensibly accept that science, or scientific knowledge, can be used as a unifying framework to consolidate multiple appreciations of risk and divergent approaches in addressing and confronting it, more things lie under the surface. An analysis of their domestic legislation shows contradictions between what was committed in international platforms, and what is implemented within domestic legislation. A different set of realities and priorities emerges, and some areas of incoherence appear. While adherence to science-based risk assessment by virtue of membership into the World Trade Organization, invocations of the precautionary principle are both commonplace and explicit. Social and cultural justifications can be widely-seen in bio-safety rules of countries like the Philippines, Indonesia, Mozambique, and Jordan.

Interfacing divergent risk perceptions that are shaped by socio-economic (nonscience) compulsions, with the neoliberal framework's aggressive endorsement of a more harmonised bio-safety policy that endorses genetic modification, we identify a 'push and pull' between a science-based assessment of risk at the top, and pluralist cultural understandings of risk from below. We also surface a strategic device that appears to be used to some success, whereby genetically-modified bananas are being promoted as the only solution, or the silver bullet, against the commercial extinction of Cavendish bananas as a result of Panama disease. Thus, we demonstrate how the risk of Panama disease is being instrumentalised in order to trigger acceptance of GM bananas within legal systems and in the markets, and reinforce the science-based global regulatory mechanisms that is necessary both to the propagation of genetically-modified crops and to the continued dominance of neoliberalism and globalisation as the organizing framework for our time.

\section{Contribution to theory: Using political ecology to understand risk}

Power, nature, and risk

How do power asymmetries in relationships among various social actors result in different ecological outcomes and cause environmental change? This appears to be the central question of political ecology. Combining it with risk theory, we reformulate the question to ask how power asymmetries in relationships among various social actors impact on how risk is perceived, distributed, and addressed, and the consequences of these risk decisions on environmental change. In the chapter on the Philippines, the power asymmetries were clear and explicit: we investigated how relationships between corporations and local communities shape environmental narratives of risk and blame, under grossly asymmetric local settings. In the other chapters, the power relations were less exposed and explicit, but were embedded in the dynamic of the social actors and drove responses and strategies to the disease. Decisions not to mobilise collective action to address Panama disease on a transnational scale because of possible repercussions on free trade, the aggressive promotion of biotechnology as a response to Panama disease, 
assessments of risk restricted by the contours and limitations of a market-driven, userpays model - we find in these operational examples of how power shapes conceptions of risk and recasts the terms of risk decision-making.

While scholars in political ecology have contributed greatly in providing a lens to examine practices of power that impact on resource use and environmental change, our research introduces an explicit interface with Mary Douglas's Cultural Theory (1992), which holds that risk perceptions and risk decisions are articulations of cultural systems and cultural practices within a particular social group. An interface with Cultural Theory provides the theoretical framework to analyse how narratives of environmental risk are shaped by power through discursive practices like blaming, for example, or, for another example, endorsements of a universal view of science. At the same time, we introduce a contribution to Cultural Theory by demonstrating that it is not only culture and social beliefs that drive responses to risk, it can also be economic compulsions and pressures whether visited on a smallholder farmer in the Philippines compelled to enter into onesided growership contracts or on developing states, compelled to accede to the terms of a globalised economy. We propose that this enriched framework of political ecology of risk might be useful in other studies on contested perceptions of risk within a context of environmental change.

Neoliberalism as driver of risk perceptions and risk decisions on Panama disease

The chapters in this research identified specific elements or features of neoliberal governance and examined how they influenced strategies for Panama disease control and management. We examined trade liberalisation and its influence on global plant health regulatory mechanisms, corporate agriculture, privatisation, and regulatory harmonization. What general conclusions can now be drawn on the ways by which neoliberalism influences, constrains, or enables Panama disease strategies?

We venture that neoliberalism influences Panama disease strategies in at least three ways: one, through the organisation and harmonisation of systems of behaviour, practices, and legislation; two, through the marginalisation of counter-narratives; and three, through the promotion of tools that support its agenda. We discuss each point one by one.

First, neoliberalism organises and harmonises systems of behaviour, practices, and legislation so that these conform with its own logic and processes. The tensions between issues of plant and crop health and the imperatives of free and unhampered trade is demonstrative of this. So is the concerted effort to ensure that domestic legislation on bio-safety is consistent with the GATT-WTO, and disclosure and transparency requirements are applied as uniformly and as consistently as possible. An intuitive abhorrence of protectionism results in the perception of plant health measures as inherently suspect and to be avoided, except in the most exigent of circumstances. The international regulatory system has been re-written so that even collective action cannot be mobilised, and international support cannot be activated without the imprimatur of 
the International Plant Protection Convention, as such might provide the basis for a future trade restriction. The global system has been re-engineered in such a way as to limit the latitude and capacity of countries to identify and designate what they believe to be a risk, fearing that a pluralistic interpretation of risk might amount to protectionism. Thus, pressures are imposed on individual nation-states to ensure that domestic legislation conforms with international standards based on a notion of universal science, and do not include 'socio-economic considerations', cultural justifications, or ecological reasons that are unintelligible to the logic of the free market. Science and scientific knowledge is deployed not in furtherance of the wider considerations of plant health, but to ensure that considerations of plant health keep 'within limits' and do not cross over to impinge on borderless international trade.

Second, a way by which neoliberalism influences plant disease strategies is through the marginalisation of counter-narratives that challenge its own dominant narrative. We have observed this in the discursive processes of blaming of smallholder farmers in the Philippines, where economically-marginalised farmers are being held responsible for the spread of Panama disease. We earlier pointed out how this narrative feeds into dominant perceptions of smallholder farming as unsustainable and less desirable to the economies of scale of corporation agriculture, and how it has the strategic value of protecting the status quo and allowing inequitable relations to persist and remain unquestioned. A narrative that blames large companies or corporations for the spread of the disease is one that challenges the wisdom of corporate agriculture, and one that may have the consequence of state regulation of corporations, which contradicts the ideological core of neoliberalism which is that the market must remain unhampered and unencumbered by state legislation.

Third, neoliberalism influences Panama disease measures through the endorsement of tools against Panama disease that are consistent with its agenda. We surfaced in Chapter 5 the aggressive promotion of biotechnology as the only solution - or the 'silver bullet' -- to the possible extermination of Cavendish bananas because of Panama disease, and the endorsement of a biotechnology-permissive global regulatory regime. Neoliberalism did not create Panama disease, nor are proponents of genetic modification always driven by market compulsions, but neoliberal globalism has been shown to reinforce and exacerbate the tendencies of the 'biotechnology revolution' to cause social polarisation (Rahaman 2011). Corollary to that, we have also observed how other tools and strategies have been quickly dismissed as ineffective and inefficient in managing Panama disease. The net effect of this, we argue, is the asymmetric support for the different strategies, with heavy financial grants pouring in for the GMO banana project, and less resources for other research strands.

In sum, neoliberalism influences Panama disease strategies by framing risk - by managing and controlling how the risk of Panama disease is perceived, measured, and decided upon by social actors. Its framing of risk is negotiable, malleable, and contingent on what the system needs at a given time. When the objective is to generate acceptance 
for genetically-modified bananas, the 'catastrophe' narrative is deployed, so that the fear of the extermination of the Cavendish overrides socio-economic reservations on biotechnology. When the objective is to resist a growing clamour for global collective action against the disease, by clever sleight of hand, Panama disease becomes less of a catastrophe, and international free trade is framed as the 'public good' that is in greater need of protection. We venture to suggest that neoliberalism instrumentalises risk by deploying it as a tool to protect the dominance of its ideology. The framing of risk - the answers to the fundamental questions of what risks matter, who decides, who should be exposed to what, and to what degree - is an exercise of power, but at the same time, it is done to protect accumulated power. This research sought to demonstrate, using the example of Panama disease, the precise ways by which neoliberalism has exercised its power in multiple levels of governance and within social relations of production to frame plant disease risk to its strategic advantage and ultimately, use it for the protection of its interests.

The urgent imperative, therefore, is to continue asserting a global counternarrative: one that pushes plant disease protection as a global public good, one that speaks to heterogeneous understandings of risk and does not require a uniform notion od science to confer legitimacy to varying standards of protection and, most importantly, one that puts the marginalised and the disproportionate risk burdens that they bear at the centre of the discourse. 


\section{References}

Adriano, F.D. 2008. CARP Institutional Assessment in a Post-2008 Transition Scenario: Toward a New Rural Development Architecture. Discussion Paper Series No. 2008-6. Quezon City: Philippine Institute for Development Studies.

Arce, M., Daniel, G., and T. Sandler. 2001. A Cooperative Game Theory of Noncontiguous Allies. Journal of Public Economic Theory, 3(4): 391-411.

Aguilar Moran, J. 2013. Improvement of Cavendish Banana Cultivars Through Conventional Breeding. Acta Hort, 986: 205-208.

Akram-Lodhi, A.H. 2007. Land, Markets and Neoliberal Enclosure: An Agrarian Political Economy Perspective. Third World Quarterly, 28(8):1437-1456.

Arias, P. 2003. The World Banana Economy, 1985-2002. Vol. 1. Rome: FAO.

Arnoldi, J. 2009. Risk. Cambridge: Polity Press.

Arshad, M. et al. 2009. Farmers' Perceptions of Insect Pests and Pest Management Practices in Bt Cotton in the Punjab, Pakistan. International Journal of Pest Management, 55(1): 1-10.

Atik, J. 1996. Science and International Regulatory Convergence. Nw. J. Int'l L. \& Bus., 17: 736.

Australian Bureau of Statistics. 2013. Available at http://www.abs.gov.au/ausstats/abs@.nsf/Lookup/7121.0main+features7201112. Last Accessed: 2 November 2015.

Bacon, D. 1999. Children in the Banana Trees. Available at http://dbacon.igc.org/Phils/02ChiBan.html.

Barraza, D., Jansen, K., van Wendel de Joode, B., and C. Wesseling. 2011. Pesticide Use in Banana and Plantain Production and Risk Perception Among Local Actors in Talamanca, Costa Rica. Environmental Research, 111(5): 708-717.

Barrett, C.B. et al. 2011. Smallholder Participation in Contract Farming: Comparative Evidence from Five Countries. World Development, 40 (4): 715-730.

Beck, U. 1992. Risk Society: Towards a New Modernity. London: Sage.

Birch, K. 2006. The Neoliberal Underpinnings of the Bioeconomy: The Ideological Discourses and Practices of Economic Competitiveness. Genomics, Society and Policy, 2(3): 1-15. 
Birdsall, N. and A. Dufasi. 2015. Global Public Goods for Development: How Much and What For. Center for Global Development. Available at https://www.cgdev.org/sites/default/files/CGD-Note-Birdsall-Diofasi-GlobalPublic-Goods-How-Much.pdf.Last Accessed: 12 May 2017.

Blaikie, P. 1995. Changing Environments or Changing Views? A Political Ecology for Developing Countries. Geography, pp. 203-214.

Borras, S. and J. Franco. 2005. Struggles for Land and Livelihood: Redistributive Reform in Agribusiness Plantations in the Philippines. Critical Asian Studies, 37(3): 331-361.

Borras, S. and J. Franco. 2013. Global Land Grabbing and Political Reactions 'From Below'. Third World Quarterly, 34(9): 1723-1747.

Botterill, L. and M. Fisher (eds.). 2003. Beyond Drought: People, Policy and Perspectives. Clayton, Australia: CSIRO Publishing.

Boudia, S. and N. Jas. 2011. Risk and Risk Society in Historical Perspective. History and Technology, 23(4): 317-331

Bridgers, M. 2003. Genetically Modified Organisms and the Precautionary Principle: How the GMO Dispute Before the World Trade Organization Could Decide the Fate of International GMO Regulation. Temp. Envtl. L. \& Tech. J., 22, p.171.

Brookes, M. and Z. Wahhaj. 2001. Global Public Goods: Arguments for Collective Action. International Council on Human Rights Policy Working Paper.

Bryant, R. and S. Bailey. 1997. Third World Political Ecology. London: Routledge.

Burawoy, M. 1998. The Extended Case Method. Sociological Theory, 16(1): 4-33.

Bureau of Agricultural Statistics (BAS). Database. Available at http://www.bas.gov.ph/?ids=fruitssituation.Last accessed: 7 June 2015.

Büthe, T. 2008. The Globalization of Health and Safety Standards: Delegation of Regulatory Authority in the SPS Agreement of the 1994 Agreement Establishing the World Trade Organization. Law and Contemporary Problems, 71(1): 219-255.

Bury, J. 2008. Transnational Corporations and Livelihood Transformations in the Peruvian Andes: An Actor-oriented Political Ecology. Human Organization, 67(3): 307-321.

Busch, L. 2010. Can Fairy Tales Come True? The Surprising Story of Neoliberalism and World Agriculture. Sociologia Ruralis, 50(4): 331-351.

Castellanos-Navarrete, A. 2015. Illusions, Hunger and Vices: Smallholders, Environmentalism and the Green Agrarian Question in Chiapas' Biofuel Rush. The Netherlands: Wageningen University. 
CBD Secretariat. 2003. Presentation on the Cartagena protocol on Bio-safety. Secretariat of the Cartagena Protocol on Bio-Safety. Montreal, Quebec, Canada.

Che Man, W.K. 1990. Muslim Separatism: The Moros of Southern Philippines and the Malays of Southern Thailand. Quezon City: Ateneo de Manila University Press.

Clapp, R.A. 1994. The Moral Economy of the Contract. In Living Under Contract: Contract Farming and Agrarian Transformation in Sub-Saharan Africa, P.D. Little and M. Watts (eds.). Madison: University of Wisconsin Press.

Cook, B., Quirk, V., and W. Mitchell. 2012. The Impact on Community Services of Staff and Service Reductions, Privatisation and Outsourcing of Public Services in Australian States. Report prepared for the Community and Public Sector Union (SPSF Group).

Córdoba, D. and K. Jansen. 2014. Same Disease - Different Research Strategies: Bananas and Black Sigatoka in Brazil and Colombia. Singapore Journal of Tropical Geography, 35(3): 345-361.

Córdoba, D. and K. Jansen. 2014. The Return of the State: Neocollectivism, Agrarian Politics and Images of Technological Progress in the MAS Era in Bolivia. Journal of Agrarian Change, 14(4), 480-500.

Dalrymple, D. August 2003. Scientific Knowledge as a Global Public Good: Contributions to Innovation and the Economy. In The Role of Scientific Data and Information in the Public Domain: Proceedings of a Symposium, 35-51.

Datta-Chaudhuri, M. 1990. Market Failure and Government Failure. The Journal of Economic Perspectives, 4(3): 25-39.

Davao Chamber. Available at http://davaochamber.com/membershipdirectory/sumifru-philippines-corporation/ Last Accessed: 25 February 2017.

De Leon, T. and G. Escobido. 2004. The Banana Export Industry and Agrarian Reform. Davao City: Alternative Forum for Research in Mindanao.

De los Reyes, J. and W. Pelupessy. 2009. Agrarian Reform in the Philippine Banana Chain. Antwerp: Institute of Development Policy and Management.

Digal, L. 2007. Agricultural Contracts in Mindanao: The Case of Banana and Pineapple. Philippine Institute for Development Studies, Discussion Paper Series No. 2007-24.

Douglas, M. and A. Wildavsky. 1983. Risk and Culture: An Essay on the Selection of Technological and Environmental Dangers. USA: Univ. of California Press.

Douglas, M. 1992. Risk and Blame: Essays in Cultural Theory. London: Routledge.

Durham, F.D. 2001. Breaching Powerful Boundaries: A Postmodern Critique of Framing. In Framing Public Life: Perspectives on Media and our Understanding of the Social 
World, Reese, S.D., Gandy, O.H., and August E. Grant (eds.). Mahwah, NJ: Lawrence Erlbaum.

Eckersley, Robin. 2004. The Big Chill: The WTO and Multilateral Environmental Agreements. Global Environmental Politics, 4(2): 24-49.

Emergency Plant Pest Response Deed (EPPRD) (2014) Government and plant industry cost sharing deed in respect of emergency plant pest responses. Available at: http://www.planthealthaustralia.com.au/wp-content/uploads/2015/08/EPPRD25-August-2015.pdf Last Accessed: 3 May 2015.

Escobar, A. 1999. After Nature: Steps to an Antiessentialist Political Ecology 1. Current Anthropology, 40(1): 1-30.

Falck-Zepeda, J. 2009. Socio-economic Considerations, Article 26.1 of the Cartagena Protocol on Bio-Safety: What are the Issues and What is at Stake? AgBioForum, 12(1): 90-107.

Ferroni, M. and Y. Zhou. 2012. Achievements and Challenges in Agricultural Extension in India. Global Journal of Emerging Market Economies, 4(3): 319-346.

Food and Agriculture Organization. 2002. Guide to the International Plant Protection Convention. Rome: FAO.

Food and Agriculture Organization. 2007. Biosecurity Toolkit. Rome: FAO.

Food and Agriculture Organization. 2014. Global Programme on Prevention of Fusarium Wilt (Foc) Disease of Banana 2015-2018. Draft Working Paper. Rome: FAO.

Fox, J. 2007. How Blaming 'Slash and Burn' Farmers is Deforesting Mainland Southeast Asia. Asia Pacific Issues, 47, Honolulu: East West Center.

Foucault, M. and A. Lewis. 1991. Politics and the Study of Discourse. Illinois: University of Chicago Press.

Fransen, L. et al.2005. Integrating Socio-Economic Considerations into Biosafety Decisions: The Role of Public Participation. Washington DC: World Resources Institute.

Fresh Fruit Portal. Land Reform Regulation Bill Threatens World's Second Largest Banana Exporter. Available at http://www.freshfruitportal.com/2015/05/08/land-reformregulation-bill-threatens-worlds-second-largest-bananaexporter/?country=netherlands. Last Accessed: 7 June 2015.

García-Bastidas, F., Ordóñez, N., Konkol, J., Al-Qasim, M., Naser, Z., Abdelwali, M. and G.H.J. Kema. 2015. First Report of Fusarium Oxysporum f. sp. Cubense Tropical Race 4 Associated with Panama Disease of Banana Outside Southeast Asia. Annual Review of Phytopathology, 53: 269-288. 
George, S. March 1999. A Short History of Neoliberalism. In Conference on Economic Sovereignty in a Globalising World, 24, 26.

Gill, S. 2002. Globalization, Market Civilization and Disciplinary Neoliberalism. In The Globalization of Liberalism, 123-151. UK: Palgrave Macmillan.

Glover, D. and K. Kusterer. 1990. Small Farmers, Big Business: Contract Farming and Rural Development. New York: St. Martin's Press.

Glover, D. 2010. The Corporate Shaping of GM Crops as a Technology for the Poor. The Journal of Peasant Studies, 37(1): 67-90.

Greenpeace. 2012. BT Talong Unsafe and Dangerous to Environmental Health. Available at: http://www.greenpeace.org/seasia/ph/press/releases/Bt-talong-unsafe-anddangerous-to-environmental-health-report/. Last Accessed: 3 April 2014.

Grosh, B. 1994. Contract Farming in Africa: An Application of the New Institutional Economics. Journal of African Economies, 3(2): 231-261.

Grossman, L.S. 2000. The Political Ecology of Bananas: Contract Farming, Peasants, and Agrarian Change in the Eastern Caribbean. NC: University of North Carolina Press.

Gruere, G. 2006. A Review of International Labelling Policies of Genetic Modified Food to Evaluate India's Proposed Rule. The Journal of Agrobiotechnology Management and Economics, 10(1), Article 6.

Gupta, A. 2000. Governing Trade in Genetically Modified Organisms: The Cartagena Protocol on Biosafety. Environment, (42)4: 23-33.

Gupta, A. 2004. When Global is Local: Negotiating Safe Use of Biotechnology. In Earthly Politics: Local and Global in Environmental Governance, Sheila Jasanoff (ed.). Massachusetts: MIT.

Guo, H., Jolly, R.W., and J. Zhu. 2007. Contract Farming in China: Perspectives of Farm Households and Agribusiness Firms. Comparative Economic Studies, 49(2): 285-312.

Hall, P.A. and M. Lamont (eds.). 2013. Social Resilience in the Neoliberal Era. UK: Cambridge University Press.

Hall, S., Massey, D., and M. Rustin. 2013. After Neoliberalism: Analysing the Present. Soundings, 53(53): 8-22.

Hay, C. 2004. The Normalizing Role of Rationalist Assumptions in the Institutional Embedding of Neoliberalism. Economy and Society, 33(4): 500-527.

Hayami, Y., Adriano, S., and M. Quisumbing. 1998. Agri-business and Agrarian Reform: A View from Banana and Pineapple Plantations. Laguna: UPLB Center for Policy and Development Studies. 
Heal, G.M. 1998. New Strategies for the Provision of Global Public Goods: Learning from the International Environmental Challenge. New York: Columbia University.

Hennessy, C., Walduck, G., Daly, A. and A. Padovan. 2005. Weed Hosts of Fusarium Oxysporum f.sp. Cubense Tropical Race 4 in Northern Australia. Australasian Plant Pathology, 34(1):115-117.

Hirshleifer, J. 1983. From Weakest-Link to Best-Shot: The Voluntary Provision of Public Goods. Public Choice, 41(3): 371-386.

Hood, C. 2011. The Blame Game: Spin, Bureaucracy and Self-Preservation in Government. Princeton: Princeton University Press.

Hooker, N.H and J.A. Caswell. 1999. A Framework for Evaluating Non-Tariff Barriers to Trade Related to Sanitary and Phytosanitary Regulation. Journal of Agricultural Economics, 50(2): 234-246.

Hunt, W. et al. 2012. The Many Turnings of Agricultural Extension in Australia. The Journal of Agricultural Education and Extension, 18(1): 9-26.

Imbruce, V. 2008. The Production Relations of Contract Farming in Honduras. GeoJournal, 73(1): 67-82.

Irwin, A. et al. 1997. Regulatory Science: Towards a Sociological Framework. Futures, 29(1): 17-31.

Isaac, G.E. and W.A. Kerr. 2003. Genetically Modified Organisms at the World Trade Organization: A Harvest of Trouble. Journal of World Trade, 37(6): 1083-1095.

Jansen, K. 1998. Political Ecology, Mountain Agriculture, and Knowledge in Honduras. Amsterdam: Thela Publishers.

Jansen, K. 2006. Banana Wars and the Multiplicity of Conflicts in Commodity Chains. European Review of Latin American and Caribbean Studies, 81: 97-113.

Jansen, K. 2008. The Unspeakable Ban: The Translation of Global Pesticide Governance into Honduran National Regulation. World Development, 36(4): 575-589.

Jansen, K. and E. Roquas. 2008. Biosafety Regulation and Global Governance: The Problem of Absentee Expertise in Latin America. Food for the Few: Neoliberal Globalism and Biotechnology in Latin America, 91-113.

Jansen, K. and A. Gupta. 2009. Anticipating the Future: 'Biotechnology for Poor as Unrealised Promise?' Futures, 41(7): 436-445.

Jasanoff, S. 1998. Contingent Knowledge: Implications for Implementation and Compliance. In Engaging Countries, E. Weiss and H. Jacobson (eds.). Mass.: MIT Press. 
Jubair, S. 1999. Bangsamoro: A Nation Under Tyranny. (Note: This is a self-published book by Mohaquer Iqbal, current head of the MILF negotiating panel. His pseudonym is Salah Jabair.)

Kaul, I., Grunberg, I., and M.A. Stern. 1999. Defining Global Public Goods. In Global Public Goods: International Cooperation in the 21st Century, 2-19.

Kaul, I. 2001. Public Goods: Taking the Concept to the 21st Century. In The Market of the Public Domain, Drache, D. (ed.). London and New York: Routledge, 255-273.

Kay, C., 2006. Rural Poverty and Development Strategies in Latin America. Journal of Agrarian Change, 6(4): 455-508.

Koeppel, D. 2005. Can This Fruit Be Saved? As Blight Threatens the Humble Banana, Scientists are Racing to Build a Better, More Resistant Fruit. Popular Science, 267(2):60.

Koeppel, D. 2008. Banana: The Fate of the Fruit that Changed the World. Hudson: Hudson Street Press.

Kroeger, T. and F. Casey. 2007. An Assessment of Market-based Approaches to Providing Ecosystem Services on Agricultural Lands. Ecological Economics, 64(2): 321-332.

Kumar, G.B., Ganapathi, T.R., and C.J. Revathi. 2005. Expression of Hepatitis B Surface Antigen in Transgenic Banana Plants. Planta, 222: 484-493.

Labarthe, P. and C. Laurent. 2013. Privatization of Agricultural Extension Services in the EU: Towards a Lack of Adequate Knowledge for Small Farms? Food Policy, 38: 240252.

Larner, W. and N. Laurie. 2010. Travelling Technocrats, Embodied Knowledges: Globalising Privatisation in Telecoms and Water. Geoforum, 41(2): 218-226.

Lawrence, G., Richards, C., and K. Lyons. 2013. Food Security in Australia in an Era of Neoliberalism, Productivism and Climate Change. Journal of Rural Studies, 29: 3039.

Le Gouis, M. 1991. Alternative Financing of Agricultural Extension: Recent Trends and Implications for the Future. In Agricultural Extension: Worldwide Institutional Evolution and Forces for Change, Rivera, W.M. and Gustafson, D.J. (eds.). New York: Elseiver.

Mackenzie, A.F.D. 2003. Land Tenure and Biodiversity: An Exploration in the Political Ecology of Murang'a District, Kenya. Human Organization, 62(3): 255-266.

Macnaghten, P. and J. Chilvers. 2012. Governing Risky Technologies. In Critical Risk Research: Practices, Politics and Ethics, 99-124. 
MacLeod, A. et al. 2010. Evolution of the International Regulation of Plant Pests and Challenges for Future Plant Health. Food Security, 2(1): 49-70.

Marquardt, S. 2001. Green Havoc: Panama Disease, Environmental Change, and Labor Process in the Central American Banana Industry. The American Historical Review, 106(1): 49-80.

Marsh, S.P. and D. Pannell. 2000. Agricultural Extension Policy in Australia: The Good, the Bad and the Misguided. Australian Journal of Agricultural and Resource Economics, 44(4): 605-627.

Maye, D. et al. 2012. Governing Biosecurity in a Neoliberal World: Comparative Perspectives from Australia and the United Kingdom. Environment and PlanningPart A, 44(1): 150.

McAllister, R.R., Robinson, C.J., Maclean, K., Guerrero, A.M., Collins, K., Taylor, B.M. and P.J. De Barro. 2015. From Local to Central: A Network Analysis of Who Manages Plant Pest and Disease Outbreaks Across Scales. Ecology and Society, 20(1):67.

McKenzie, R.B. and D.R. Lee. 1991. Quicksilver Capital: How the Rapid Movement of Wealth has Changed the World. New York: Free Pr.

McMichael, A.J. and A. Haines. 1997. Global Climate Change: The Potential Effects on Health. BMJ: British Medical Journal, 315(7111): 805.

McMichael, P. 2006. Peasant Prospects in the Neoliberal Age. New Political Economy, 11(3): 407-418.

Mendez, R.P. 1999. Peace as a Global Public Good. Global Public Goods, 382-416.

Morpurgo, R. et al. 1997. Banana Research in the FAO/ IAEA Agriculture and Biotechnology Laboratory. In Improvement of Basic Food Crops in Africa through Plant Breeding, Including the Use of Induced Mutations. Vienna: IAEA.

Mullen, J., Vernon, D., and K. Fishpool. 2002. Agriculture Extension Policy in Australia: Public Funding and Market Failure. The Australian Journal of Agricultural and Resource Economics, 44(4): 629-645.

Nelson, M., Roffey, P., McNevin, D., Lennard, C. and Gahan, M.E., 2014. An overview of biosecurity in Australia. Australian Journal of Forensic Sciences, 46(4), pp.383-396.

Ntawuruhunga, P. and J. Legg. 2007. New Spread of Cassava Brown Streak Virus Disease and its Implications for the Movement of Cassava Germplasm in the East and Central African Region. USAID, Crop Crisis Control Project C3P.

Oberthür, S. and T. Gehring. 2006. Institutional Interaction in Global Environmental Governance: The Case of the Cartagena Protocol and the World Trade Organization. Global Environmental Politics, 6(2): 1-31. 
Ofreneo, R.E. 1987. Deregulation and the Agrarian Crisis. Quezon City: Institute of Industrial Relations, University of the Philippines.

Okeno, J.A. et al. 2013. Africa's Inevitable Walk to Genetically Modified (GM) Crops: Opportunities and Challenges for Commercialization. New Biotechnology, 30(2): 124-130.

Omobowale, E.B., Singer, P.A. and A.S.Daar. 2009. The Three Main Monotheistic Religions and GMFood Technology: An Overview of Perspectives. BMC International Health and Human Rights, 9(1):18.

Ordoñez, N. et al. 2015. Worse Comes to Worst: Bananas and Panama disease-When Plant and Pathogen Clones Meet. PLoS Pathogens, 11(11).

Ordoñez, N. and F. Garcia-Bastidas. 2015. First Report of Fusarium Oxysporum f. sp. Cubense Tropical Race 4 Causing Panama disease in Cavendish Bananas in Pakistan and Lebanon. Plant Disease.

Oya, C. 2012. Contract Farming in Sub-Saharan Africa: A Survey of Approaches, Debates and Issues. Journal of Agrarian Change, 12(1): 1-33.

Palley, T.I., 2005. From Keynesianism to Neoliberalism: Shifting Paradigms in Economics. Neoliberalism: A Critical Reader, pp.20-29.

Paulson, S. et al. 2004. Political Ecology Across Spaces, Scales, and Social Groups. NJ: Rutgers University Press.

Pérez-Vicente, L. 2004. Fusarium Wilt (Panama disease) of Banana: An Updating Review of the Current Knowledge on the Disease and its Causal Agent. Orozco-Santos, M; Orozco-Romero; J; Velázquez-Monreal, J, 1-16.

Pérez-Vicente, L., Dita, M.A., and E. Martinez de la Parte. 2014. Final Report: Regional Sensitization Seminar and Workshop on the Prevention and Diagnostic of Fusarium Wilt (Panama disease) of Bananas and Plantains Caused by Fusarium oxysporum $\mathrm{f}$. sp. cubense - Tropical Race 4. Trinidad and Tobago, 27 April - 10 May, 2014. FAO/CARDI.

Perrings, C. et al. 2002. Biological Invasion Risks and the Public Good: An Economic Perspective. Conservation Ecology, 6(1): 1.

Philippine Center for Investigative Journalism. 2006. Running Amok: Landlord Lawlessness and Impunity in the Philippines. Final Report on the 2-15 June 2006 International Fact-Finding Mission on Agrarian Reform Related Violations of Human Rights in the Philippines. Quezon City.

Philippine Statistics Authority. 2015. Philippine Agriculture in Figures. Available at: http://countrystat.psa.gov.ph/?cont=3 Last Accessed: 30 June 2016. 
Plant Health Australia.2009.Farm Biosecurity Manual for the Banana Industry: Reducing the Risk of Exotic and Damaging Pests Becoming Established in Crops. Version 1.0. Deakin, Australia:Plant Health Australia.

Ploetz, R.C. 1994. Panama disease: Return of the First Banana Menace. International Journal of Pest Management, 40(4): 326-336.

Ploetz, R.C. 2005. Panama Disease, an Old Nemesis Rears its Ugly Head: Part 2, The Cavendish Era and Beyond. Plant Health Progress, pp.1-17.

Ploetz, R.C. 2006. Fusarium Wilt of Banana is Caused by Several Pathogens Referred to as Fusarium Oxysporum f. sp. Cubense. Phytopathology, 96(6): 653-656.

Ploetz, R. 2015. Management of Fusarium Wilt of Banana: A Review with Special Reference to Tropical Race 4. Crop Protection, 73: 7-15.

Pocasangre, L.E. et al. 2011. Raising Awareness of the Threat of Fusarium Wilt Tropical Race 4 in Latin America and the Caribbean. Acta Horticulturae 897: 331-337.

Polanyi, K. 1944. The Great Transformation: Economic and Political Origins of Our Time. New York: Rinehart.

Porter, G. and K. Phillips-Howard. 1997. Comparing Contracts: An Evaluation of Contract Farming Schemes in Africa. World Development, 25 (2): 227-238.

Prabhu, K.V. 2009. Use of GMOs under Containment, Confined and Limited Field Trials and Post-release Monitoring of GMOs. In Biosafety of Genetically Modified Organisms: Basic Concepts, Methods and Issues, pp.157220.http://www.fao.org/docrep/012/i1252e/i1252e.pdf. Last Accessed: 6 March 2013.

Prinsley, R. et al. 1994. The Role of Private Sector in Extension: A Report to the Research and Development Corporations. RIRDC Occasional Paper No. 94/3. Canberra: Rural Industries Research and Development Corporation.

Queensland Government Department of Agriculture, Fisheries and Forestry (QDAFF) (2014) Bananas. Available at: http://www.daff.qld.gov.au/plants/fruit-andvegetables/fruit-and-nuts/bananas Last accessed: 3 May 2015.

Queensland Government Department of Agriculture, Fisheries and Forestry (QDAFF) (2015) Panama disease: Current situation. Available at: https://www.daf.qld.gov.au/plants/health-pests-diseases/a-zsignificant/panama-disease2 Last accessed: 3 May 2015. 
Quitoriano, E. 2008. In the Hands of Farm Workers: Can Banana Commercial Farms Survive? Quezon City: Development Academy of the Philippines and La Liga Institute.

Quitoriano, E. 2009. Land, Foreign Aid and the Rural Poor in Mindanao. Quezon City: Focus on the Global South.

Rahaman, M. 2011. Biotechnology, Neoliberal Politics of Life and the Spirit of Biocapital. Social Studies of Science, 41(5): 759-763.

Read, R.A. 1993. The Banana Industry: Oligopoly and Barriers to Entry. Transnational Corporations and the Exploitation of Natural Resources, 10, 198.

Remy, S. et al. 2013. Genetically Modified Bananas: Past, Present and Future. Acta Hort, 974, 71-80. Proc. 2nd Genetically Modified Organisms in Horticulture Symposium, M.A. Veale (ed.).

Ríos-González, A., Jansen, K., and H.J. Sánchez-Pérez. 2013. Pesticide Risk Perceptions and the Differences between Farmers and Extensionists: Towards a Knowledge-inContext Model. Environmental Research, 124: 43-53.

Risse, T. 2007. Transnational Actors and World Politics. In Corporate Ethics and Corporate Governance. Berlin Heidelberg: Springer.

Rivera, W.M. 1996. Agricultural Extension in Transition Worldwide: Structural, Financial and Managerial Strategies for Improving Agricultural Extension. Public Administration and Development, 16(2): 151-161.

Rivera, W.M. and J.W. Cary. 1997. Privatizing Agricultural Extension. BE Swanson, RP, 250: 203-211.

Robbins, P. 2011. Political Ecology: A Critical Introduction. Vol. 16. New York: John Wiley \& Sons.

Rothstein, H., Irwin, A., Yearley, S., and E. McCarthy. 1999. Regulatory Science, Europeanization, and the Control of Agrochemicals. Science, Technology \&Human Values, 24(2):241-264.

Rout, G.R., Samantaray, S., and P. Das. 2000. Biotechnology of the Banana: A Review of Recent Progress. Plant Biology 2.5: 512-524.

Samuelson, P. 1954. The Pure Theory of Public Expenditures. Review of Economics and Statistics, 36(1954): 387-389.

Sarewitz, D. 2000. Science and Environmental Policy: An Excess of Objectivity. In Earth Matters, R. Frodemen (ed.). Prentice-Hall. 
Scoones, I. 2002. Can Agricultural Biotechnology Be Pro-Poor? A Sceptical Look at the Emerging Consensus. IDS Bulletin, 33(4).

Scott, D.N. 2008. Confronting Chronic Pollution: A Socio-Legal Analysis of Risk and Precaution. Osgoode Hall Law Journal, 46(2): 293-343.

Sheridan, T.E. 2001. Cows, Condos, and the Contested Commons: The Political Ecology of Ranching on the Arizona-Sonora Borderlands. Human Organization, 60(2): 41-152.

Simmons, P. 2002. Overview of Smallholder Contract Farming in Developing Countries. Rome: FAO.

Simon, J. 2005. Risk and Reflexivity: What Socio-Legal Analysis Add to the Study of Risk and the Law. 57 Ala. L. Rev. 119 (conclusion to the Meador Lecture Series on Risk and the Law, delivered at the University of Alabama School of Law, 17 October 2005).

Singh, S. 2002. Contracting Out Solutions: Political Economy of Contract Farming in the Indian Punjab. World Development, 30(9): 1621-1638.

Singh, H.P. et al. 2011. Micropropagation for Production of Quality Banana Planting Material in Asia-Pacific. India: Asia-Pacific Consortium on Agricultural Biotechnology. 92.

Smith, W.C., Acuña, C.H., and E.A. Gamarra (eds.). 1994. Latin American Political Economy in the Age of Neoliberal Reform: Theoretical and Comparative Perspectives for the 1990s. USA: North-South Center, University of Miami.

Soluri, J. 2002. Accounting for Taste: Export Bananas, Mass Markets, and Panama Disease. Environmental History, 7(3): 386-410.

Stover, R.H. 1962. Fusarial Wilt (Panama Disease) of Bananas and Other Musa Species. Phytopathology, 177.

Tadem, E.C. 1992. The Political Economy of Mindanao: An Overview. In Mindanao: Land of Unfulfilled Promise. Cellar Book Shop. 7-30.

Tadem, E.C. 2007. The Crisis in Philippine Agriculture. Kasarinlan: Philippine Journal of Third World Studies, 1(2): 35-39.

Tamanaha, B. 2001. A General Jurisprudence of Law and Society. Oxford: Oxford University Press.

Toleubayev, K., Jansen, K. and A. van Huis. 2007. Locust Control in Transition: The Loss and Reinvention of Collective Action in Post-Soviet Kazakhstan. Ecology and Society, 12(2). 
Torrance, A.W. 2007. Intellectual Property as the Third Dimension of GMO Regulation. Kansas Journal of Law \& Pubic Policy, 16(3): 257-285.

Tyers, R. 1993. The Cairns Group and the Uruguay Round of International Trade Negotiations. Australian Economic Review, 26(1): 49-60.

Van Zwanenberg, P., Ely, A., Smith, A., Chuanbo, C., Shijun, D., Fazio, M.E. and L. Goldberg. 2011. Regulatory Harmonization and Agricultural Biotechnology in Argentina and China: Critical Assessment of State-centered and Decentered Approaches. Regulation \& Governance, 5(2): 166-186.

Vellema, S. 1999. Agribusiness Control in Philippine Contract Farming: From Formality to Intervention. International Journal of Sociology of Agriculture and Food, 8: 95-110.

Vellema, S. 2002. Making Contract Farming Work? Society and Technology in Philippine Transnational Agribusiness. Maastricht: Shaker Publication.

Vellema, S. and F. Lara Jr. 2011. The Agrarian Roots of Contemporary Violent Conflict in Mindanao, Southern Philippines. Journal of Agrarian Change, 11(3): 298-320.

Vishnevetsky, J. et al. 2011. Improved Tolerance Toward Fungal Diseases in Transgenic Cavendish Banana (Musa spp. AAA group) cv. Grand Nain. Transgenic Research, 20(1): 61-72.

Waage, J.K. and J.D. Mumford. 2008. Agricultural Biosecurity. Philosophical Transactions of the Royal Society B: Biological Sciences, 363(1492): 863-876.

Walker, A.B. 1995. 'Some New Zealand Observations on the Two Way Street of PublicPrivate Extension', paper presented at the Dairy Horizons Conference, Melbourne, Australia.

Warrington, I.J., Wallace, B.D., and S. Scarrow. 2004. International Perspectives in Horticultural Extension-A New Zealand Viewpoint. HortTechnology, 14(1): 20-23.

Watts, M. et al. 1990. Peasants Under Contract: Agro-food Complexes in the Third World. In Food Question: Profits Versus People? 149-162.

Whitehead, M., Jones, R., and M. Jones. 2007. The Nature of the State: Excavating the Political Ecologies of the Modern State. UK: Oxford University Press.

Wynne, B. 1992. Uncertainty and Environmental Learning: Reconceiving Science and Policy in the Preventive Paradigm. Global Environmental Change, 2(2): 111-127.

Wynne, B. 2001. Creating Public Alienation: Expert Cultures of Risk and Ethics on GMOs. Science as Culture, 10(4): 445-481.

Zerbe, N. 2004. Feeding the Famine: American Food Aid and the GMO Food Debate in Southern Africa. Food Policy, 29(6): 593-608. 
Zhang, Q.F. 2012. The Political Economy of Contract Farming in China's Agrarian Transition. Journal of Agrarian Change, 12(4): 460-483.

Zimmerer, K. and T.J. Bassett. 2003. Political Ecology: An Integrative Approach to Geography and Environment-Development Studies. New York: Guilford. 


\section{ACKNOWLEDGEMENTS}

At many parts of my PhD journey, I felt I did not have what it takes to see the process through. Fortunately, there were a number of people who did not agree with me.

I thank first of all my supervisor Kees Jansen, whose patience and steadfast hand accompanied me throughout all the phases of my research. He confronted and challenged me, affirmed me and supported me, and most of all provided me an intellectual space that did not suppress my political expression. As for my promoter, Philip Macnaghten, I cannot be more grateful for the enthusiasm and commitment that he has thrown into my project, and for helping me sift through the tiny details while never forgetting the big questions.

I thank the members of the management team of the INREF banana project, namely Sietze Vellema, Jetse Stoorvogel, and Gert Kema. Discussions with them have allowed me an understanding of the multi-disciplinary approaches to plant disease and have made my research richer. I thank too, with a lot of affection, my colleagues at the INREF project, namely Rockefeller Erima, Fernando Garcia Bastidas, Marilou Montiflor, Nadia Ordonez Roman, Maricar Salacinas and Rafael Segura Mena. They have become more than colleagues -- I am certain they are examples of how bonds of friendship forged in (PhD) hardship will last a lifetime.

This research benefited from the contributions of several people. My gratitude goes out to my KTI colleagues, with whom I have shared not just intellectual exchanges, but also late-night pizzas and Game of Thrones theories. I thank in particular Antonio Castellanos, Paola Chavez, Horacio Narvaez and Rica Joy Flor. They have made our little corridor in De Leeuwenborch feel like home. Heartfelt acknowledgements must also go to the administrative staff of KTI, particularly Bea Prijn and Inge Ruisch. No PhD process is ever easy, but they made the ride as painless as they possibly could. I thank Manju Sadashiva, for helping me in the final stretches of work when everyone else was either on holiday or sick of talking about bananas and the evils of unfettered capitalism with me.

I thank my family, especially my parents Mio and Bing de la Cruz, who always encouraged (pushed, nagged, cajoled) me down the road of overeducation, even at the risk of delaying their grandparent aspirations. I thank my Dutch family, especially my parents-in-law Jan and Nel Bekema, who loved me as their own and with their love, made me see the Netherlands not just as the country that gave me two graduate degrees, but also as my second home. I thank my husband, baby-daddy and best friend Jan Bekema. Of his patience and kindness, I will always be unworthy.

Most of all, I thank this little sticky bean inside of me, you are ether and energy, you are the universe in a whisper. For coming when you did, for holding tight, for being a reminder of what truly matters - my gratitude is as boundless as my love. 


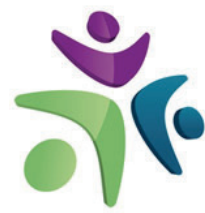

Wageningen School of Social Sciences

\section{Name of the learning activity \\ A) Project related competences}

\section{Department/Institute}

Year

ECTS*

Guided study of literature on technical

$\mathrm{KTI}$ and $\mathrm{PRI}$

2012

3

issues involving Panama disease - its

historical evolution, causes, spread and

mitigation strategies

Guided study on international legal and

KTI

2012

3

policy regimes and standards involved in plant disease regulation

Writing of research proposal

$\mathrm{KTI}$

2012

6

'Panama Disease Control and Surveillance

WASS PhD day

2013 1

as Global Public Good: Gaps and

Challenges'

Research visit in Brisbane, Australia

Queensland University of

2015

Research visit in FAO - Italy

Technology

Participation in thematic workshop in the

WASS and FAO

$2015 \quad 1$

Philippines

Participation in thematic workshop in the

INREF

2014

Netherlands

INREF

2015

Participation in INREF workshop in Miami

INREF

2016

and Conference sponsored by Corbana

'Public Private Collaborations Amidst An Emergency Plant Disease Outbreak: The

ICAEM, School of

2016 1

Australian Experience With Panama Disease'

Management, Davao,

Philippines

\section{B) General research related competences}

Workshop: interviewing professionals

WASS

$2012 \quad 0.5$

Information Literacy

WGS

2013

0.6

WASS Introduction course

WASS

2013

1

Qualitative Data Analysis: Procedures \&

WUR

20126

strategies, YRM-60806 


\section{C) Career related competences}

Participation in discussion groups

KTI

2013

2016

KTI Seminar series

KTI

2013-

2016

Social Dutch 1

Into Languages

2015

1.5

Total

40.1

*One credit according to ECTS is on average equivalent to 28 hours of study load 


\section{FINANCIAL SUPPORT}

Financial support for this $\mathrm{PhD}$ project was provided through the Interdisciplinary Research and Education Fund (INREF) Programme. 
